San Jose State University

SJSU ScholarWorks

Master's Theses

Master's Theses and Graduate Research

Fall 2010

\title{
Outcomes of Dialogic Communication Training on a City Government Management Team
}

Minna Johanna Holopainen

San Jose State University

Follow this and additional works at: https://scholarworks.sjsu.edu/etd_theses

\section{Recommended Citation}

Holopainen, Minna Johanna, "Outcomes of Dialogic Communication Training on a City Government Management Team" (2010). Master's Theses. 3867.

DOI: https://doi.org/10.31979/etd.36j3-4rv9

https://scholarworks.sjsu.edu/etd_theses/3867

This Thesis is brought to you for free and open access by the Master's Theses and Graduate Research at SJSU ScholarWorks. It has been accepted for inclusion in Master's Theses by an authorized administrator of SJSU ScholarWorks. For more information, please contact scholarworks@sjsu.edu. 


\title{
OUTCOMES OF DIALOGIC COMMUNICATION TRAINING ON A CITY GOVERNMENT MANAGEMENT TEAM
}

\author{
A Thesis \\ Presented to \\ The Faculty of the Department of Communication Studies \\ San José State University \\ In Partial Fulfillment \\ of the Requirements for the Degree \\ Master of Arts \\ by \\ Minna J. Holopainen
}

December 2010 
(C) 2010

Minna J. Holopainen

ALL RIGHTS RESERVED 
The Designated Thesis Committee Approves the Thesis Titled

\section{OUTCOMES OF DIALOGIC COMMUNICATION TRAINING \\ ON A CITY GOVERNMENT MANAGEMENT TEAM}

by

Minna J. Holopainen

APPROVED FOR THE DEPARTMENT OF COMMUNICATION STUDIES

SAN JOSÉ STATE UNIVERSITY

December 2010

Dr. Shawn Spano, Chair Department of Communication Studies

Dr. Hanns Hohmann Department of Communication Studies

Dr. Federico Varona Department of Communication Studies 


\title{
ABSTRACT \\ OUTCOMES OF DIALOGIC COMMUNICATION TRAINING \\ ON A CITY GOVERNMENT MANAGEMENT TEAM
}

\author{
by Minna J. Holopainen
}

Managing diversity in today's organizational environments can challenge many organizations. This action research study addresses that challenge by investigating the outcomes of dialogic communication training on a city government management team experiencing organizational diversity. The study consisted of four phases: (1) individual interviews for needs assessment, (2) focus group meeting for training design, (3) dialogic communication training, and (4) individual interviews for assessment of the outcomes. The results of this study indicate that dialogic communication and the development of dialogic style of leadership through dialogic communication training provide a valuable and practical approach for work teams. Specifically, management team members' communication skills improved, they adopted a more participatory management style, and they reported higher levels of relational satisfaction. Study findings highlight the need for practitioners to assist in developing communication training that facilitates emergent dialogue. 


\section{ACKNOWLEDGEMENTS}

Many individuals contributed significantly to the successful completion of this thesis. First, I am most thankful to the nine senior managers from the participating city government organization who graciously donated their time and attention to this study, and who were willing to adopt new ideas and apply them in their daily work and beyond. Without their efforts and availability, this study would simply not exist. Second, I am deeply grateful to the Assistant Director who did not only make her team of managers available for this study, but whose insightful ideas, theoretical knowledge, sensitivity, and thoughtfulness contributed to the many theoretical and practical revelations during the study process. Her inside perspective into the organization of study was invaluable.

The idea for this study was sparked by Dr. Shawn Spano's inspiring passion to dialogic communication and his compassion toward humanity. I want to express my most sincere appreciation and gratitude to him for chairing my thesis committee and being my advisor, mentor, and role model. I feel greatly indebted to him for his more than generous availability, unswerving mentoring, and his devotion to sharing his extensive knowledge and experience as a scholar, teacher, and practitioner. His responsiveness, encouragement, and trust in my potential truly sustained me during this long study process.

Thanks are due to two distinguished scholars, Dr. Hanns Hohmann and Dr. Federico Varona, whose stimulating questions and comments clarified many ideas and opened up new perspectives along the way. Dr. Hohmann's expertise in rhetoric and philosophy, his sharp reasoning, and his spirited discussions made the foundation of this 
thesis stronger and energized the study process. Dr. Varona's international understanding of organizational communication and appreciative inquiry provided this thesis with a contemporary global perspective.

I am most grateful to Dr. Deanna Fassett, whose guidance as my supervisor in SJSU's Graduate Teaching Associate program gave me the confidence and the skills required for conducting the training in this study. She is the teacher I want to become. Thanks are also due to Bettina Brockmann, my colleague and thesis friend for listening and sharing her enthusiasm with me.

Lastly, wholehearted thanks to my husband Timo, who has supported and sponsored my studies over the last seven years, and our daughters Sonja and Sara for their patience and support during the process that fulfilled a life-long dream. Without you, there would be no point. 


\section{TABLE OF CONTENTS}

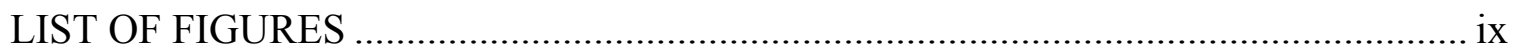

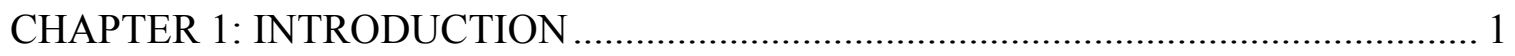

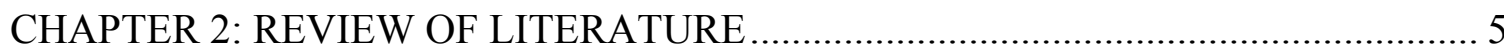

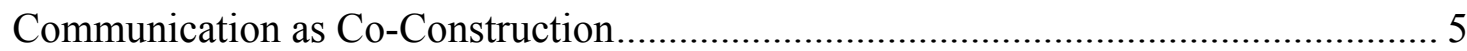

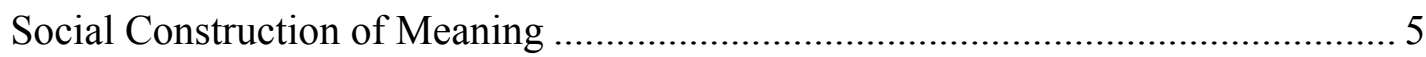

Interpretive Nature of Knowledge ....................................................................... 6

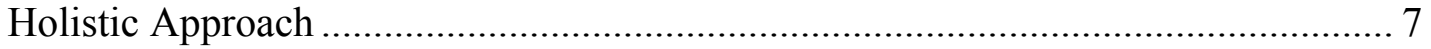

Practical Application of the Social Construction Theory ............................................ 8

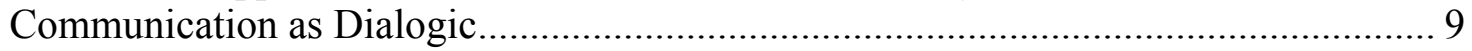

Prescriptive Approach to Dialogue ……………………..................................... 10

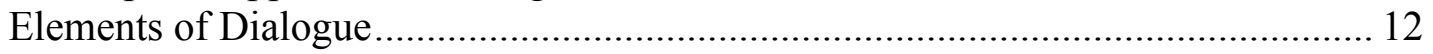

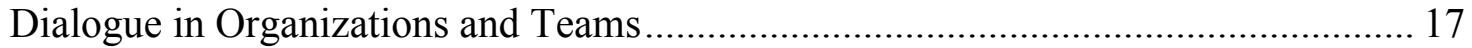

Better Adaptability to Organizational Environments ................................................ 18

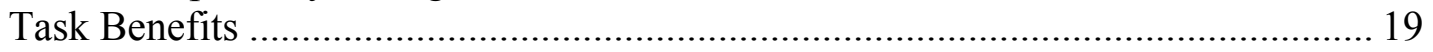

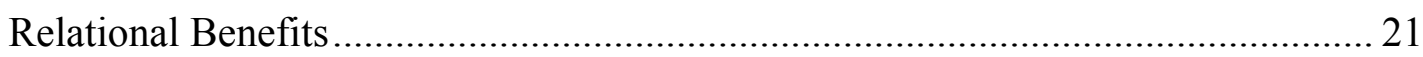

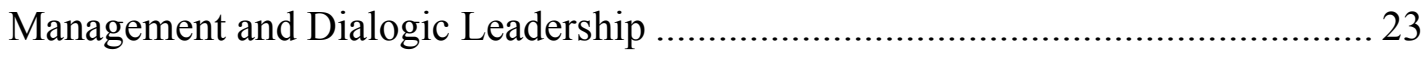

Need for Dialogue Practitioners and Trainers ……………...................................... 27

The Focus for This Research Study ...................................................................... 30

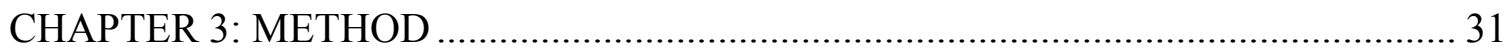

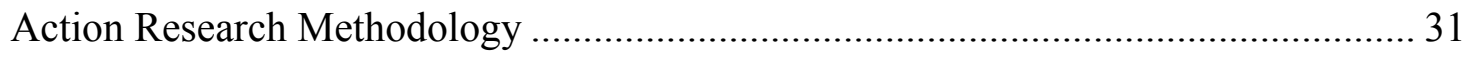

Collaborative and Participatory Research Method .................................................. 32

Practical Outcomes Informed by Theory ................................................................ 33

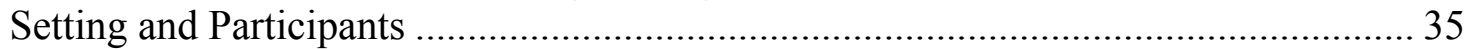

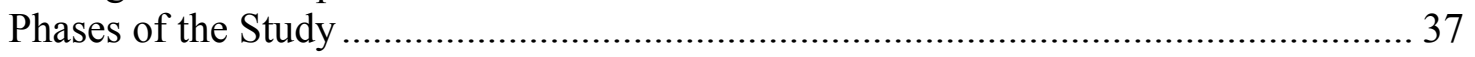

Looking Phase for Interviews ........................................................................... 38

Thinking Phase for Focus Group Discussion.......................................................... 42

Acting Phase for Dialogic Communication Training .............................................. 48

Looking Again Phase for Final Evaluation................................................................. 64

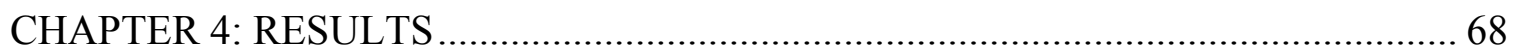

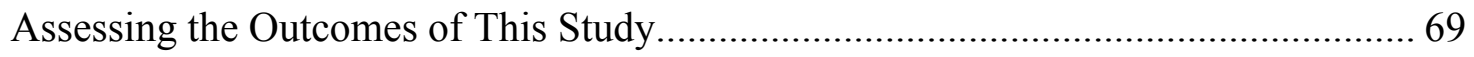

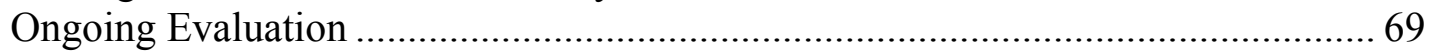

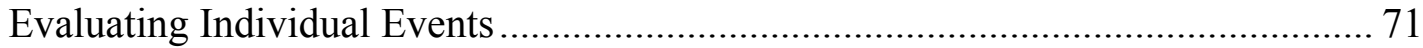

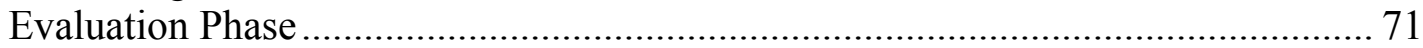

Communication Challenges Facing a City Government Management Team .............. 71

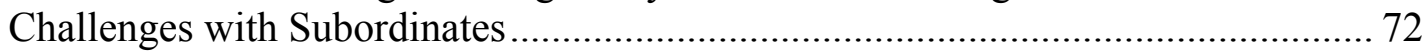

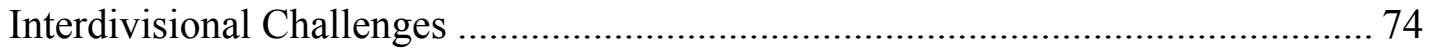

Challenges with Organizational Hierarchy …………............................................. 77

Challenging Organizational Climate................................................................. 78

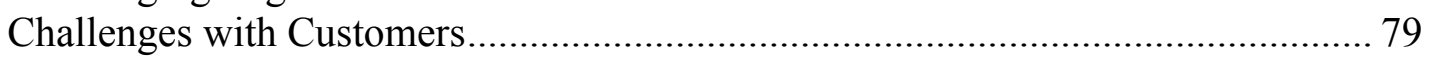


Outcomes of Dialogic Communication Training on a City Government Management

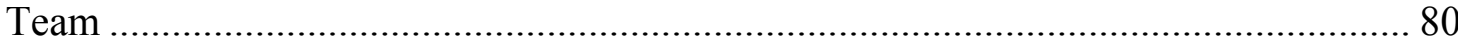

Shared Conceptual Communication Model ………………................................... 80

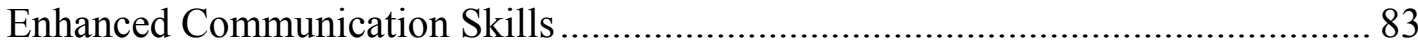

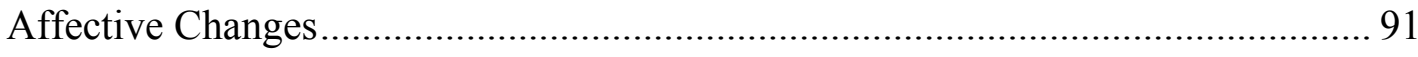

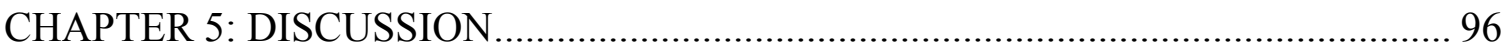

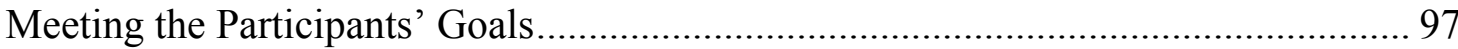

The Current Urgency for Dialogic Leadership ........................................................... 98

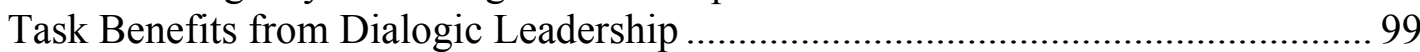

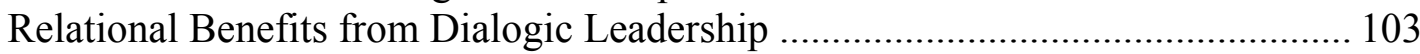

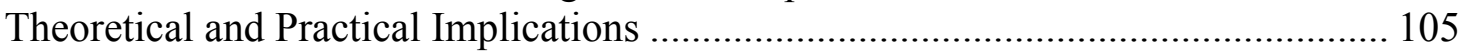

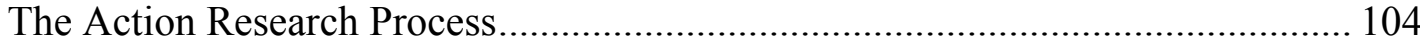

Episodic Approach and Dialogue Practice ........................................................... 106

The Value of Learning both Theory and Practice.................................................... 108

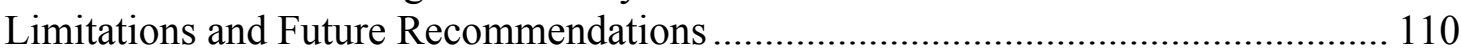

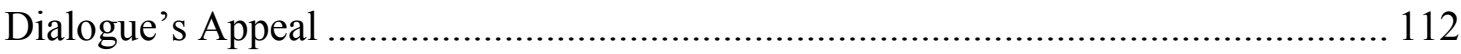

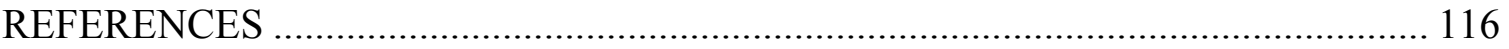

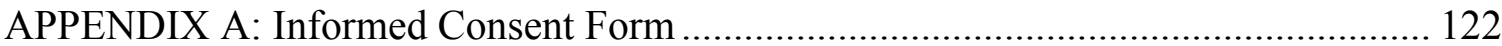

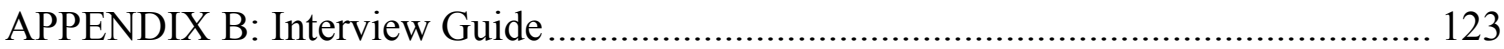

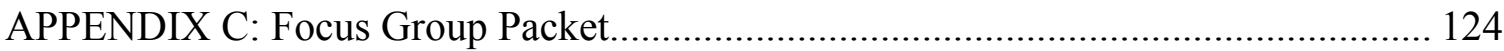

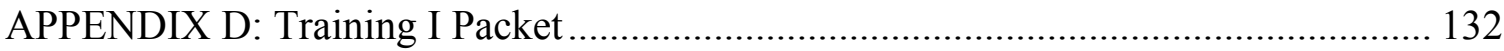

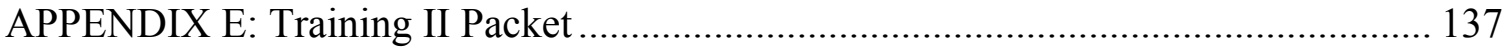

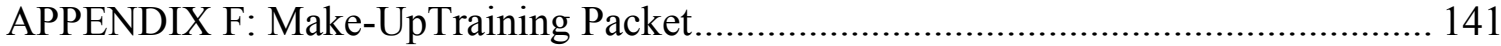




\section{LIST OF FIGURES}

Figure 3-1. Social constructionist model of communication (taken from Spano, 2010) 51

Figure 3-2. Conflict model (reproduced from Littlejohn \& Domenici, 2007) ............... 52 



\section{Chapter 1: Introduction}

The history of madness would be the history of the Other-of that which, for a given culture, is at once interior and foreign, therefore to be excluded (so as to exorcize the interior danger) but by being shut away (in order to reduce its otherness); whereas the history of the order imposed on things would be the history of the Same - of that which, for a given culture, is both dispersed and related, therefore to be distinguished by kinds and to be collected together into identities. (Foucault, 1966/1994, p. xxiv)

Globalization drives today's work force into increasingly international labor markets. In organizations, this trend calls for rapid change and the emergence of a growing number of multicultural teams (see Kimmons, 1999; Konopaske \& Ivancevich, 2004). As a result, not only are the work teams becoming more diverse than before, but so are the individuals themselves who constitute a rich "spectrum of human differences" (Konopaske \& Ivancevich, 2004, p. 223).

Organizations form work teams to achieve performance that results in desired outcomes. In teams, people pool their knowledge and efforts to accomplish common goals by aligning individual team members' contributions. Although there are undoubtedly many benefits for working in teams, such as a possibility for increased creativity and diversity of views (Adler, 2008, p. 135), some researchers have found that individuals often work better by themselves (Diehl \& Stroebe, 1987; Lamm \& Trommsdorff, 1973; Taylor, Berry, \& Block, 1958), and that teams rarely meet their full productive capacity (e.g., Davis, 1969; Steiner, 1972).

The challenges of effective teamwork are often greatly exacerbated by diversity, an array of human variation deriving from differences in age, ethnicity, culture, gender, physical attributes, race, affective orientation, educational background, marital status, 
religious belief, health disabilities, work experience, etc. (see Konopaske \& Ivancevich, 2004, p. 211), as well as any other positions that contribute to the richness of opinions, perspectives, preferences, and styles in organizations and teams. Diverse or heterogeneous teams may experience a lack of cohesion, increased mistrust, miscommunication, and stress. Moreover, members might not be able to validate other members and their ideas, agree when necessary, gain consensus on decisions or take concerted action together (Adler, 2008, p. 135). In heterogeneous teams, diversity is not always valued and pressures for conformity often thwart opinions that are held by a minority of members (Deetz \& Simpson, 2004). Difference after all, as Foucault (1966/1994, p. xxiv) describes in the quotation above, can feel threatening, like "madness," whereas sameness is more comprehensible, sensible, and orderly. Importantly, however, diverse teams can be more creative, effective and productive than homogeneous teams because they can elicit more ideas and perspectives in quantity and quality than homogeneous teams (Adler, 2008, p. 135). For this reason, diverse teams are often indispensable for thriving organizations in today's dynamic, multicultural working environments.

I was introduced to an Assistant Director of a diverse city government organization in one of my graduate classes in fall 2009. At the time, she was working with nine senior managers who were coping with significant organizational changes due to three rounds of budget cuts during that year. Organizational restructuring, layoffs, and diminishing organizational resources created a bleak and depressing organizational climate that challenged managers as they were trying to sustain their teams' spirit, 
performance, productivity, and morale. Moreover, this difficult situation taxed managers' interpersonal relationships as diversity of views and personalities were sometimes difficult to appreciate and reconcile.

Managing differences in diverse teams so that they can excel in today's diverse and dynamic working environments is a challenge dialogic communication, in which all interactants simultaneously express and hold valuable their own as well as others' views, can help address. There are several reasons why teams can benefit from leadership that employs dialogic communication practices. First, dialogic communication can help teams surface multiple perspectives, including views and frameworks that cross established boundaries and are not normally accepted within particular disciplines, industries, or organizational contexts (Pearce, W. B. \& Pearce, K. A., 2004, pp. 119-120). Dialogic communication can enable teams to hold these varying perspectives, often competing and seemingly contradictory, in tension with one another, providing unique opportunities for creativity, innovation, and transcendence. Thus, dialogic communication can facilitate learning and assist teams in better understanding the complexity of issues and problems the teams are confronted with. Second, dialogic communication can bring forth a deeper understanding of the people themselves and their interpersonal relationships within their teams (Baxter, 2007). As a result, members of teams are better able to resolve successfully the key issues and problems they face at the moment and also those that may arise in the future.

Dialogic communication, however, is not normally practiced in most organizations, and most work teams and their managers lack the necessary knowledge 
and skills to engage in dialogue. Besides, dialogic communication can be timeconsuming and its results unpredictable due to the emergent nature of dialogue. For these reasons, there is a need for skilled dialogue practitioners who are able to apply dialogue theory in ways that are meaningful to work teams in order to produce practical outcomes that are important to team members. And at the same time, as the practitioners facilitate dialogic communication, they do not only engage in mutual consultation, but they also build capacity in the organization to communicate in a non-adversary, collaborative and productive manner in the future.

The Assistant Director from a city government organization invited me to conduct an applied communication research study that was designed to build dialogic communication capacity in her management team. This invitation resulted in the current thesis research study, which was designed to achieve three purposes: first, identify the team's communication strengths and challenges; second, design a customized dialogic communication training program for the team to help it make use of its strengths and to meet its challenges; and third, evaluate the outcomes of the dialogic communication training on the team. 


\section{Chapter 2: Review of Literature}

The multifarious usage of the word dialogue - from literary and theatrical forms of conversation to digital marketing tools that help organizations effectively reach target audiences (see Leino, 2010) — can be rather bewildering. In order to avoid confusion, it is essential that the term dialogic communication, the key idea of this thesis, be thoroughly explained within the context of this work. Hence, the first two parts of this literature review focus on the theoretical definition of dialogic communication, and then, the last part situates dialogic communication in the organizational context in which this study was conducted.

\section{Communication as Co-Construction}

Human communication is an intricate process of co-coordinated meaning making. This assertion derives from social construction theory (Berger \& Luckmann, 1967), and has ontological and practical implications that are discussed in what follows.

Social construction of meaning. Building on the phenomenological sociocultural tradition of communication research, this study focuses on interaction between people rather than on individuals' inherent qualities or on mental models of "transferring information from one mind to another" (Craig, 1999, p. 125). Within social interaction, meanings for various symbols, roles, rules, and values of various social groups, organizations, and cultures are created and negotiated in communication by people together (Littlejohn \& Foss, 2005, p 45). In fact, human communication is a dynamic meaning-making process in which meanings are expressed in actions, and the 
actions, in turn, reconstruct meanings (Pearce, W. B., 1989, pp. 23-25; cf., Craig, 1999, p. 126).

Meanings, the inputs and outcomes of social interaction processes, are polysemic, contextual, processual, conventional, and value-laden (Spano, 2007). The polysemic nature of meaning points to the coexistence of multiple meanings for one symbol of an idea that can take drastically different shapes within various life situations. For example, among other meanings, the word book can refer to a bound collection of pages (a book on a table), a written text ("She wrote a book") or a verb ("Would you book me a room, please.") Meanings are also highly contextual; they change depending on the context they are expressed in. Moreover, since meanings are continuously created and recreated in social interaction, they are processual, dynamic, negotiable, and always in flux. Worthy of notion is also the sequence of the events leading to a creation of new meaning, because when the sequence changes, so does the meaning. And although some meanings have more established definitions than others, all meanings are conventional and valueladen social agreements that call forth moral evaluations.

Interpretive nature of knowledge. Striphas (2006) defines communication as "the intersubjective co-construction and sharing of meaning, value, and experience, a process made possible by various forms of symbolic exchange" (p. 234). Symbols, the carriers of socially constructed meanings, are deposited in a sign system, "a large aggregate of collective sedimentations" (Berger \& Luckmann, 1967, p. 69) called language. Language has a profound impact on the nature of knowledge. Berger and Luckmann explain: 
Language objectivates the shared experiences and makes them available to all within the linguistic community, thus becoming the basis and the instrument of the collective stock of knowledge. Furthermore, language provides the means for objectifying new experiences, allowing their incorporation into the already existing stock of knowledge, and it is the most important means by which the objectivated and objectified sedimentations are transmitted in the tradition of the collectivity in question. (p. 68)

It can be concluded, then, that knowledge is constructed with and through language in social interaction (i.e., communication). Because meanings are polysemic, contextual, processual, conventional, and value-laden, there is no one "true" meaning for a linguistic expression, but instead, multiple and occasionally conflicting meanings may exist simultaneously. For example, depending on the nature of the work, some managers may consider quiet work in which subordinates keep to themselves as productive, whereas some other managers might regard subordinates' more lively interaction as productive work. Thereby, knowledge in the sociocultural tradition is highly interpretive (Littlejohn \& Foss, 2005, p, 45). Accordingly, this study regards research data as only one, socially constructed interpretation of a collection of relatively randomly selected phenomena.

Holistic approach. Through the communication perspective, individuals can be seen as engaging in "deeply textured clusters of persons-in-conversation" (Pearce, W. B. \& Pearce, K. A., 2004, p. 41). The holistic research approach, which is typical for the sociocultural tradition (Littlejohn \& Foss, 2006, p. 45), does not break these clusters into smaller analyzable parts (i.e., reductionism), but rather tries to understand broader contexts and possible synergistic connections (Ellinor \& Gerard, 1998; Stewart, Zediker, \& Black, 2004). 
Unlike the traditional logical positivistic approach to knowledge, the holistic perspective treats values, emotions, and intuitions as valuable data. For example, Yankelovich (2001) believes that combining traditional knowledge with values and emotions produces "wisdom" (pp. 190-191). Also, many other scholars point out the importance of non-traditional knowledge. Stewart (1978) sees intuition as a form of rigorous thought, and Wonder and Donovan (1984) show that the use of both logical/rational and intuitive/creative parts of the brain seems to be the most valuable combination for problem solving. De Bono (1985) defends intuition and feelings as essential parts of effective decision making since they constantly color thinking in the background, and once a decision has been made, react to the value base of the decisions (pp. 67-79). Kim and Kim (2008) argue that intuition is essential for rational deliberation because the "prerequisities of deliberations" (i.e., shared values, procedural rules, public reasons, etc.) emerge from casual, spontaneous, and nonpurposive discussion that is seemingly irrational, characterized by free interaction among people, and aimed at mutual understanding.

This study adopts a holistic research approach, paying attention to multiple contexts and factors affecting the process of emerging meanings while also being conscious of the finiteness and selectiveness of human observation and the infinite layers of meanings: There is always more to find out.

Practical application of the social construction theory. The social construction theory (Berger \& Luckmann, 1967) has remarkable value in its practical application to real-world communication situations. The construction process of knowledge, or 
meaning making, is fashioned by the way people talk about issues, the language they use, the nonverbal actions they perform when using spoken language, and the way in which they orient themselves to their common experiences. Fundamentally, this process forms the identity of the emerging meaning (Littlejohn \& Foss, 2005, p. 46), or, in other words, the way people communicate shapes the meanings they make.

The meaning-making process becomes visible in communication patterns, the mutual back-and-forth responding of interactants. Communication patterns are constituted in co-constructed individual utterances or speech acts (see Austin, 1962/1975; Searle, 1969). The whole meaning of these acts emerges from the interaction between the interactants and their patterns of speaking and responding.

Whereas some of these patterns are beneficial and build desirable social worlds, some others can be harmful and destructive. This is especially problematic when harmful patterns become conventionalized and when they are enacted as usual, taken-for-granted ways of interacting. For example, highly adversarial meaning making processes may result in wars, whereas inclusive and restorative communication can build peace. When the process of meaning making is made visible and speech patterns are examined, change can take place; things can be made differently. Undesirable and unproductive communication patterns can be changed into more desirable, productive, and constructive ones by changing the construction process, they way people communicate.

\section{Communication as Dialogic}

Since realities are constructed in communication, different forms of communication create different kinds of realities. Dialogic communication is a form of 
communication that can construct positive realities that enable participants to effectively manage and learn from their differences and diversity.

The scholarly literature defines dialogue in an array of different ways. Herzig and Chasin (2006, pp. 139-140) conceptualize dialogic communication as being the opposite of argumentative debate: Whereas in argumentation participants compete and try to win, in dialogue they collaborate and mutually try to understand each other.

Based on Herzig and Chasin's (2006) work, Spano (2010) describes what differentiates dialogic communication from argumentative communication (p. 9). First, dialogic communication values empathetic listening and authenticity, and in dialogue, participants speak from their personal experience and ask questions out of true curiosity, not because they try to win over the other participant as in argumentative communication. Second, dialogue creates an inclusive atmosphere of safety in which new significant things can be discovered, while in argument participants try to defend themselves and their pre-existing views. Third, dialogue is creative. It aims to complexify issues being discussed, whereas in argumentation participants tend to simplify and polarize their views and take sides. Because dialogue focuses on discovering shared concerns between the participants and surfacing differences when they are not obvious, it can result in original insights and perspectives.

Prescriptive approach to dialogue. One way to distinguish between the various views on dialogue is to differentiate descriptive approaches from prescriptive ones. Descriptive approaches regard dialogue as inherent to all human interaction, "the irreducibly social, relational, or interactional character of all human meaning-making" 
(Stewart \& Zediker, 2000). Theorists such as Mikhail Bakhtin, H. Romano Harré, Kenneth J. Gergen, Barbara W. Montgomery, Leslie A. Baxter, and Hans-Georg Gadamer represent this orientation (Stewart, Zediker, \& Black, 2004).

Prescriptive approaches conceptualize dialogue as a certain quality of communication — dialogic communication — a non-confrontational method set apart from other forms of communication, such as debate, discussion, or deliberation (Pearce, W. B. \& Pearce, K. A., 2000). Stewart, Zediker, and Black (2004) list Martin Buber, David Bohm, Paulo Freire, and John Shotter as prescriptive dialogue theorists.

Prescriptive dialogue's central point is ethical. Stewart and Zediker (2000) parallel it with Aristotle's notion of praxis, pointing out that prescription calls forth participants' moral judgments about communication. Thus, prescriptive approaches require participants to make conscious choices about how to communicate with others. Accordingly, prescriptive dialogue can be seen as empowering. In the words of Rothenbuhler (2006), "What a nicer world would it be if we always stopped to think before we spoke, 'I will create a new reality, do I want to live in it?'” (p. 19).

Descriptive theories can certainly provide some analytical insights for opening space for multiple perspectives and creativity as well as for improving interpersonal relationships in work teams. Prescriptive approaches, however, go further by making dialogue pragmatic (see Kim \& Kim, 2008) because they regard each participant as a moral agent who makes choices. For that reason, they provide better possibilities for active, practical change in work teams than descriptive approaches do. Accordingly, I 
have chosen the prescriptive perspective for this study, which also aligns noticeably well will the action research methodology used in this study.

Elements of dialogue. Martin Buber (1937/1950), a Jewish philosopher and a prominent dialogue scholar, theorizes that people who engage in dialogue are able to maintain the validity of their own viewpoints while remaining open to others' viewpoints in a context in which there are no predetermined outcomes. In dialogic communication, full meaning is not clear from the outset but unfolds in the course of a particular conversation or social interaction. This process takes place between the self and the other.

Self, other, and between. The social constructionist view sees self as a process that is constantly made and remade in communication. In the words of George Herbert Mead (1934), "all selves are constituted by or in terms of the social process, and are individual reflections of it" (p. 201). Also Poulakos (1974) believes that self arises in interaction with others while one's experience of otherness mirrors the experience of self.

Since self arises in interaction with others, one is able to experience self only in relation with another self (Shepherd, 2006, p. 24). Shepherd illuminates this process in a very uncomplicated manner: "You and me jointly make up you and me. My understanding and your understanding jointly make up my understanding and your understanding. And the 'making up' part is communication" (p. 27). To the point, Shepherd writes that "communication is the simultaneous experience of self and other" (p. 22, emphasis omitted). In work teams, this means that communication is not only the vehicle to coordinate action in order to accomplish tasks, but it also has a profound 
impact on interpersonal relationships between the team members and the development of their identities.

Buber (1937/1950) suggests that the self can be different depending on the way it relates to others. He suggests that the construction of an authentic self, $I$, and a familiar other, Thou, requires special communicative conditions, namely, dialogic I-Thou communication, in which one is holding his/her own ground while being open to another (p. 28). Buber contrasts I-Thou with I-It relations, in which the self is more strategic and the other more instrumental. He sees all meaning making as a stream running through both I-Thou and I-It relations:

The particular Thou, after the relational event has run its course, is bound to become an $I t$. The particular $I t$, by entering the relational event, may become a Thou... Without $I t$ man cannot live. But he who lives with $I t$ alone is not a man $\left[\mathrm{sic}^{1}\right]$. (pp. 33-34)

So, according to Buber, I-Thou communication (i.e., dialogue) is not absolutely necessary for all meanings to emerge, but dialogue is the quality of communication that makes people human.

Dialogic communication requires a mutual, symmetrical relationship in which the participants are turned toward each other in the tension of holding their own grounds while being open to the other. According to Kaplan (1969), this requires mutual implication and communion. In dialogue, self and other are not blending together, however. Poulakos (1974) points out the importance of the distance between these two, because only detachment makes the distinction possible. These entities have blurry

\footnotetext{
${ }^{1}$ In the original German text, Buber uses a non-gendered pronoun "Mensch," which can be translated as "human being." The gendered "man" comes from the English translation.
} 
boundaries on the borders of the between, the "sphere of the interhuman... without which dialogue cannot be conceived" (Poulakos, 1974, pp. 207, 209). Stewart (1978) sees this between as an arena for dialogue; he defines dialogue as dynamic, complex, contextdependent communicative transaction that focuses on reciprocal relationship between the communicators.

Once established, the between is constantly changing and evolving (Poulakos, 1974), just like the other two basic building blocks of dialogue, the self and the other, that are continuously expressed in practices that, in turn, recreate and shape each other.

Tensionality. Tensionality describes the fluidity and dynamism of any construct, the dialectical pull of complementary and contradictory (Stewart, Zediker, \& Black, 2004, pp. 23, 27) or the centripetal (i.e., unity) and the centrifugal (i.e., difference) (Bakhtin, 1981, p. 272). A fundamental tensionality of dialogue derives from the Buberian holding one's own ground (I) while remaining open to the other (Thou). In dialogue, the participants are constantly balancing the tension between these two forces. Holding one's own ground means that participants regard their own thoughts and ideas as legitimate and willingly expresses them. At the same time, being open to the other means that they recognize the validity of others' thoughts and ideas. In dialogue, openness to the other does not threaten or weaken one's own ground nor does it necessarily try to change it, but instead, openness requires genuine interest and curiosity to see the other's perspective (Buber, 1937/1950; Spano, 2010).

Poulakos (1974) defines three other tensionalities of dialogue. First, self is continuously balanced by the tension between individuality (undivided self) and 
dividuality (divided self). In order to grow, either the undivided self or the divided self needs to change. Dialogue happens when both these selves agree to alter their conditions. The second tensionality in dialogue occurs between the self that becomes created and the self that is resistant to change. And third, the active participant self remains in tension with the passive observer self in dialogue.

Experientiality. According to Stewart (1978), experiential knowledge is the foundation of knowing. Put in a very simple way, "people can know what they are doing only after they have done it" (Weick, 1995, p. 24). Dialogue shifts the focus from a transcendental knowing into intersubjective experience of the self and the other (Stewart, 1978). Being "open to the other" (Buber, 1937/1950) and letting the other "happen to oneself" (Pearce, W. B. \& Pearce, K. A., 2000) without a premeditated agenda, is experiencing communication in the moment.

Holism. Stewart (1978) and Baxter (1982) recommend a holistic approach for researching dialogue. A holistic perspective is appropriate for the practice and study of dialogue because it strives to reveal rich layers of meaning, recognizes those layers' and various meanings' interrelatedness, and invites the emergence of new meanings by questioning and complexifying old ones. Accordingly, this study adopts a holistic research perspective to study communication.

Temporal nature. Peters (2006) defines dialogue as an immediate form of communication that shrinks communicative distances both in time and space (p. 213). Also Buber (1937/1950) points out the temporal nature of dialogue (I-Thou) in contrast to I-It communication: "The $I t$ is the eternal chrysalis, the Thou the eternal butterfly" (p. 
18). These unexpectedly emerging butterflies are sometimes called dialogic moments (e.g., Cissna \& Anderson, 1998). Cissna and Anderson (1998) describe dialogic moments as follows:

The basic character of such a dialogic moment, therefore, is the experience of inventive surprise shared by the dialogic partners as each "turns toward" the other and both mutually perceive the impact of each other's turning. It is a brief interlude of focused awareness and acceptance of otherness and difference that somehow simultaneously transcends the perception of difference itself. (p. 74)

Some scholars focus less on dialogic moments, however, and instead, emphasize an approach to dialogue that expands the scope of interest from single moments into larger communication episodes (e.g., Pearce, W. B. \& Pearce, K. A., 2004, p. 46). From this episodic perspective, dialogue is conceptualized as a quality of interaction that manifests itself in reflexive relationships within communication actions and episodes. More specifically, this approach focuses on the communication acts that are performed in various social contexts, giving attention to how those acts both shape and are shaped by the episode that the participants are enacting. Within a particular communication episode, some communication acts move the quality of interaction toward dialogue, and thus, help construct the larger communication episode as dialogic. Conversely, some communication acts might not appear to have dialogic qualities, but when examined in combination with other communication acts within the episode, they might indeed reflect moves toward dialogic communication. So, instead of looking solely for moments of dialogue, the episodic approach examines how communicative actions are linked together to construct and re-construct larger social episodes. This study adopts an episodic 
approach by assuming that dialogic communication depends on the specific actions being performed and the larger social episode that shapes the meaning of these actions.

Requisites for the emergence of dialogue. Buberian dialogue focuses on the interhuman space of meeting, the between, where human interaction unfolds spontaneously (Buber, 1937/1950; Spano, 2006, pp. 4-5). Although, in this space, dialogue emerges in unpredictable moments that cannot be planned for, forced, or made to happen (Anderson, Baxter \& Cissna, 2004, p. 15), dialogue can be fostered by certain conditions. Poulakos (1974) lists four conditions that need to be met for the emergence of the between (or this space): physical presence, mutual awareness, interaction, and attitudinal openness to be influenced by the other. Alternately, consonant with Buber's dialogue theory, Spano (2006) has highlighted three requisites for the emergence of dialogue: authenticity of being oneself, empathic otherness, and immediate presentness (p. 5). These three requisites underlie the dialogue practices that will be used for this study.

\section{Dialogue in Organizations and Teams}

Effective teams excel in two areas: they accomplish their tasks and build good interpersonal relationships. These two areas are profoundly interconnected with a third factor affecting teams' success, the contexts in which teams work. Littlejohn and Foss (2005) recommend careful consideration of teams' communication in order to make sure that these three factors are contributing to a team's success (pp. 233-236). Next, each of these three factors is examined separately, starting with the last one, and analyzing some reasons why dialogic communication can make organizations more responsive to the 
demands of their organizational environments (context). Then a discussion about how dialogic communication can help tackle task and relational challenges follows.

Better adaptability to organizational environments. Today's rapidly changing organizational environments challenge conventional power structures that reside in tall, rigid, and hierarchical organizations. In general, faster responsiveness and adaptability to these unstable environments require flatter, more organic organizational structures that provide innovativeness and low vertical differentiation that facilitate fluid communication channels and fast decision making. As a result, organizations have less hierarchy and fewer members who exercise positional power and authority over others. These flattened organizations may cause a considerable amount of conflict among organizational members when managed poorly (Yankelovich, 2001, pp. 12-13), which is one of the most compelling reasons why today's managers urgently need dialogic communication skills. Dialogic communication helps organizational members to level traditional power differences by empowering all organizational members to share their perspectives, experiences, and contributions.

Another reason why managers need dialogic communication skills today is that dialogue can help organizations respond to the increasing demand for a vigorous customer orientation by stimulating unconventional thinking and novel approaches to problem solving (Yankelovich, 2001, p. 13). Dialogue promotes a deeper understanding of issues because it can boost employees' creativity, innovation, and initiative, all talents that are acutely needed in highly unstable organizational environments. 
Present-day managers need dialogic communication skills because an increasing number of organizations are forming strategic alliances in order to stay in the market and to gain competitive advantage (Yankelovich, 2001, p. 13). Alliances bring together people from different organizational cultures, structures, and sometimes languages. Working with people from diverse backgrounds in multicultural organizations can be a challenge for effective teamwork, particularly because as organizations join forces with other organizations or respond to declining markets, they tend to downsize relevant functions and lay off employees. Dialogic communication can mitigate the negative organizational impact of these changes because it promotes positive change, helps repair remaining employees' potentially damaged morale, and makes conflicting value systems more compatible (Yankelovich, 2001, pp. 214-216).

Lastly, dialogic communication contributes to aligning organizational teams to implement their shared visions and strategies (Yankelovich, 2001, p. 13). As an inclusive and empowering form of communication, dialogue builds trust between people, increases comfortableness and cooperation between them, gives them a sense of a shared identity, and facilitates working relationships across institutional boundaries.

Task benefits. Dialogue can potentially spawn creativity and innovation. Differences in teams can be valuable since they challenge group's uncritical satisfaction with its own abilities, counteract groupthink (Janis, 1972), boost growth and adaptation, and increase the stability of an organization (e.g., Putnam, 1995). Kelshaw (2006) points out that differences are critical for growth:

If we view meaning as made within our interactions, then it follows that interactions are dynamic, creative processes. The creativity of relating cannot 
happen by means of stasis, which would result, impossibly, in the death of meaning. If you and I were perfect replicas and if there were no one else on Earth to interfere with us, we would neither disagree nor change (nor need to communicate, for that matter), and we would live together in perfect peace (not to be confused with harmony, which requires aligned difference; ours would be unison). (p. 158)

The way a team handles its differences contributes directly to its success in accomplishing its task (Gouran \& Hirokawa, 2003; Janis, 1989). Irrelevant differences may often remain unnoticed, but differences that challenge team members call for special management. When relevant differences are managed well, they can be valuable by providing opportunities for growth, change and vitality (Baxter, 2006, pp. 103-104). When differences are managed poorly, they can be harmful and even destructive.

Since differences are created, recreated, maintained, and eradicated in communication (Pearce, W. B. \& Pearce, K. A., 2004, pp. 41-42), they are also managed in communication. Monologue, static authoritative discourse, suppresses creativity and innovation in work teams. In such situations, considering multiple perspectives is difficult because team members are pressing for a resolution in which one, often the dominating side wins while the other ones are ignored. This kind of management of difference is characterized by inertia, semantic limitedness, and calcification of meanings, which might make teams less effective (Baxter, 2007). Various techniques, such as devil's advocate (Janis, 1972), have been suggested for surfacing differing viewpoints and motivating criticism toward a team's decisions. Schulz-Hardt, Jochims and Frey (2002), however, show that genuine dissent is more effective for information seeking than contrived dissent. 
It is evident that the outcomes of monologic management of difference are different from the outcomes of dialogic management of difference that regards alternate views as potentially valuable. Dialogic communication provokes intuitive and unorganized ways of thinking (Buber, 1937/1950, pp. 30-31) because it genuinely encourages the expression and the emergence of multiple and novel ideologies and perspectives, and because it embraces differences without pressing for resolution (Pearce, W. B. \& Pearce, K. A., 2004, pp. 119-120). Dialogue welcomes multivocality, cacophony, and discord, opens communication to creativity (Baxter, 2007), and steers away from polarizing positions. Being multivoiced and non-polarized (Littlejohn \& Domenici, 2007, p. 245), dialogue is especially beneficial in teams that are threatened by groupthink (Janis, 1972), that is highly cohesive teams' tendency to uncritically suppress dissent.

Because dialogic communication provides space for understanding issues better from multiple perspectives, unique insights, creativity, and innovation, dialogic communication skills are crucial for leaders who need to manage highly responsive and adaptable teams in rapidly changing environments.

Relational benefits. As noted before, effective teams are able to build and maintain good interpersonal relationships (Littlejohn \& Foss, 2005, p. 235). All relationships are dynamic: team members actively manage tensions that stem from their differences (see Littlejohn \& Foss, 2005, pp. 207-210). The way differences are defined and the way in which they are managed have direct consequences not only on team members' relationships but also on the outcomes of team's current and future work. 
Moreover, interactions between individuals in teams vibrate outside the team into other contexts, and thus have consequences elsewhere (Littlejohn \& Domenici, 2007, p. 55), such as in the larger organization and in people's private lives.

Relationships are built, maintained, modified, and coordinated in communication. Dialogic communication is an effective way to manage interpersonal differences in teams since it appreciates individual variance and looks deeper into diverse realities (e.g., Baxter, 2007; Littlejohn \& Domenici, 2007; Pearce, W. B. \& Pearce, K. A., 2004). Dialogic communication discourages both rivalry and forced unanimity. It fosters listening and respect while it steers team members away from power struggles, bargaining, and competition.

Dialogue also promotes deeper understanding of people and their perspectives. This does not necessarily mean that people always have to accurately grasp each other's ideas. In fact, Gurevich (1989) states that understanding follows the ability to first not to understand the other. Assuming a not-knowing position requires an empathic attitude of openness to new insights from the side of the other interactant and an attempt to experience the world from that perspective by simultaneously withholding one's own position and ideas (Spano, 2010). Thus, understanding others is more an attitude, as Shepherd (2006) explains:

[U]nderstanding one another has nothing to do with accurately interpreting one another. Rather...understanding has to do with the adoption of a certain stance or orientation of sympathetic awareness (a common secondary definition of understanding). When we experience another in communication, we come to be in sympathy, or in common feeling, with that other. This common feeling is the sense of sharedness we often assume in engaging with others. (p. 24) 
Dialogue is an inherently ethical way of communicating (Stewart \& Zediker, 2000) because it recognizes the legitimacy, value, and potential contributions of all people, including all members of an organizational work team. As a non-adversarial, alternative dispute resolution method, dialogue helps teams to better understand their conflicts, to manage them more constructively, and to frame their differences affirmatively because all participants are treated as "fully formed, whole and complex human beings" (Littlejohn \& Domenici, 2007, p. 245).

Management and dialogic leadership. Numerous forces contribute to internal and external uncertainty of today's organizations, pushing them for constant adaptation and change. One of the most powerful forces at play today is the rapid globalization and diversification of societies that are affecting practically all industries (Lewis, Goodman, Fandt, \& Michlitsch, 2007). As a result, the workforce is more heterogeneous and employees are less loyal to their employers than before. Often, employees are demoralized by oversized workloads or other effects of downsizing. In order to manage these challenges successfully, organizations need leaders who are able to motivate and bring together new kinds of people and organizations (Lewis et al., 2007, p. 319).

Old managerialist leadership. Formal theories of management started to evolve with the Industrial Revolution in the United States and Europe in the late-19th century, focusing on employees' productivity (scientific management; Taylor, 1911/1998), management's functions (administrative management; Fayol, 1930), and the overall organizational system (bureaucratic management; Weber, 1927) (Lewis, Goodman, Fandt, \& Michlitsch, 2007, pp. 33-39). Rooted in Taylorism, the old paradigm of 
"command and control," the managerialist model of leadership that is still practiced in many organizations, is based on the basic assumption that managers have control of all resources and that they are entitled to use these resources as they see fit (Belasco \& Stayer, 1993, pp. 47-48).

Lewis, Goodman, Fandt, and Michlitsch (2007) define management as "the process of administering and coordinating resources effectively, efficiently, and in an effort to achieve the goals of the organization" (p. 5). Stanley Deetz (1992), a critical theorist, considers managerial capitalism an attempt to ultimately protect the survival (and material well-being) of management itself, not that of the organization or its employees (p. 333). In uncertain, changing environments, managerialist leadership is not sufficiently adaptable to respond to dynamic environments because it resists change. In fact, it can have detrimental effects on the survival of an organization.

New dialogic leadership. Heifetz, Grashow and Linsky (2009) believe that the current economic urgency and uncertainty caused by the global recession will continue as the norm in the future world. They believe that within these conditions, sometimes referred to as the "new normal," successful leaders must be capable of fostering organizational cultures and practices that promote adaptation, embrace environmental disequilibrium productively, and generate new leadership approaches. Participatory, adaptive and transformational leadership approaches cultivate such organizational cultures and practices and provide means for surviving in turbulent and unpredictable environments. Inherently, these approaches to leadership are enacted and practiced in dialogic forms of communication. 
Participatory leadership. Successful leadership today needs to be participatory for at least two reasons. First, organizations are increasingly focused on higher customer satisfaction and faster responses that require decentralization of decision making to lower organizational levels (Lewis, Goodman, Fandt, \& Michlitsch, 2007, p. 159). Second, contemporary leaders need to distribute their leadership and employ collective intelligence that draws on a range of perspectives and resources because their individual capacities cannot grasp the complexities of quickly changing global environments (Heifetz, Grashow, \& Linsky, 2009). Most often, organizations' adaptability results from numerous microadaptations to microenvironments and bottom-up change that involve all organizational members (Heifetz et al., 2009). Among the benefits of participatory leadership are deeper understanding of complex issues, learning, better adaptability, and higher satisfaction of organizational members (Heifetz, 1994, p. 187; Lewis et al., 2007, p. 162). Since dialogic communication provides these same benefits, it aligns well with participatory leadership.

Adaptive leadership. Whereas managers are concerned with responsibilities, authority, and execution of tasks, leaders direct their attention to providing a vision and gaining people's commitment to work toward that vision without coercion (Heifetz, 1994, p. 15; Lewis, Goodman, Fandt, \& Michlitsch, 2007, p. 321). In this commitment, leaders will need to embrace diversity in order to apprehend the widest possible range of perspectives (Heifetz, Grashow, \& Linsky, 2009) and to thrive within the larger context of various cultures (Lewis et al., 2007, p. 325). On top of that, adaptive leaders need to understand that interaction between leaders and followers is reciprocal: While leaders 
influence their followers, likewise, they need to adjust to the expectations of the followers (Heifetz, 1994, p. 17). Sharing their vision, embracing diversity, and engaging in mutual interaction with employees require adept and sophisticated communication skills from the leaders. Most importantly, adaptive leaders need to create a "culture of courageous conversations" that welcomes discussion on difficult topics with unfamiliar voices, candor, and dissent (Heifetz et al., 2009).

Dialogic communication promotes open and legitimized organizational discourse that restores autonomy, choice, and emancipatory democracy (Deetz, 1992; Littlejohn \& Foss, 2005, p. 263) in ways that help teams better adapt to their changing environments. Thus, dialogic communication supports adaptive leadership practices.

Transformational leadership. Transformational leaders act as mentors, promote creativity and innovation, provide inspirational motivation, and share risks with their teams. They are ethical, moral, and considerate of their team members' needs (Lewis, Goodman, Fandt, \& Michlitsch, 2007, p. 332). Transformational leaders nurture teams that are able to exceed expectations. Dialogic communication gives rise to this kind of leadership: It stimulates creativity and innovation (Baxter, 2007; Buber, 1937/1950, pp. 30-31; Pearce, W. B. \& Pearce, K. A., 2004, pp. 119-120), and is a profoundly ethical and compassionate way of interacting with others (Littlejohn \& Domenici, 2007, p. 245; Stewart \& Zediker, 2000).

Dialogic leadership. In many contexts, old managerialist leadership models have become dysfunctional in today's uncertain, dynamic environments. Dialogic leadership 
can provide the means for successful adaptation because it is participatory, adaptive, and transformative.

Dialogic leadership puts communication and dialogue in the center of organizational life, calling forth team members' authentic voices, promoting empathetic listening, respecting other peoples' views as legitimate, and providing broader and deeper understanding of issues (see Isaacs, 1999a). And since communication is the focus of dialogic leadership, dialogic leadership employs dialogic communication practices.

This study provided a city government management team with training in dialogic communication. It was hoped that the team members would adopt dialogic communication practices for managing the teams they supervise, and hence develop their dialogic leadership skills.

Need for dialogue practitioners and trainers. Regardless of the benefits of dialogic communication, dialogue is not often practiced in today's work teams. The most obvious reason for this is teams' and their managers' lack of necessary knowledge and skills to engage in dialogue. Another possible reason for this is the widespread, authoritative top-down communication model, residue of old, hierarchical organizational structures. Although modern, flatter organizations nurture less authoritative communication, old communication patterns are hard to change without conscious effort. Furthermore, teams, managers and organizations can be resistant to change and suspicious about diversity that can be intuitively threatening. Traditional, authoritative organizations often prefer sustaining a conventional status quo, and they are not likely to embrace communication processes that create space for unanticipated, emergent 
outcomes. Besides, dialogue can be perceived as unnecessarily time-consuming with results that are unpredictable.

For these reasons, there is a need for competent dialogue practitioners and trainers who are able to apply dialogue theory in ways that are meaningful to organizations and teams, who can help bring about practical outcomes, and who can help build capacity in teams to engage in dialogic communication in the future.

Currently, the mainstream approach to dialogue emphasizes convergent dialogue (Deetz \& Simpson, 2004; see Isaacs, 1994, 1999b; Senge, 1990). Convergence is a phase of a meaning-making process in which participants' individual understandings create clusters of shared understanding. Although without convergence no intersubjective meanings would emerge, in traditional team decision making, this phase is often unnecessarily rushed. Instead of exploring new definitions of issues, participants focus first on finding common ground, next, build on those predispositions, and then, aim to find a resolution. This method fails to elaborate on and jointly create new creative meanings and insights. As a result, convergent dialogue can reproduce conventional meanings, solutions, and decision-making patterns that privilege the "already dominant set of understandings" (Deetz \& Simpson, 2004). Convergent dialogue is often a mere sum of people's individual definitions of problems and solution alternatives. Quite obviously, this approach lacks synergistic value and the potential for innovation and creativity. It also limits organizations' adaptability to their environments.

The second major limitation of the mainstream approach to dialogue is the fact that dialogue is often considered a separate process preceding deliberation rather than a 
quality of interaction that can guide the whole deliberation process (see Black, 2008).

Like the push for convergence, this results in limited understanding of issues and decisions that favor those who are already privileged in the society.

These two limitations are typical for convergent or Bohmian dialogue (see Bohm, 1980; 1996). Spano (2006) contrasts Bohmian dialogue with Buberian emergent dialogue: Whereas the Bohmian approach starts on an epistemological basis, thinking together, Buberian dialogue begins on an ontological base, turning toward each other. Bohmian dialogue is also less experiential and more abstract or idea-based than Buberian dialogue that situates dialogue in concrete, embodied experiences. As a convergent form of communication, Bohmian dialogue locates meaning internally in individuals whereas Buberian emergent dialogue regards meaning as socially constructed. Lastly, Bohmian dialogue practitioners consider dialogue as an instrumental formula that is focused on outcome and content. In contrast, Buberian dialogue, while being instrumental, is also reflexive, spontaneous, and more focused on metacommunication and the process than on outcomes (Spano, 2006).

Emergent dialogue opens up possibilities to explore and consider multiple meanings simultaneously without the pressure of resolving the tension between conflicting meanings or pushing for coherence (Spano, 2006). Emergent dialogue requires a not-knowing position from the participants (see Gurevitch, 1989), and therefore, it is likely to provide them with a more creative and richer understanding of issues than solely convergent dialogue does. 
Without ignoring the value of convergent dialogue, dialogue trainers and practitioners can help teams to resist gravitation toward convergence and hold space open for the emergence of meanings, which is critical for effective decision making in diverse teams who operate in rapidly changing, complex environments. Accordingly, this study emphasizes the importance of emergent dialogue.

\section{The Focus for This Research Study}

The overall purpose of this applied communication research study was to examine the outcomes of a communication training program provided by a dialogue scholar and practitioner on a city government management team. The goals of this study were to,

first, identify the communication challenges of the management team (needs assessment), second, train the team in dialogic communication, and third, assess the outcomes of the training.

The two research questions for this study were:

- RQ 1: What are the communication challenges facing a city government management team?

- RQ 2: What are the outcomes of dialogic communication training on a city government management team? 


\section{Chapter 3: Method}

A traditional research process starts by defining a problem, reviewing the literature, formulating the research questions, selecting the best method to answer these questions, and then contacting the study population (Rubin, Rubin, \& Piele, 2005, p. 207). In contrast, the action research process starts with the study participants who define the problem and help solve it with the researcher (Stringer, 2007).

In line with this latter approach, before consulting theory, I initiated this research project by getting acquainted with the Assistant Director, my contact person in the city government organization under study. Informal discussions with her directed the selection of the study method and the guiding theoretical framework. Action research methodology and dialogic forms of team communication seemed most suitable for this research since she expected practical outcomes from the research process.

\section{Action Research Methodology}

In action research, the research process needs to unfold organically as the study evolves. The steps of the process can be roughly sketched out but not completely planned in advance, and while a research question might be clear in the beginning, the method to answer it is revealed in the process. For example, before contacting the study group, I had not yet decided if I should interview the participants individually or as a group. After consulting the Assistant Director and discussing her organization's situation and the focus for this study, she and I decided that I should start with individual interviews. To give another example, it was unclear until the end of the second phase of this study if a quantitative measure should be developed for evaluating the outcomes of 
dialogic communication training. After discussing the issue with the participants and the Assistant Director, it became evident that a qualitative evaluation tool would be more appropriate. Thus, an action researcher needs to remain open to consider the best next steps together with the study participants while engaging in rigorous theoretical reflections throughout the research process.

Collaborative and participatory research method. The primary goal of action research is to make a difference in the lives of local participants (Stringer, 2007, p. 12). Action research considers the best experts in this task to be the study participants themselves who are invited to engage in systematic inquiry that is aimed at providing viable solutions to problems that are relevant to them (Pearce, K. A., Spano \& Pearce, W. B., 2009, p. 617; Stringer, 2007, pp. 1-6). In this process, the role of the researcher is to facilitate research by helping the participants to define their problems, understand their situation better, and generate solutions (Stringer, 2007, pp. 24). Thus, an action research project is always a group effort.

Action research is participatory, and ideally, all stakeholders of an issue are included in the process of inquiry (Stringer, 2007, p. 6). Action research methodology favors inquiry from the bottom up because people themselves are the ones who best understand all the complexities of their own lives (Stringer, 2007, pp. 25-26). Indeed, action research is inclusive, democratic, equitable, liberating, and enhancing (Stringer, 2007, pp. 11, 38). Consequently, action research challenges the old authoritarian paradigm of command and control that regards managers and leaders as possessing superior knowledge. 
Due to the constraints of time and resources, only one horizontal layer of managers from a city government organization was involved in the dialogic communication training of this study. Managers' subordinates, superiors, outside customers and other stakeholders were indirectly involved in this study, however, since the participants were asked to practice their dialogic communication skills in their daily work situations. Thus, although the parameters were centered on this one management team, the effects of this project had a potential to ripple out to a larger organization and participants' other social contexts.

Practical outcomes informed by theory. Action research can be characterized as a phenomenological, interpretive, and hermeneutic method of inquiry that aims to produce practical outcomes. These outcomes inform and are informed by theory (Stringer, 2007, p. 20; see Craig, 2006, pp. 42-44).

Phenomenological method. As an applied research methodology, action research focuses on people's lived experiences, tying together practical knowledge and theory. This requires a constantly reflexive relationship between theory and practice throughout the research process. Karl Weick (1995) provides an apt illustration of this relationship: "Experience as we know it exists in the form of distinct events. But the only way we get this impression is by stepping outside the stream of experience and directing attention to it" (pp. 24-25). Action researchers need to keep one foot in the stream of experiences while the other foot is grounded on the shore of theory.

In this study, practice and theory were tightly intertwined: First, the interviews were designed (theory), and then conducted (practice), interpreted and reflected upon 
(theory). Next the focus group session was designed (theory), conducted (practice), and its results interpreted (theory). Based on the results from the interviews and the focus group session, a dialogic communication training was designed (theory), conducted (practice), and evaluated (theory). Due to the organic nature of this research project, it was essential that as the successive phases followed each other, appropriate literature was consistently consulted in order to evaluate and guide the selection and application of the following research practices. This way, each successive stage emerged from the theoretical reflections of the previous phase's results.

Interpretive method. Because action research focuses on people's interpretation of their acts and experiences and aims to achieve richer understanding of their issues, it is mainly located in the interpretive paradigm and utilizes qualitative methods (see Stringer, 2007, p. 19).

Accordingly, in this study, qualitative interviews and focus group methodology were employed in order to collect and analyze data. Particular attention was paid to the forms and patterns of participants' communication, their word choices, and their interpretations of various meanings (see Littlejohn \& Foss, p. 46). Interpretation of qualitative data was reflected back to the participants for their validation, and several times, the formulation of data was revised based on participants' feedback.

Hermeneutic method. Like other hermeneutic methods of inquiry, action research is oriented toward applying theory and research findings in practice (Stringer, 2007, p. 20). Generalized solutions, however, must always be adjusted to fit particular 
contexts and the needs of the participants (Stringer, 2007, p. 5), which requires innovation and creativity from the study participants and the researcher.

In this study, the accumulating data were regularly evaluated in the light of theory, and then, reflected back to the participants. After participants' feedback, the following course of action and the content for the next phase of the study were chosen and refined by the participants and the researcher together. In this process, not only the content but also the process became apparent as new things were discovered, and theory was put into practice as the previous findings formed a basis for the following phases. For example, the content for dialogic communication training in the third phase of this study emerged from the first phase's interview data that were discussed in a focus group meeting in the second phase.

\section{Setting and Participants}

Nine senior managers representing four different divisions in a large city government organization participated in this action research study. In order to protect their anonymity, participants were asked to choose pseudo names for the purposes of this study. In this report, they are called "5," “17," “22," "Bob," "Flying Tomato,” Lee," "Lisa," "Merlon," and "Sue."

Eight study participants were Division Managers, and one participant was an Administrative Officer. Throughout this study, the terms manager and division manager represent this whole group because referring to the Administrative Officer would compromise his/her anonymity. In order to provide further protection to participants' 
identities, their four divisions were renamed as: (a) The Strategists, (b) The Investigators, (c) The Guards, and (d) The Catalysts.

Managers' average service time in the city organization was 19 years (range $=$ $22.5, \mathrm{SD}=7.7)$. On average, they were managing teams of 27 people $($ range $=51, \mathrm{SD}=$ 18). The managers engaged regularly in interdivisional meetings, and some of them worked in temporary project teams that formed and dissolved across divisional boundaries as needed.

During the past year, managers' teams had undergone drastic organizational changes. Severe reductions in personnel, in February, July, and November 2009, added up to $25-53 \%$ in all but one division. In addition to these cuts, some remaining employees had been asked to accept demotions through a process called bumping, in which employees are reassigned to a different, lower job classification. One division that had been minimally impacted by city government's budget cuts was facing significant staff reductions at the time of this study in June 2010. Naturally, these organizational changes greatly challenged divisions' productivity, spirit, and interpersonal relationships.

The Assistant Director, who introduced me to this management team, was already familiar with Buber's dialogue theory. She believed that dialogic communication training would help the managers and their divisions better adapt to their changing working situations. 


\section{Phases of the Study}

For a basic action research routine, Stringer (2007) recommends a Look-ThinkAct model (pp. 8-10), according to which the four main phases of this study were organized:

1. Looking phase for interviewing the participants and assessing their communication needs;

2. Thinking phase for reflecting on the interview findings and planning the dialogic communication training;

3. Acting phase for conducting the training;

4. Looking again phase for evaluating the success of the training.

In addition to its macro level application, the Look-Think-Act model was used also within each individual phase. For example, in the first phase before the interviews, I discussed the interview questions with the Assistant Director (Look), designed the interview guide (Think), and conducted the interviews (Act). Indeed, the model is an "interacting spiral" in which each phase follows another, multiple times, rather than a linear model moving from a start to an end (Stringer, 2007, p. 9).

According to Littlejohn and Farge (2006), dialogue event design should strive to encourage constructive communication and collaboration while restraining destructive communication. Adhering to these guidelines, I approached each contact with the study participants as a dialogue event that required planning and a dialogic attitude. Moreover, since I wished to keep the research process as transparent as possible, these guidelines 
also protected participants and their integrity by providing a safe communication environment, and set a stage for practicing dialogic communication.

Multiple methods, such as qualitative interviews and communication training, were used in this study. As a result, the research data constituted a mixed collection of records including research notes, digital recordings, transcriptions, focus group notes, various summaries, agendas, handouts, lesson plans, homework assignments, evaluations, informal discussion notes, and numerous email messages. These data were generated with the study participants' input and feedback, which was requested in designing the study methods, interview guides, event agendas, training plans, and evaluation tools. Due to this organic methodology, the format of this section might seem unconventional.

I will next give a detailed account of the four phases of this study: Looking phase (individual interviews), Thinking phase (focus group discussion), Acting phase (training in dialogic communication), and Looking again phase (final evaluation).

Looking phase for interviews. The purpose of this phase was to answer the first research question "What are the communication challenges facing a city government management team?" In more detail, this phase aimed to describe the division managers' current situation, gather information about their communication strengths, and identify the most significant communication challenges they were facing. This information was necessary for describing the study group's baseline situation before the training so that it could be compared with the study results after the training. This phase also provided a needs assessment for the group, which was used for determining the content for the forthcoming dialogic communication training. 
First contact with the participants. The city government management team under study met with its executives regularly once a month in order to assess each division's performance and to discuss their current and upcoming issues. I had a chance to join one of these meetings in January 2010.

Before attending the meeting, I studied organization's structure from its website, which was very helpful in understanding each division's functions within the larger city organization. In the meeting, the Assistant Director introduced me and the purpose of this study to the division managers: The dialogic communication training would, in her words,

- provide a professional development opportunity to organization's middlelevel managers, building capacity and expanding their existing facilitation and communications skills;

- assist organization's middle-level managers with engaging their staffs around budget information, process improvement, and other issues; and

- contribute to organization's culture of communication, listening, and teambuilding.

The meeting provided me with an opportunity to learn more about each division's functions and division managers' working tasks. It also provided me with an opportunity to observe managers' and their superiors' interaction. After the meeting, I was warmly welcomed "into the team" by the Director whose permission to conduct this study was vital for its successful execution. 
Individual interviews. From the social constructionist perspective, meanings in teams are created together by all team members. Many times, the most powerful, dominant, and privileged team members get to frame and drive the meaning-making process. In order to avoid this typical effect of group discussion, I decided to interview each study participant separately. Individual interviews also provided a safe environment for the participants to express their views and maximized the clarity and depth of their perspectives in defining their current work situations. Additionally, personal contact with them gave me the opportunity to build rapport with the study participants.

Interview sessions. The interviews were conducted in February and March 2010, over a five-week period. Each interview lasted about 60 minutes, some taking place in an interviewee's office, some in a nearby library study room. The interviews were digitally recorded with each interviewee's permission. Before turning the recorder on, I asked each interviewee to read and sign an informed consent form (Appendix A) and to come up with a pseudo name in order to protect his/her anonymity.

To ensure the transparency of the action research process, each interviewee received an interview guide (Appendix B) at the beginning of his/her interview. After I described the objectives and a tentative schedule for this study, I explained the purpose of this specific interview phase: to explore what the division managers considered to be the most significant communication strengths and challenges in their work with various stakeholder groups.

Interview questions were designed so that the first question would set the whole interview in an appreciative frame, first highlighting interviewees' strengths before 
moving on to exploring the communication challenges interviewees faced in their work. The questions were broad and open-ended, designed to elicit multiple perspectives about the participants and their work situations and to provide opportunities for original insights. Tentative follow-up questions were included in the interview guide for helping to reveal systemic connections between ideas.

An outside transcriber who was not familiar with the study participants or their organization transcribed the digital interview recordings. Transcriptions were emailed to each corresponding interviewee for verifying their accuracy. At this point, the interviewees were offered a chance to remove any comments they wished to exclude from the data.

Interview data analysis. After getting a response from each interviewee and revising the transcriptions accordingly, I used qualitative textual analysis (see Rubin, Rubin, \& Piele, 2005, p. 224) to analyze the interview data. I first read each interview transcription with its corresponding interview notes twice. On the second reading, I circled and underlined the most prominent themes in the text, paying special attention to interviewees' word choices so that I would be able to distinguish and preserve participants' authentic language while also revealing more universal meanings across the interviews.

After identifying the emerging themes from each interview, I constructed an Excel spreadsheet in which the interview questions were placed in rows and interviewees' pseudo names in columns. Then, I placed the emerging themes from each interviewee's transcription under their names on the line of the questions they responded 
to. Once every interviewee's themes were transferred into the spreadsheet, I regrouped the answers in thematic families. I kept rearranging kindred themes, such as budget cuts with reactions to budget cuts, until I had a few general themes that provided high-level answers to the interview questions. I described the strongest themes across most interviews in an interview summary, and omitted the themes that were less prominent.

Next, I wrote a lengthy interview summary, which included a great deal of interviewees' direct quotations. I saved this summary as my own reference summary for designing the following phases of this study. For the participants and the Assistant Director, I wrote an abbreviated interview summary that better protected interviewees' anonymity. This summary was distributed to the participants in the Thinking phase's "Focus Group Packet” (Appendix C).

Thinking phase for focus group discussion. According to Stringer (2007), the Thinking phase is used for exploring, analyzing, interpreting, and explaining the data. In this study, the data from the preceding Looking phase were used to guide the design for the following Acting phase. Furthermore, this phase gave the study participants a chance to reflect on the interview findings.

All of the nine study participants attended a 90-minute focus group meeting in May 2010. The meeting had three goals: (a) to validate the interview findings and to elaborate on them; (b) to agree on the focus and the topics for the upcoming training; and (c) to identify the outcomes of a successful training (evaluation criteria) and the method(s) for assessing those outcomes. 
Originally, I had planned to digitally record this session. Due to the sensitive content of the main challenge areas that were identified in the interviews, I decided not to use the recorder. My hope was that without the recorder the participants would be more candid in expressing their views. Alternatively, I decided to rely on my research notes that I wrote during and after the meeting.

At the beginning of the meeting, the participants received a Focus Group Packet (Appendix C) whose components were organized around the six segments of the meeting: (a) Context setting, (b) Interview summary report, (c) Discussion questions, (d) Training plan, (e) Evaluation, and (f) Closing. A description of each segment's progression follows below.

Context setting. The Assistant Director opened the focus group meeting by welcoming the participants to the event. After explaining the rationale for this study in the city organization she thanked the participants for investing their time in the study, and left the meeting; she believed that the team might engage in more open and candid discussion without her presence as the supervisor of some team members.

Further context setting spelled out the desired outcomes for the meeting, guidelines for constructive communication, and a suggested agenda for the 90-minute meeting (Appendix C), which the participants accepted.

Interview summary report and discussion questions. Discussion about the interview summary report (Appendix C) covered the two main areas examined in the Looking phase's individual interviews: managers' communication strengths and challenges. 
Managing philosophy. Participants' managing philosophy was synthesized from managers' answers for interview questions two and four (see Appendix B): what the division managers reported they are doing well, and what they think the ideal communication in their organization would be like.

Most of all, the managers saw themselves as public servants and advocates for their subordinates. As managers and members of various groups, they considered themselves collaborators who sought to promote independence of thinking and doing. However, the most prominent theme of participants' managing philosophy was openness that denoted willingness to consider new ideas and suggestions, accessibility to information, and also interpersonal approachability. As communicators, the participants valued empathetic, personal, effective, and frequent communication and feedback.

Challenges. Division managers' most significant communication challenges in their work situations were grouped into five areas:

1. Challenges with subordinates (challenges with one's own teams);

2. Interdivisional challenges (challenges for the management team);

3. Challenges with organizational hierarchy;

4. Challenging organizational climate (organizational environment); and

5. Challenges with customers.

The third challenge area was not included in the summary report (Appendix C), because, at the time of the meeting, study's main focus was on interdivisional interaction, and because vertical organizational challenges were thought to unreasonably broaden the scope of this study. Despite this, I acknowledged this challenge area in the meeting 
verbally. It turned out that the participants felt that this issue was quite urgent, and they hoped that this issue would be addressed in the upcoming training. Furthermore, the participants raised a concern that when training was targeted only on one horizontal level in an organization, it might not be as effective as training that would address communication skills in the organization vertically.

While designing the focus group session, I had planned to facilitate a separate dialogic discussion with the participants about their divisional differences. The questions were designed to elaborate on the divisional differences and to prepare the participants to consider communication as a social construction process (see Appendix C). Since at the time when I presented the summary of the differences to the participants they were enthusiastic to respond to the descriptions spontaneously, and since they seemed truly amused to discuss and compare their differences with the help of these descriptions, I decided to infuse the questions into their discussion.

Training plan. Because the upcoming training needed to serve all nine managers who were facing more or less unique challenges within their own divisions and organizational situations, the participants needed to negotiate what to include and what to leave out of the training. For a starting point to this discussion, I suggested a two-session training plan, in which the first session would be based on social construction theory (Berger \& Luckmann, 1967) and communication perspective (Pearce, W. B., 1989), and the following session would introduce some dialogic communication skills (Spano, 2010). In order to help the participants to understand the suggested content better, I briefly explained how dialogue is a distinct form of communication—separate from 
argumentation, for example - and Buber's (1937/1950) three conditions for dialogue: (a) standing own ground, (b) being open to the other, and (c) remaining in tension between (a) and (b).

The participants accepted the suggested training plan. Most of them seemed to look forward to the training, and some participants started to immediately think where to apply their new communication skills. This was very encouraging to me as a researcher and trainer.

Evaluation. For an action research project, it is essential that the participants decide how the success of the project should be assessed. This question was addressed in the next part of our focus group discussion.

The participants wished to gain tangible and practical outcomes that would address the challenge areas that had been identified in the interviews. They wished that the assessment tool would be a qualitative form with open-ended questions so that the evaluation would be flexible enough for all the participants. The participants and I decided that I would formulate some questions for the participants who would then decide which ones they think would best evaluate their success.

In addition to the final evaluation of this research project, the participants decided that also both training sessions should have their own evaluation measures.

Closing. The remaining steps of the research process and the schedule for their completion were discussed before adjourning the meeting. The participants wished that I would schedule the training sessions via email as soon as possible. Finally, I thanked the 
managers for participating in the focus group discussion and invited them to contact me with any comments or concerns about the research study they might have.

Respect and confidentiality issue. After the focus group meeting, some participants were troubled about the tone of some parts of the focus group discussion. Moreover, they raised concerns that other discussants might have shared confidential research data with people outside the study group.

I decided to address both of these issues in an email:

In the course of this study, we are discussing issues that might feel sensitive to some participants or people outside our group. For that reason, it is very important that we pay special attention to discussing these issues in a respectful manner without sacrificing openness. Furthermore, we need to remind ourselves about the confidentiality of this study. Before we have agreed on what will be ultimately published, it might be wise not to discuss any sensitive issues outside this study group.

Later on, talking about these issues proved to be very fruitful for at least two reasons. First, these issues provided commonly shared, real-life material of how meanings are socially constructed for the two training sessions. Second, and more importantly, I gained visceral knowledge about the significance of the emerging issues to the participants, which was extremely important to me as a researcher. Instead of treating participants' lived experiences as bland "data," I now had another view to see how profoundly immediate the issues were to them.

Dialogue is often unnecessarily characterized as a peaceful and friendly form of communication that suppresses people's authenticity. The episode that took place in the focus group meeting is an illustrative example of a dialogic discussion that does not automatically result in harmonious happiness. Dialogue in which people are invested can 
elicit passionate responses, which, at times, may sound discordant, unorthodox or unprofessional. In these situations, it can be a real challenge for the dialogue facilitator to create an inviting space for authentic voices while keeping the communication climate respectful, constructive, and safe for everyone. It requires good judgment to know when to tactfully acknowledge uncomfortable situations and when not to intervene. Furthermore, in some cases, recognizing comments that make some discussants uncomfortable can be very difficult when the participants are seemingly agreeing and do not explicitly voice their concerns.

Acting phase for dialogic communication training. According to Stringer (2007), the Acting phase is meant for planning, implementing, and evaluating the results of the research. In this study, this phase consisted of two 90-minute dialogic communication training sessions-“"Communication Construction" and "Dialogic Communication Skills"- and participants' reflective evaluations of those sessions. The purpose of the first training session was to provide a theoretical framework for the dialogic communication skills that would be learned in the second training session.

The content of both training sessions was based on the social constructionist communication perspective in which meanings (resources) influence actions, and actions, in turn, reconstruct meanings (Pearce, W. B., 1989; see Berger \& Luckmann, 1967) and on Buber's (1937/1950) dialogue theory in which dialogue participants simultaneously express their own views and remain open to see others' views. The selected focus of the content assessed managers' five challenge areas that were identified in the interview findings. 
An evaluation and feedback tool was designed for both training sessions in order to collect data about the preliminary outcomes of the study. The evaluation data from the first training were also used to ensure that the training was moving in the direction that the team members considered most meaningful for their work.

Training I: Communication construction. The first training session was held in late June 2010. Eight of the nine study participants were able to participate.

The training and the "Training Packet I" (Appendix D) consisted of six segments: (a) Context setting, (b) Outcomes of the previous meeting, (c) Constructing communication, (d) Practice \& analysis, (e) Dialogic communication, and (f) Closing and evaluation.

Context setting. The first training session started with a list of the desired outcomes for the training:

- to see communication as a socially constructed meaning-making process;

- to understand one's own contributions to the meaning-making process as shaping the emerging meaning;

- to regard individual differences as potentially valuable; and

- to apply the learned concepts into practice in the previously identified challenge areas.

Next, a list of guidelines for constructive communication followed: (a) Listen openly, speak candidly; (b) Confidentiality; and (c) Everyone contributes. The participants agreed to follow these guidelines during the training. One participant suggested that "Be concise" should be added into the guidelines so that all participants 
would have enough time to contribute to the discussions. Everyone agreed that this guideline would prove useful.

In order to orient themselves to the training, the participants previewed and accepted the 90-minute training agenda (Appendix D).

Outcomes of the previous meeting. After context setting, I asked the participants to briefly share their thoughts about the previous focus group meeting. The purpose of this question was to refocus participants' thoughts around the study topic six weeks after the previous meeting. This question was also meant to offer a chance to reflect on the respect and confidentiality issues that arose afterward. It was important that this matter would be discussed as a group in order to provide a sense of closure before moving forward.

As they answered the question, the participants mentioned that they appreciated having a chance to compare their experiences, similarities and differences, with other division managers' experiences. One participant acknowledged that learning about Buber's dialogue theory had already been useful to him/her. Another participant mentioned that s/he did not appreciate the negative tone of discussion in the last meeting, but all in all, the focus group meeting seemed to have gone well. In the words of one participant, "The meeting was not as bad as I expected. We had to do a lot to participate, and I was positively surprised."

Constructing communication. The first communication concept that was introduced to the participants was the social constructionist model of communication in which meanings influence actions, and actions, in turn, reconstruct meanings (Pearce, W. 
B., 1989; see Berger \& Luckmann, 1967). The model offers an alternate view to the conventional transmission model of sending and receiving messages (e.g., Shannon \& Weaver, 1949), and conceptualizes communication as a process of making and doing; people co-construct meaning (e.g., relationships) through communication actions. Coconstructed meanings of various individuals and groups can be contradictory, and sometimes, incommensurable together. At times, it can be a challenge to make sense of the meanings that do not align neatly with one's own understanding. Spano's (2010) graphic representation of the model is depicted in the following figure (Figure 3-1).

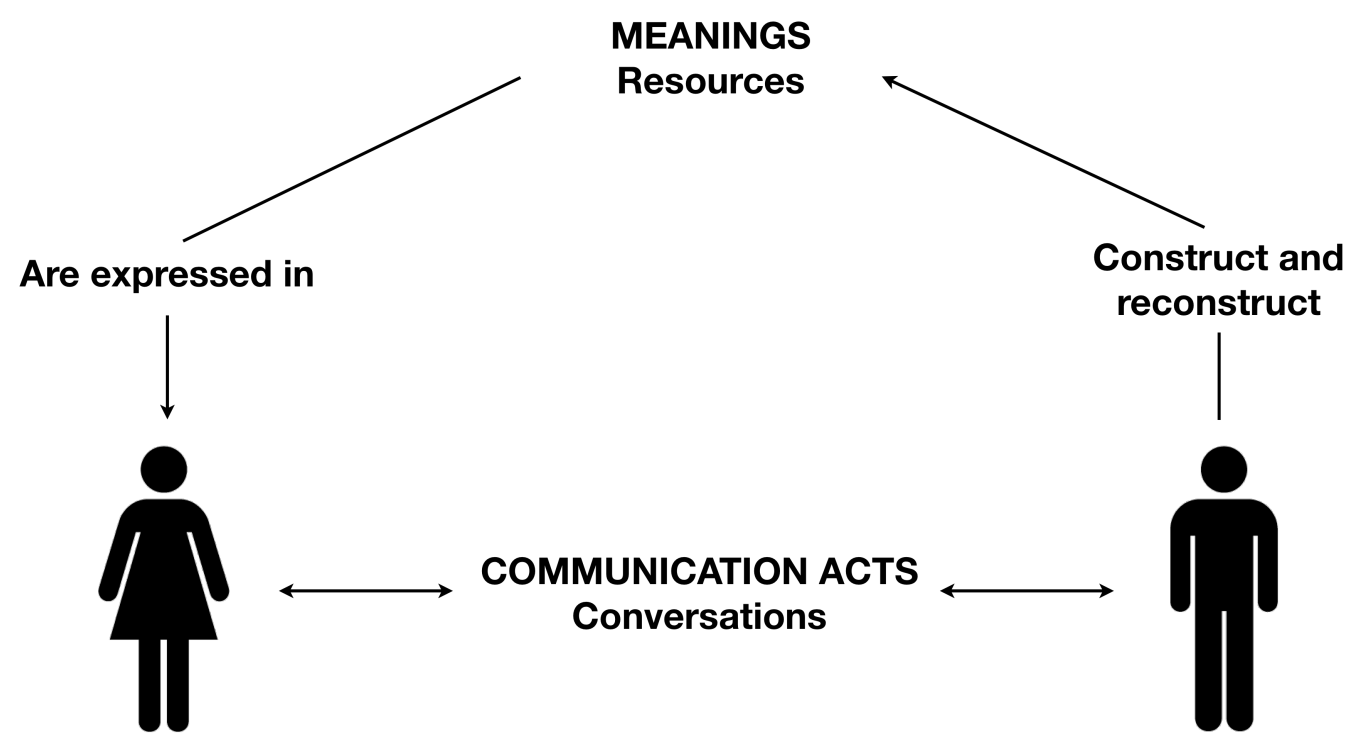

Figure 3-1. Social constructionist model of communication (taken from Spano, 2010). Meanings are expressed in communication acts that, in turn, construct and reconstruct meanings.

The participants learned that communication actions that construct meanings could be analyzed on a microlevel as speech acts (Austin, 1962/1975) or communication acts. Since each individual communication act, such as stating, questioning, promising or 
commanding (Littlejohn \& Foss, 2005, p. 46), contributes to the outcome of interaction, all communication acts have an effect on the direction of discussion. Accordingly, interactants always impact the outcomes of the discussions they participate in. Therefore, they always have some say in what the outcomes will be like. Speech act theory is remarkably useful in analyzing institutionalized, undesirable speech patterns, because by changing any one communication act, the outcome of interaction inevitably changes.

The next concept turned participant's attention to a logical follow-up question: What are we making together in communication? Describing the potential value of differences, Littlejohn and Domenici's (2007) conflict model (Figure 3-2) provided a common framing for answering this question.

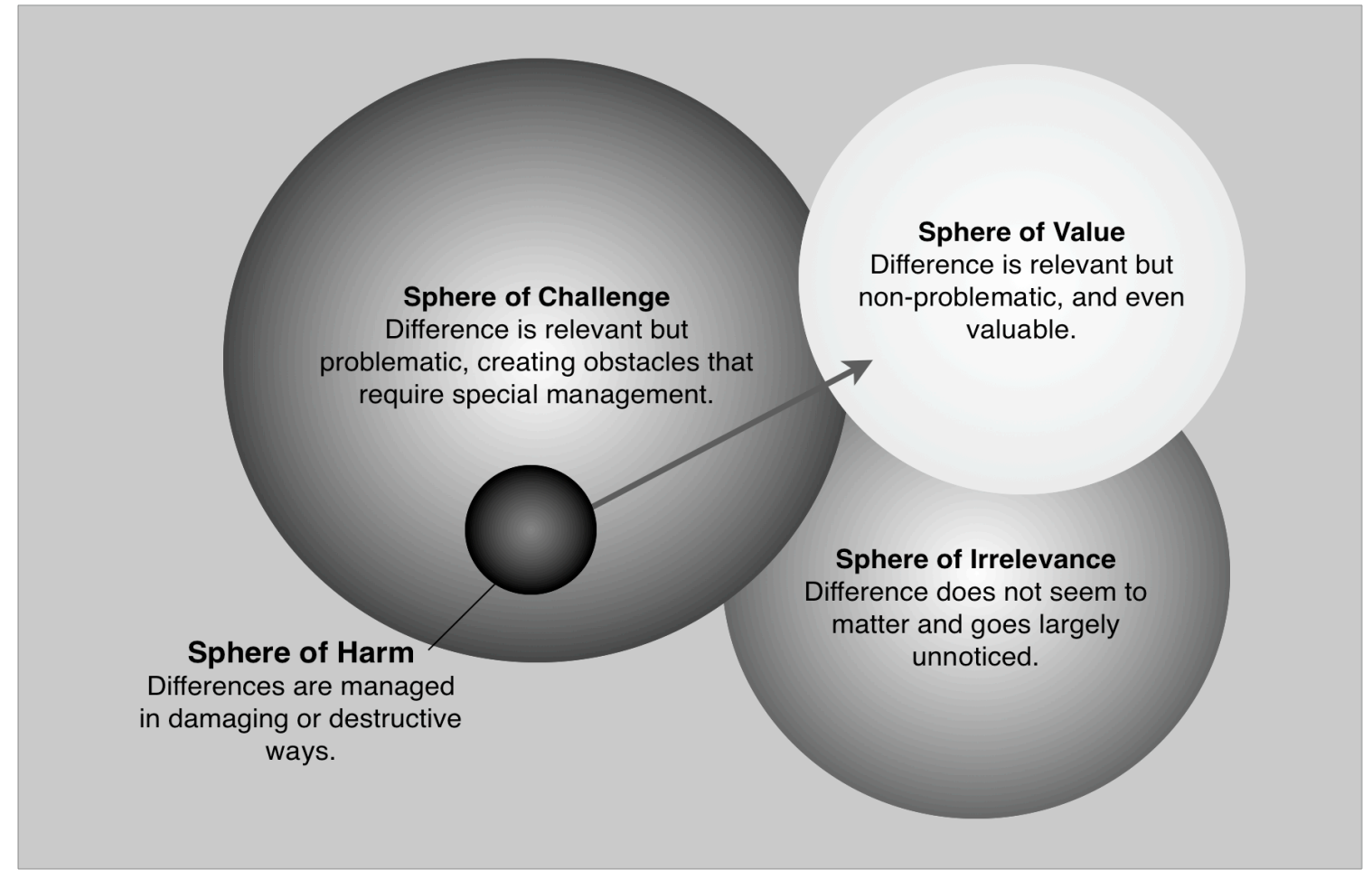

Figure 3-2. Conflict model (reproduced from Littlejohn \& Domenici, 2007). The model shows four orientations to difference: spheres of irrelevance, challenge, harm, and value. 
The model is based on a premise that each interactant has a different set of resources to draw meanings from, and therefore, they continuously encounter differences of data, interests, relationships, values, and structures. In the graphic representation of the model, four overlapping circles or spheres illustrate different orientations to differences: irrelevance, challenge, harm, and value.

In the sphere of irrelevance, differences are insignificant and often unnoticed. Conflicts arise in the sphere of challenge where differences may create problems and call for special management. If the differences are managed poorly, they might move into the sphere of harm and become destructive. When differences are managed constructively, they can be valuable (sphere of value; Littlejohn \& Domenici, 2007, pp. 9-14).

Combining all three concepts—-social construction of meaning, speech act theory, and the conflict model — people co-construct their social lives and relational meanings by engaging in communication with each other and by contributing to this process through individual communication acts. As they encounter difference, they are moving within the various spheres, depending on how the interactants manage their differences through their communication acts and the larger communication construction process.

In the training, the participants demonstrated their deep-level understanding of these theoretical concepts as they contributed to the following application discussions by sharing numerous examples from their work and private lives. Examples also arose from the interview summary data and from the focus group discussion.

Practice \& analysis. Before the training, I had divided the participants into four teams, each team to represent one of the challenge areas that had been identified in the 
interviews (challenges with subordinates, interdivisional challenges, challenges with organizational hierarchy, and challenges with customers; challenging organizational climate was excluded as non-practical within this context). The teams were asked to prepare a 2-4-minute role play scene about a typical challenging situation at work in their assigned challenge area. The role plays were to be used for analyzing real-life communication situations with the three communication concepts that had been just learned: social construction of meaning, communication acts, and the conflict model. The main reason to ask the participants to write the scenarios themselves rather than giving them ready-made scripts was to utilize participants' superior knowledge about their everyday working situations, which would likely result in deeper insights in analyzing the situations.

Role plays provided the participants with experiential learning and rooted the new communication concepts in real-life situations that mattered to them. As the participants explored and analyzed situations they were familiar with, they also practiced how to apply their new theoretical knowledge. Analyzing and replaying alternate scenarios of these role plays proved very effective in terms of seeing how one person can truly change the outcome of a situation. Particularly, the discussion that followed the role plays was useful in seeing how these challenges could be tackled in a constructive manner. By applying theory to practice, the participants were also working on their shared challenge areas, which they had mentioned as one of the desired outcomes of the training.

The role plays were probably the most enjoyable part of the training for the participants. They were delighted to see some challenging working situations played out 
in humorous and playful ways. Unfortunately, there was time for only two role plays during this training session; we decided to save the remaining two for the next training session that was a week away.

Dialogic communication. After applying the social construction theory, speech act theory, and the conflict model in practice, it was time to discuss what kind of communication would create meanings that are satisfying, encouraging, ethical, and enriching. According to Spano (2010), dialogic communication is a form of communication that "helps create unique and distinctive social worlds, different from what gets made in other, non-dialogic forms of communication." In order to motivate the participants to learn communication skills that promote dialogue, I reminded them about Buber's (1937/1950) three conditions for dialogue: (a) holding own ground, (b) being open to the other, and (c) remaining in the tension between holding own ground and being open to the other.

Once again, we were able to use participants' own examples in illustrating this theory. During the discussion, the team members were able to indirectly address the respect and confidentiality issue that surfaced after the focus group discussion. We did not discuss this topic directly, but the participants became conscious of how each communicator needs to own his/her part of the meaning-making process. This was one of the most profound revelations during this training.

Closing and evaluation. For the last five minutes of our meeting, I asked the participants to reflect on their learning using the evaluation sheet that was included in the Training Packet I (Appendix D). As agreed to in the earlier focus group meeting, I 
composed the evaluation sheet before the training, solicited the participants' feedback on it, and then revised it accordingly.

Instead of "Evaluation," the form was named "Reflection." The first two questions asked participants' direct feedback for the training session: what went well and what could be improved. The participants reported that they enjoyed the role play exercises and the following analytical discussions (five participants), theoretical content of the training (two participants), and spending time together with their colleagues (two participants). Two participants would have preferred to have more time for the first training; one participant thought that the content was too theoretical; and one participant reported that s/he did not enjoy the role plays. Four participants did not offer any suggestions for improving the training.

The remaining five questions were designed to address the major challenge areas that had been identified in the interviews, and asked how the participants would apply the content of the training to tackle these areas. The answers to these questions are included in the Results section of this study report.

As the participants left the training, each of them received a copy of Spano's (2010) "Dialogue Resource Guide” for further reading about dialogic communication. The booklet also included descriptions about dialogic communication skills, the topic for the next training session scheduled for the following week.

Training II: Dialogic communication skills. As a research facilitator and dialogue practitioner, I made an effort to practice and model dialogic communication 
skills throughout this research project. The specific dialogic communication skills I used have been listed by Spano (2010, pp. 17-22):

- good time management,

- neutral position toward the content of the discussion,

- curious and not-knowing attitude toward the participants and their issues*,

- acknowledging participants' situation, process, constraints, resources, and behavior*,

- summarizing shared information,

- restating of the key points of discussion*,

- reflecting participants' feelings*,

- reframing of issues*,

- appreciative questioning of issues*,

- systemic questioning for revealing connections between ideas, organizations, and people*, and

- managing behavior that can potentially disrupt the dialogic process.

From this list, I chose seven skills (marked with * in the list above) for the dialogic communication training that, in my opinion, best addressed the study participants' challenge areas. The content for the next training session was built around these skills.

The second training session was held one week after the first one in early July 2010. Since two participants were unable to attend the training, there were seven attendees. The training and the "Training Packet II" (Appendix E) consisted of seven segments: (a) Context setting, (b) Warm-up discussion, (c) Characteristics of dialogic 
communication, (d) Role plays, (e) Dialogic communication skills, (f) Closing, and (g) Evaluation.

Context setting. The sole purpose of the second training session was to practice dialogic communication skills. Before starting the session, the participants reviewed the guidelines for constructive communication and previewed the lesson plan (see Appendix E).

Warm-up discussion. In order to remind the participants of the three communication concepts that they had learned in the last training session-social construction of meaning, communication acts, and the conflict model —I posed them a warm-up question: "How are the challenge areas made?" To my delight, the group had very insightful and constructive ideas about this topic, and they shared many specific details that demonstrated application and understanding of these concepts. The warm-up question was also meant to orient the participants toward the use of dialogic communication skills: This is how the challenge areas can be transferred into something more desirable.

Characteristics of dialogic communication. We started our training with Buber's $(1937 / 1950)$ idea that dialogue takes place in the tension between holding one's own ground while being genuinely open to the other. We went on to discuss how this form of communication enriches understanding of issues by moving away from simplistic either/or definitions to multidimensional both/and definitions and by inviting multiple perspectives into the meaning-making process. 
Buberian dialogue focuses on the interhuman space of meeting, where human interaction unfolds spontaneously (Buber, 1937/1950; Spano, 2006, pp. 4-5). Although, in this space, dialogue emerges in unpredictable moments that cannot be planned for or made to happen (Anderson, Baxter \& Cissna, 2004; p. 15), dialogic communication can be fostered by certain attitudes and actions. In other words, using dialogic communication skills does not guarantee dialogue, but it might enable and kindle it.

Most dialogic communication skills are simple and mundane, and they can be used for constructive as well as destructive purposes. For example, acknowledging other's strengths appreciatively will help to construct positive relationships, whereas acknowledging other's deficiencies by ridiculing them is destructive and can hurt relationships. For this reason, it was necessary to discuss the dialogic, constructively strategic predisposition toward the other that holds oneself as well as the other valuable. This attitude is essential for the emergence of dialogue. Summarizing Buber's dialogue theory, Spano (2006) lists the requisites for this stance: "authenticity of being oneself," "empathic otherness," and "immediate presentness" (p. 5). These essential requirements result in communication that can be characterized as mutual, creative, inclusive, authentic, empathic, and collaborative (Spano, 2010, pp. 12-13). While discussing these concepts with the participants, I was, once again, amazed by their energy and deep conceptual understanding.

Role plays. Since there was not enough time for all four role plays in the previous training session, two teams were asked to perform a scene demonstrating a typical challenging situation at work in this training. Unfortunately, one person was missing 
from each of the two performing teams. Luckily, however, the remaining members from both teams came up with an impromptu scene about a challenging situation with a customer. This time, we spent less time in analyzing the scenario since the purpose of this session was to focus on practicing dialogic communication skills.

Dialogic communication skills. Dialogic communication is not rare, but it does emerge spontaneously. Although we cannot force dialogue, we can create conditions that stimulate it. The following list is an example of communication skills that help us to create such conditions: demonstrating curiosity and wonder, acknowledging, restating, reflecting feelings, reframing, appreciative questioning, and systemic questioning. These skills were chosen from Spano's (2010) “Dialogue Resource Guide” as potentially effective tools in addressing the study participants' challenge areas.

After introducing each of the seven skills, I divided the participants into four teams and assigned two of the seven dialogic communication skills for each group. I asked the teams to come up with an alternative scenario for the earlier role play about a challenging situation with a customer, in which they would apply their two assigned dialogic communication skills. An analytic and reflective group discussion followed each demonstration. In addition, a participant who had a currently pressing situation with two of his/her subordinates provided extra material for practicing appreciative questioning and systemic questioning.

The participants decided to exceed their 90-minute training time by 30 minutes in order to practice the dialogic communication skills. Their application exercises demonstrated participants' ability to understand and practice most of the new 
communication skills, but some of the more advanced skills, such as systemic questioning, remained somewhat obscure and would have required more time for clarification.

I suggested that the participants should practice their skills over the next three weeks in their work situations and contact me with any questions or concerns during that time. After several weeks, I would contact them to schedule our final evaluation discussion. This way, they would have a chance to observe what kinds of outcomes the dialogic communication skills would produce in their real-life work situations.

Closing. In the end, I summarized the content of both training sessions and reminded the participants about practicing their dialogic communication skills in various settings in their work for the next few weeks before the final evaluation. Study materials were sent to the two participants who were absent.

Evaluation. Before concluding the training, the participants were asked to fill out a similar reflection sheet as for the first training session. The first two questions asked for participants' feedback about what they enjoyed the most about the second training session and what suggestions they would have for improvement. As the participants reported, some of them (three participants) liked the application exercises and the following analytical discussions the most. Just as many (three participants) enjoyed the theoretical content of the training. One participant mentioned that $\mathrm{s} /$ he appreciated the real-world examples and another one liked the open discussion. In the additional feedback section some participants reported that the training had improved division 
managers' shared understanding about their situation: "More of us are aware that we are all facing similar challenges \& have shared experiences.”

This time, two participants wrote that they did not enjoy the role plays. One participant was disappointed that not all study participants were present at the training. This issue was also discussed in the additional feedback section provided in the evaluation sheet. Three participants reported that they would not change anything about the training.

Next, the participants were asked to reflect on their learnings in response to the challenges identified in the interviews. Their responses for this section are included in the Results section of this study report.

Make-up training: Dialogic communication. One participant missed both training sessions and another participant was unable to attend the second one. After considering their and the study group's situation with the Assistant Director, I decided to provide an additional training opportunity for them that would combine the content from the both previous training sessions. The training session was held in late July 2010. The "Make-Up Training Packet" that was prepared for this session is appended to this report (Appendix F).

Instead of two 90-minute training sessions, the Assistant Director suggested that I conduct just one two-hour training session. Since this training needed to be scheduled on a very short notice, the two participants would likely be more available for one session than for two. Moreover, it was reasonable to expect that the discussion about the 
communication concepts in the training would require less time with just two participants than with eight participants.

Since one of the two make-up training participants had already attended the first training, we did not spend much time discussing the social construction model of communication, communication act theory, and the conflict model; the main focus for this training session was on the application of dialogic communication skills. As in the previous training sessions, the two participants came up with a challenging situation at work, this time with a subordinate. This scenario was used in analyzing how meaning was co-constructed and for practicing various dialogic communication skills.

This training offered fewer opportunities for interdivisional interaction than the two previous training sessions. But, with only two participants attending, there was more time for individual comments and questions, which proved to be one of the strengths of this training session.

After the training, the participants were asked to fill out the same reflection sheet as the other participants after their two training sessions. The two first questions asked for feedback about what the participants enjoyed the most about the training session and what would they improve on. The answers to these questions were very similar to those from the previous training sessions, but in order to protect confidentiality, those answers are not reported here separately.

Next, the participants were asked to reflect on their learnings in response to the challenges identified in the interviews. These data are included in the Results section of this report. 
Looking again phase for final evaluation. The purpose for the final phase of this action search study was to answer the second research question by evaluating the success of the research process in study participants' work situations and social environments. Although ongoing evaluation was essential for retaining the flexibility and organic nature of this research process and for designing each successive phase, this final evaluation was considered a separate study phase.

The final evaluation was based on an idea that the success of the training would depend on the degree to which it had a positive impact on the five diagnosed challenge areas (challenges with subordinates, interdivisional challenges, challenges with organizational hierarchy, challenging organizational climate, and challenges with customers). These challenge areas were identified in the initial interviews of this study and verified in the focus group discussion where all participants were present.

Since the study participants were the best experts in evaluating the success of this study and defining the final assessment instrument, they had an important role in designing it. They decided to keep the final evaluation very open because each of them had very diverse working tasks and outcomes, varying team sizes, customer contact, and so on. Instead of designing a uniform evaluation questionnaire, we decided that I should meet with each participant for an informal, 30-minute evaluation discussion. Personal interviews would also give me a chance to grasp participants' feedback more fully by providing opportunities to ask follow-up questions and observe participants' paralinguistic and nonverbal behaviors that would not be conveyed by email. I invited the participants to meet me via email: 
For the final evaluation of the success of this project, we need to answer the research question: What are the outcomes of dialogic communication training in your organization? In answering this question, I suggest that you think about the impact the training has had on you, your team, and your work with your colleagues, subordinates, superiors and customers. Did the training affect the bigger organization in any way? In your answer, include lots of details, thoughts, experiences, and stories - the more the better.

Instead of asking you to write your evaluation on paper/email, I would like to have a 30-minute informal discussion with you at your earliest convenience. What time(s) would you be available?

Before the meetings, I reviewed each participant's interview materials from the first phase, reminding myself of their individual strengths and the communication challenges they had reported. During the interviews, I kept that material in mind for possible follow-up questions.

After the training, the participants were asked to practice their dialogic communication skills and observe the outcomes of practicing those skills for three weeks before the final evaluation discussion with me. Instead of after a three weeks' gap, however, the first evaluation discussion was held four weeks and most discussions six weeks after the training. The last evaluation discussion was held almost eight weeks after the second training session. The main reason for this delay was the fact that the training sessions were held in July, shortly before this organization's summer vacation season.

In order to keep the final evaluation interviews as open and organic as possible, I decided to let the interviewees frame and decide the content and direction of our discussion. In addition to the prompt I had emailed the participants earlier, I decided not to prepare an interview guide. 
Although I was not planning to transcribe the interviews, I asked for a permission to digitally record them so that I would not need to write notes during the discussion. After the interviews, I typed my notes and transcribed the most relevant parts of the discussions. I emailed these records to each corresponding interviewee in order to verify the accuracy of the data.

After interviewing the study participants, I had a 30-minute evaluation discussion with the Assistant Director. This discussion was invaluable to me in many ways. First, the Assistant Director provided me with an "outsider" perspective to the study group. She could assess the outcomes from a higher organizational level than the participants themselves. At the same time, the Assistant Director was an "insider" who was supervising the participants and who had been involved with the study from the beginning. Moreover, since she was already familiar with dialogue theory, she was able to analyze the changes in her organization from a perspective informed by scholarship.

After verifying my interview notes and the transcriptions, I analyzed them thematically and grouped the themes around the challenge areas that were identified in answering the first research question. Themes that did not fit under any of the challenge areas were listed separately. Next, I compared the results with the reflective information on the challenge areas that was collected after both training sessions. This enabled me to see the extent to which the participants had put their dialogic communication skills into practice as they had intended to after the training. The comparison showed me also which focus areas were more prominent throughout the study and which areas had less importance. A summary of these outcomes provided answers to the second research 
question of this study: What are the outcomes of dialogic communication training on a city government management team? 


\section{Chapter 4: Results}

The goal of action research is to provide applicable, meaningful solutions to problems that are relevant to the study participants (Stringer, 2007). In all respects, this is what the participants of this study wished to gain from their dialogic communication training: practical outcomes that would address their five, previously diagnosed challenge areas. The outcomes, however, were not limited only to these challenge areas. In addition to finding solutions to discrete problems, this research process was also designed to equip participants with sustainable and transferable communication capacities (i.e., knowledge and skills) that would enable them to effectively address their present-day challenges as well as future ones.

In addition to viable solutions, action research aims to improve and enhance participants' social and emotional lives by building democratic, equitable, liberating, nonexploitative and inclusive interaction and relationships between people (Stringer, 2007). Kelly and Gluck (1979) suggest that the outcomes of action research should also be evaluated based on how the results impact people's lives in terms of their feeling of

self-worth, autonomy, independence, competence, identities, control over resources, accountability, responsibility, solidarity, and attachment to places and historical, cultural, or social ties (Stringer, 2007, pp. 24-25). My hope is that the many voices describing the outcomes of dialogic communication training below demonstrate how participants' social lives have been enhanced as a result of the training program. 


\section{Assessing the Outcomes of This Study}

In writing this research report, drawing a distinction between the method and the results was difficult because the method was built on the results of previous phases, which were then used to design the emerging method in the phases that followed, which again, generated new results. For that reason, the method section of this report should be, in a way, read as a part of the results. The distinction between the method and the results sections, however, is this: the method gives a detailed account of the way this study process unfolded, and the results section focuses on answering the two research questions:

- RQ 1: What are the communication challenges facing a city government management team?

- RQ 2: What are the outcomes of dialogic communication training on a city government management team?

Due to the complexity of the study method and the multi-event nature of the research design, assessment data have been generated in three ways: by continuously evaluating the study process, by evaluating individual events, and by a separate evaluation phase.

Ongoing evaluation. Throughout this study, an ongoing discussion with the participants and the Assistant Director gave direction to the selection and construction of the study method, evaluation tools, and interpretation of results. Below is an example of an email exchange that demonstrates how the research process was constantly assessed and how the Assistant Director collaborated in designing the evolving research process. 
The first quotation is my email to the Assistant Director (personal communication, March

18, 2010):

Hi [Assistant Director],

It's a pleasure to email you that all the individual interviews are now done and transcribed. I'm still waiting for a few individual feedbacks, but other than that, we should start planning for the focus group meeting.

I suggest three major goals for the focus group meeting:

1. to agree on the interview summary,

2. to decide the focus for the upcoming training sessions, and

3. to define the evaluation criteria for the success of the training.

I'm going to analyze interview data this and next week. After that, it would be great if you and I could arrange for a short check-up meeting if you think it would be necessary. Then after that, we would be ready for the focus group meeting. When do you think would be a good time for it?

I want to express my gratitude to you for providing me with this fantastic opportunity to do my study in a "real-life" organization. The group of professionals I have been interviewing has truly impressed me with their generosity, openness, and flexibility. I feel very lucky to work with you and them on this research.

Best regards,

Minna Holopainen

The Assistant Director responded to me the next day (personal communication,

March 19, 2010):

Hi Minna:

Congratulations on passing a key milestone yesterday! We are excited about the collaboration with you and we feel very lucky, too, to have this unique opportunity. Thank you!!

Yes, let me know when you think you might be done with your analysis so we can set a time to meet. If you want to project (e.g., first week in April), I am happy to get something on the calendar so you have that time reserved. In terms of the focus group, as soon as you are ready, let's get that on the calendar, too. 
I am noticing an improvement in the quality of the communication between staff. I don't know if it is directly related to the individuals reflecting on the questions you have asked, if they are more thoughtful/mindful in their communications, or something else. Thank you for already helping us.

Enjoy your weekend, [The Assistant Director]

Evaluating individual events. A summary report was written and emailed to the Assistant Director at each stage of this study. These evaluations were reflective, highlevel summaries whose purpose was to keep the Assistant Director informed on the progression of the research process as well as to invite her feedback and insights.

Formal evaluations were collected from the participants after the two dialogic communication training sessions (see Appendices D-F).

Evaluation phase. A qualitative assessment of the outcomes of the dialogic communication training was done in August 2010 by conducting 30-45-minute evaluative interviews of all the participants and the Assistant Director. The notes and transcriptions of these discussions were analyzed for content, and the results are included in this section of the study report.

\section{Communication Challenges Facing a City Government Management Team}

The answer to the first research question, "What are the communication challenges facing a city government management team?" emerged from the Looking phase's interview data and was further refined and validated in the Thinking phase's focus group interview. The five main areas of challenges were (a) challenges with subordinates, (b) interdivisional challenges, (c) challenges with organizational hierarchy, (d) challenging organizational climate, and (e) challenges with customers. 
In order to get a more coherent picture of the management team, in addition to participants' communication challenges their communication strengths and conceptions about ideal communication were analyzed. In the Looking phase's interview results, these two areas were combined as "Managing philosophy." In this section, both challenges and strengths are incorporated into the data describing the challenge areas.

Challenges with subordinates. Most study participants saw themselves as nonauthoritative managers who supported their subordinates in being successful and who strived to help their teams to perform better. While encouraging critical and independent thinking from their subordinates, the managers were also concerned about their subordinates' physical and emotional well-being. The managers were empathetic and intended to provide a safe place for their teams to express opinions and concerns, cultivate respect, trust, and honesty, and show appreciation for one's work.

Managing openness within divisions. The study participants made an effort to be readily available and approachable for their subordinates. In practice, this meant minimizing barriers to open communication, such as spending time "on the floor," having face-to-face discussions with the subordinates, and having an open-door policy: "It's a feeling of freedom to pop into my office." Openness and accessibility were also manifested in managers' appreciation for a free flow of organizational information. On one hand, they wanted to disseminate information from the top down efficiently and effectively. On the other hand, they favored an open, bottom-up flow of information as they encouraged their subordinates to voice their opinions and suggestions. 
A challenge most managers regularly faced was giving constructive feedback to their subordinates without negatively criticizing them. Furthermore, at the time of organizational restructuring and budget cuts, discussions about reorganizing the distribution of tasks and the structure of work processes raised a number of fairness and equity issues. In order for their communication to be effective, managers thought that they would need to learn to better adapt their communication to suit each subordinate.

An additional challenge, which was rarely discussed openly among the study participants, was the organizational expectation of maintaining the high quality of work after the budget cuts with fewer resources than before. Employees who had been proud to produce "A++" work in time, now had to get used to deliver lower-quality, "C-level," or " $80 \%$ " work and see their names in overdue work reports.

Acknowledging loss and effort while dealing with the reality. At the time of this study, all divisions had significantly decreased in the number of their employees. "Lee" described the situation like this:

We've had a lot of negative things happen, and I'm not quite as joyful as I was before. We've had a $14 \%$ pay decrease (total value + benefits), and I've had to lay off about $10 \%$ of my staff. From the group of eight people I've hired, I've had to lay off six. The people who are left are apprehensive. They feel that they are now in peril of losing their jobs because any further cuts would affect them. A lot of their friends and colleagues are gone. And since we only hire people we really like and who work well with us_-good workers and well-liked people have survived and stayed-layoffs impact us a lot. So, it's been hard on people. Besides, we've had to reorganize [our functions] based on available resources, and that's been a challenge. I've spent a lot of time managing people's expectations, which has also been hard because we've always been proud of being very responsive. And now we don't have the staff to perform on the same level as before. It makes you feel bad. 
One of the most significant challenges to the managers was to acknowledge this loss and the efforts to recover from the budget cuts while dealing with the reality of diminishing resources. In addition, many teams struggled with typical symptoms of budget cuts: short tempers, arguments, and rumors. In other words, managers had to motivate their teams to "do more with less" in an uncertain organizational environment. A quote from "Sue" illustrates this challenge, "I'm struggling with how to continue to provide the emotional support my employees need, and yet push them over the edge so that they will start swimming again... so that we can get our jobs done.”

Meanwhile, the division managers themselves also struggled with the organizational changes. First, they mourned the loss of organizational members who had been dear, long-term friends, "We have lost family members we grew up together with. This has changed the dynamics in our family considerably." At the same time, the managers were concerned about the continuity of their work since they had lost all their "babies, the youthful and vital new generation and their ideas." Who would train the next generation after they were gone? The managers also felt challenged because, as the organizational structure was flattening, their span of control was increasing, which made them feel "stretched thin" and somewhat challenged in terms of knowing enough of their subordinates' fields of expertise.

Interdivisional challenges. Within the senior management team, the participants saw each other as collaborators who willingly shared their expertise, information, and staff. Since many of them had been working in different positions in the larger organization, some had formed close interpersonal relationships. The recent restructuring 
of the organization had moved some people around, which was believed to be beneficial for the management team.

Managers valued effective and frequent communication, and they preferred faceto-face communication to less personal emails because more immediate forms of communication were believed to build better interpersonal relationships among the management team. Better relationships, in turn, facilitated better communication: "Good relationships make it easier for us to communicate."

\section{Competition over resources and departmental differences challenge}

communication and relationships. Despite managers' affinity toward each other, their communication and interpersonal relationships were challenged by organizational changes, flattening hierarchy, and increasing demands for efficiency. Interview material from the Looking phase shows how participants' language invoked battle positions (war language and metaphors are emphasized):

We have pulled all the rabbits out of our hat financially, and we have been pretty good at that. And now we are getting to the point where there are no more rabbits left in the hat. We cannot see any ears even. People are going to be laid off. I think the most stressful thing is the internal stress that is caused by other departments that are going like the Donner Party. (In 1846 Great Migration, there was a group of individuals who were trying to cross over to California. A number of them got stuck in the snow and ended up resorting to cannibalism, including my ancestors, by the way.) When things get stressful, you see the true nature of people come out and people are doing what they need to do to survive... We are constantly defending our finances so that we can maintain our staff and the services we provide.

The battle positions and the increasing competition over resources gave strength to divisional generalizations and decreased appreciation for departmental diversity.

Participants talked about their divisions as "silos" that "speak different languages," "think 
differently," and have "different outcomes." As a result of the training program, the managers hoped to increase their understanding and appreciation about other divisions so that they could work better together.

A description of the divisional generalizations was synthesized from Looking phase's interview data, after which it was set in an appreciative frame guided by the Assistant Director's insights, and lastly, fine-tuned with the participants:

The Investigators. The Investigators were seen as hard-working, cautious people who avoided high risks. Their world was dualistic; to them, issues were absolute matters of black/white, life/death, and yes/no. In work situations, they provided answers immediately.

The Strategists. While the Investigators were seen as rigid and absolute, the Strategists were considered flexible, indeterminate, and their decisions almost always negotiable. The Strategists were idealistic, "flowery" people who spent a great deal of time thinking and reflecting. Getting an answer from the Strategists took considerably longer than getting an answer from the Investigators.

The Guards. Ideologically, the Guards fell between the strict Investigators and the liberal Strategists. The Guards were nice "party people" who understood many shades of gray. Because they had not been touched by budget cuts in the beginning of this study and because they were housed in a separate building from the other three divisions until June 2010, they were seen as "insulated" from the larger organization.

The Catalysts. After the focus group meeting, a generalized description for the Catalysts was added: "The Catalysts are focused on process, not the outcomes. They are 
experts on details and individual pieces — someone else puts the pieces and details together. Since the Catalysts have to interact with every division, they translate well across divisions."

While the participants used these descriptions as their study and practice material in the dialogic communication training, at the same time, they were able to analyze how these generalizations were co-created in communication. The action of analyzing and discussing these differences contributed to more positive definitions of these generalizations; participants' appreciation about their divisional differences increased, and their understanding about these differences became deeper and more nuanced.

Challenges with organizational hierarchy. The nine division managers wanted to be good advocates for their subordinates. At times, they put considerable effort into representing their teams well in the organization and "fighting" necessary "battles" for their subordinates. Still, the managers themselves felt that their efforts to recover from the budget cuts and their "pain" had gone largely unmatched elsewhere in the city organization. Insufficient organizational recognition, appreciation and feedback were thought to deflate motivation, which was believed to encourage mediocrity.

The managers hoped that dialogic communication training would also improve their communication across vertical organizational levels with people who held more organizational power than they did. They were concerned, however, that a training covering only one horizontal layer in their organization — senior and middle-level managers - would not result in adequately successful changes in organizational communication practices because those who hold more power tend to define the rules for 
interaction. They assumed that if the hierarchical top were not trained in dialogic communication, it would be difficult to engage in dialogue with them.

Challenging organizational climate. Due to the recent organizational changes, the mood in the city government organization under study was far from cheery; the participants characterized their organization's climate as "a cloud hanging over us." Many managers were worried about their or their subordinates' positions and performance while they were trying to adapt to the changes that had already taken place. Flattening organizational hierarchy, restructuring, and substantial budget cuts had stretched managers' span of control thin, and substantially increased demands for efficiency and productivity. The stability of their old organization had been lost, and reaching a comforting equilibrium in the near future seemed uncertain.

Some participants, however, characterized their organization before the restructuring as too tall and heavy on the management side. They believed that restructuring was vital because it made the organization and its procedures more efficient. Thus, although the organizational climate was grim, the managers felt that at least some changes had been necessary. While they were proud of their accomplishments in a difficult financial situation, they were wondering if other city organizations had managed to become as efficient as they had: “We have taken [budget] cuts but we haven't lost any productivity because we plan well. We have cut personnel tremendously while there are considerable inefficiencies elsewhere in the City organizations."

Challenges with customers. The participants were proud to be public servants, and they made an effort to do their work well and be readily available to their customers. 
Over the last couple of years, however, this part of their identity had changed. "Lee" explained:

The media as a whole and certain individuals in the community have taken a dim view of public employees, their pensions, salaries, and so on. So, most people who used to be proud of being public employees are now hiding it. From being an asset, we have become a liability.

While this attitudinal shift might not have been very prevalent or detectable within managers' day-to-day routines, those managers who had had more customer contact in their work shared more immediate concerns about interacting with people who persistently complained about various issues, engaged in ongoing fights with other customers, or simply lied. Such situations demanded extra time and attention from the managers. As an example, one division manager said that she had had to revise some of her team's procedures to eliminate the extra work generated by lying customers. Another challenge for the managers was to deal with customers' frustration of the City's constantly changing contact persons, which was directly attributable to organizational restructuring caused by the budget cuts.

Although customer interaction was not the primary focus of this study, the participants hoped that the dialogic communication training would give them tools to approach their customers and their issues in productive ways.

These five areas - challenges with subordinates, interdivisional challenges, challenges with organizational hierarchy, challenging organizational climate, and challenges with customers - were used as a needs assessment guiding the selection of communication concepts that would be included in the two-event training plan. The outcomes of the training are reported next. 


\section{Outcomes of Dialogic Communication Training on a City Government Management}

\section{Team}

The main purpose of this study was to answer the second research question: What happens in a city government manager group when its members are trained in dialogic communication? In order to answer this question, all the collected data were pulled together and arranged in three thematic groups: shared conceptual communication model, enhanced communication skills, and affective changes.

Shared conceptual communication model. Dialogic communication is not practiced only by the erudite few. In fact, dialogic moments arise frequently in everyday encounters, and once dialogue is labeled and brought into attention, it might seem very familiar and even mundane.

During the training, the participants noticed that they were already occasionally practicing dialogic communication. What was new and most useful to them, however, was a common conceptual communication framework, the social construction of communication, by which those indistinct, free-floating occurrences of dialogue could be seen as parts of a larger process of making desirable outcomes. Looking at communication through this framework helped the participants to become more aware of their communication practices and more analytical about the process of making things together in communication. In the words of " 17, ," "I think that I already knew some of the skills before, but the training and the framework has helped me to elevate the use of those skills. So, it's more like a set of glasses I can put on.” 
Demonstrating this analyticism, the participants noticed that they had become more introspective about their own communication. For example, participant "5" describes: "The training just brought it [communication] to the forefront, so that I can now better see what I'm doing. I'm more analytical about my communication." Also "Sue" had become more introspective about her communication: "I try to hear myself when I say stuff. And I try not to be so directive when I'm talking to people."

At the same time, the participants became more aware of the way their colleagues who had also received the training communicated. Within the new framework, they had formulated a revised set of rules for their language game (see Wittgenstein, 1953/2001; Littlejohn \& Foss, 2005, p. 46). Others' conforming to the new rules as well as deviations from them were noticed:

Another thing from the training is that I pick up more on the people who have had the training or who get it. You can hear conversations just out there where one of the two people are taking that phrasing or taking different tactics. So, it's like you're noticing.

In Wittgenstein's (1953/2001) terms, those who had learned to play this new language game particularly well, like "Bob," had become game masters:

There has definitely been an increased awareness on my part in trying to really assess how I am approaching and communicating with both my subordinates and also my superiors: How would I present an issue to others so that it would be more readily received? So, there has been more awareness on my part and more intentional thought process in terms of communicating, and maybe some strategizing before approaching certain situations.

"Lisa's" approach is somewhat similar to "Bob's," and it exemplifies game mastery as well: "A lot of [how people communicate] has to do how you are raised and 
with your previous experiences. You need to break that mold and do something different.

You need to be able to step outside from a moment, and decide what to make."

Using the new analytical framework did not evoke solely delighted insights

among the study participants. One division manager discussed her frustration that had been caused by the increased awareness of some unproductive communication patters and her hesitance of interrupting them:

The training made us almost more frustrated about some settings we are regularly finding ourselves in, because now we have more ways to look at how communication in these settings is not good. For example, in our recurring meetings, we are now better able to see unproductive, almost predictable patterns of communication, such as getting into too much detail about issues that are not relevant to everybody or starting from too far in history and never having enough time to get in today's issues, so that you never get to discuss the important things.

After the recent layoffs, the group that remains has had 20-25 years of history together. During that time, we have been longstanding with however we behave in our meetings, and probably, if we all just sit there, the meetings go the way they always do. Participating in the training sessions heightened the need to take some ownership of these settings, and we know that we are partly responsible in producing them. But at the same time, we are not quite sure if it is even our responsibility to interrupt these patterns. We feel that those who run the meeting should address the issue and not confirm the ineffective communication patterns by not addressing the fact that they are patterns.

To summarize, the participants noticed that they were able to use some of the communication skills they already had and place them in a new framework. Sharing the same framework made the participants more analytical and insightful about their own as well as others' communication. It also increased their awareness that people have choices about how they communicate.

Enhanced communication skills. Understanding the implications of the social construction of meaning increased participants' appreciation for diversity. The social 
construction model helped them to see that not all realities are the same and that, sometimes, these realities do not have to make sense together. In order to manage different realities well, the participants received training in dialogic communication skills.

The core idea of dialogic communication is to remain profoundly open to hear other's point of view while, at the same time, effectively express one's own ideas. In Buber's (1937/1950) terms, in dialogue, people are "open to the other" while they are "standing their own grounds." After the training, "Merlon" noticed that he had learned to balance these two conditions:

Generally, I think it's a good thing that I can now find the balance of standing my own ground and being open to the other. I have tended to be more open and listen more. Now, I understand that it's important that other people really understand what you say.

In the management team, the dialogic communication training resulted in two sets of improved skills: listening (being open to the other) and expression of one's own ideas (standing one's own ground).

Improved listening skills. The training in dialogic communication improved division managers' listening skills in terms of gaining a greater appreciation of diversity and an increased motivation and skills to acquire a better understanding of issues. The managers were also more resolute to stay focused on those issues while they did not get diverted by trivialities or personalities as easily as before. Moreover, they noticed that the training helped them to be less defensive when communicating with others.

The greater appreciation of diversity was manifested as an increased motivation to listen to others more holistically. The participants strived to understand others' intentions 
better by paying attention to multiple levels of meaning (e.g., factual, emotional, and identity) and inquiring into issues in order to find out things that had not yet been revealed. Participant " 5 " gave an example of a recent encounter with her subordinate:

One person who was quite resistant to our organizational changes came to talk to me because she thought I had been disrespectful to her when I had not informed her about some changes. Although her work assignments had not been changed, she was quite upset. I told her that I am sorry that she is upset, and asked what made her think that I had been disrespectful to her. After talking with her for a while, she still seemed unreasonably upset about the issue. So, I asked if there was something else going on in her work or personal life. I thought that maybe this organizational restructuring had been the "last straw" to her. It turned out that since this person is going to retire next year, she was expecting to "coast" along and get a lighter workload instead of doing her full share of the work. I explained to her that we had just lost people, and that her full contributions were urgently needed in our organization.

Some managers had started to include their subordinates in making decisions. For example, "Sue" wanted to have a fuller picture of issues before implementing changes altogether:

At the moment, I'm restructuring our processes. My challenge is to figure out how my managers will be motivated to do things they are not used to take care of. As a Division Manager, I want their input. The training helped me to surface and address people's concerns better.

Of the specific dialogic communication skills, the managers found particularly useful to demonstrate curiosity and wonder, acknowledge priorities, values, differences and emotions, restate main ideas, and to assume an empathetic attitude. These skills helped them to uncover a more intricate picture of issues and their contexts, which increased mutual understanding among discussants. "Sue" had noticed this with her subordinates:

I've been inquiring into my subordinates' issues more. In one specific case, someone seemed to have done a wrong decision. Instead of trying to prove that 
s/he had been wrong, I tried to find out why his/her decision seemed odd to me. The discussion with her gave both of us time to develop a more solid understanding of the issue.

Now that the managers were able to acquire a more holistic picture of various issues, they found it also easier to stay focused on issues and not get diverted by trivialities or personalities. As an example, "Lisa" describes one occasion with her subordinate:

The training helped me to talk about a particularly difficult issue with one of my subordinates. It was now easier to stay focused talking about the point of the discussion, and not get sucked into talking about trivial details. The training helped me to keep things on a higher level and not getting diverted.

The training helped the managers be more comfortable with issues where different views did not constitute a coherent, fathomable whole. The social construction model implies that people's social realities can be considerably different. For that reason, instead of one absolute view, multiple views may exist simultaneously, each with their own validity. A dialogic approach does not attempt to resolve the tensions between these different, even contrasting views, but upholds them simultaneously as equally valid. Understanding that someone's differing view does not have to challenge the existence of one's own view was liberating to the managers and resulted in decreased defensiveness in interaction with others. Participant " 22 " describes how this realization helps her in interacting with her subordinates, colleagues, and superiors:

I really learned the importance of listening. I might still feel threatened by others' differing opinions, but I don't act that way any more. And, I'm really trying to understand what they are saying. 
The managers were not only finding their improved listening skills valuable, but they were equally delighted to notice others' improving listening. One participant gave an example:

After the training, one division manager has been much more relaxed and much more patient than before. So, I think, if anyone is listening better, it's him/her. And that was something s/he needed to work on. S/he has also become more aware if others are not listening to him/her. I think that in the past s/he would be very determined in his/her own way (my way is the right way). Having him/her slow down and take the time to be careful of his words and how s/he approaches people is a real value because $\mathrm{s} / \mathrm{he}$ has a lot to give.

In short, the dialogic communication training improved division managers'

listening skills in four ways:

- Managers became to value diversity more.

- Managers acquired a more comprehensive and nuanced understanding of issues.

- Managers became more focused on issues and less prone to get sidetracked by trivialities or challenging personalities.

- Managers were less defensive when they found themselves challenged by diversity.

More effective expression of one's own ideas. Most participants reported that the training helped them to express their ideas more effectively, gain a stronger sense of agency and more confidence in expressing their own points of view, become more aware of their audiences, and be able to practice more open communication with their subordinates.

Managers reported that the training gave them more confidence in expressing their opinions within their organization. They were more prepared to make sure that their voices were heard and that they would request more clarity about issues that were 
relevant to them. In the final evaluation interviews, many participants shared detailed stories about how they had successfully stood their own grounds. Managers reported also that the training had helped them to trust the validity of their own viewpoints without challenging the validity of others' viewpoints. Participant "22" explains how she now felt more comfortable with contradicting positions:

After the training, I'm more comfortable in standing my own ground. I've learned to keep my position more confidently, and I don't give it up as easily as before. I don't have to give up my position, and neither does the other because my point of view is valid and valuable just like the other one's is. And, if the other person disagrees, that can be okay.

Since one's own position is not threatened when conflicting positions are discussed, all interactants can maintain their authenticity. "Bob" was very pleased to find out that in order to communicate effectively, he does not need to sacrifice his integrity:

I think, the training helped me to see that good communication doesn't necessarily mean to not being true to myself, but it's more about how do I effectively communicate what I feel or what's my understanding about an issue or my experience. And, good communication means also that I'm just communicating my own view and not The View. It's about the process of how you communicate things. And that for me, personally, is probably the biggest takeaway from the training.

One of the major revelations the participants achieved in the training was that when communication is seen from the social constructionist perspective, all interactants become responsible about the outcomes of their interaction. The managers realized that it is important to express their views in issues that matter to them. In "Merlon's" words: "It has been very eye-opening to have a different framework of how we are creating meaning together and the notion that you need to express your side. Running away is not responsible." 
Also the Assistant Director had noticed that some participants had become more confident and assertive:

One particular division manager has become more assertive. Whereas, in the past, s/he was very good at understanding others' perspectives and very quick to give up his/her own view, s/he now weighs the two perspectives, and then, if s/he feels his/her own opinion makes the most sense, s/he'll hold that.

During the evaluative interviews, participants' increased assertiveness emerged as one of the strongest themes. As a communication practitioner, I was glad about the increased confidence, but at the same time, I found myself slightly concerned if the managers would be able to find the dialogic balance between standing their own grounds and being open to the other. So, I decided to ask about this issue from the Assistant Director in her final evaluative interview. This is how she responded:

In the past when people were standing their own ground, it was more about stating one's own position for negotiating or persuading the other. After the training, I think my managers are now listening to each other, but they are also concerned with how to be more effective around sharing their own ideas.

I did notice one participant was a little more assertive in a group meeting than what I have seen in the past. He did a really nice job in expressing himself. I think he was also more aware of who his audience was so that he could be as effective as possible. So, that is very, very good.

Another one of my managers is now finding her voice, which is delightful. And she is very excited to be able to apply some of these techniques in her own team, and to be able to have all her team members to appreciate the learnings she got from the training. I have noticed that the training has given her a little boost in terms of finding her voice. But she has always been a very good communicator. She also plans how she should approach various issues or persons so that she would stay focused on the issue, not the person.

As the Assistant Manager points out in the previous quote, dialogic standing one's own ground is profoundly different from stating one's position in other kinds of communication. In debate, for example, positions are first stated, after which the 
interactants start persuading or negotiating the outcome for the interaction. In these situations, the outcome is often a compromise or the designation of a winner or loser. In contrast, dialogue rarely sees differing views as polarized opposites. As a result, dialogue reveals one position out of many possible ones giving rise to synergistic insights and novel ideas.

The dialogic communication training did not only help the division managers to feel more confident about expressing their opinions, but it also increased their awareness about their audiences, which is one of the key skills indicating communication competence. The managers said that they now strive for more clarity in communicating instructions or discussing important issues with their colleagues, subordinates, and customers, and they make an effort to adapt their communication so that others can understand them better. Participant "17" explains how she has become more aware of group dynamics, which affects how she adapts her communication:

The training has made me more observant of [interpersonal and group] dynamics, and I try to know my conversation partners better. I try to understand how they converse because once I know the others better I can alter what I do and adapt better to their communication.

Increased audience awareness and sensitivity to diversity impacted "Flying Tomato's" communication practices and interaction with his staff:

After the training, I was more conscious about how I interacted with my staff. For example, I would listen more and I would ask for more input from people because now I was conscious that people interacted in very, very different ways.

The increased audience awareness made the managers more aware of how receptive others were to hear them out. Communication was not only about striving to send a clear message any more; it had become a two-way process. As a result, the 
managers now wanted to communicate in a way that would help others to engage in communication with them. "Bob" explains how he tries to prepare for a challenging communication situation by planning in advance:

There have been some new things that are rolling out and that have been discussed about in our organization. And, I have ambivalent feelings about those issues. Part of me wants to just do what I can, and the other part of me, my nature, wants to speak up and let them know my concerns or disagreements of their styles or approach. So, I've been struggling with whether I even want to come out of my shell and talk with others about this issue or not. If I do go forward and speak with them, I'm going to lean heavily on some of the tools [we learned in the training] and refresh myself on the skills because I don't want to come across as somebody who is just complaining.

Within divisions, the dialogic communication training program resulted in more

open communication. In some cases, increased openness had stimulated passionate

discussions, which shows that people in dialogue are engaged and invested in issues that matter to them. One manager shared such an example:

One of the things I'm having problems with in my division is a very polarized usand-them mentality between the union representation and the management. After the training, I have tried to be more candid with them. I've met with the representatives, and I've also sent out some written communication to all my subordinates explaining what I'm working on. In the past, I assumed that they already knew where I was coming from, and that I was genuinely willing to work with them. But now I just decided to spell it out very explicitly. This has spurred discussions, some good ones and some heated ones. As a result, however, I've had a lot of very positive feedback from many individuals. Moreover, the union confronted me, which clarified issues between them and I. So, that's a positive thing.

To sum up, the dialogic communication training helped the division managers, in general, to express their own ideas more effectively in four ways:

- Managers gained more confidence to express their ideas.

- Managers trusted that their ideas were as valid as others' ideas. 
- Managers became more aware of their audiences.

- Managers engaged in more open communication with their subordinates.

Affective changes. In the final evaluative interviews, many participants talked about a profound attitudinal change rather than specific dialogic communication skills. The attitude they described reflects Buber's (1937/1950) openness to the other while standing one's own ground, which is also described by Shepherd (2006):

In the experience of communication, I experience your presence and mine at once. Communication, in this way, is the experience of being-together. I express that as one word, being-together, in an attempt to capture both the togetherness of the experience as well as the "becomingness" or "being-ness" of the experience- the processual sense of always-becoming, and always-becoming more, together... Perhaps another way of getting at the special nature of this simultaneity is to say that communication is the desirable (even if sometimes unhappy) experience of attending not just to me, at the ignorance of you, nor just to you, at the loss of me, but the sympathetic awareness of and attendance to both you and me in simultaneous regard. (p. 25)

Participant " 22 " describes her new dialogic attitude as "being empathetic and acknowledging your own stance at the same time." "Merlon" believed that learning about the social construction model and dialogue theory had caused an attitudinal change in him. During her learning process, "Lisa" had noticed some features of associative learning:

It's almost like a built-in shock treatment: If you don't communicate well, you don't feel good about it. I don't know very many people who don't feel good about not being in a good, productive relationship. And when you're at odds, your whole body reacts to it. So, it [communicating well] is kind of selfrewarding.

In addition to finding a new framework for good communication and enhanced communication skills, some managers had established practical changes in their 
divisions. "Sue's" example demonstrates more inclusive decision-making and

communication practices within her division:

We just had a person who rotated out of a section, and we had to take her project and distribute it. Rather than using the old way of reassigning projects to people, I decided to include people in this decision so that the project managers would get to choose the parts they wanted to take from a list they would need to create themselves. When they would participate in making the decision, they would assume more ownership of the process. And, then, there would be less pointing fingers. Everyone has to buy in and participate in deciding how can we do things better.

Also "Flying Tomato" had made changes in his team: he had established a new

procedure for regular meetings:

I have several meetings per week with my managers. After the training, I have realized that although I have an agenda in these meetings and people know that they are free to give their input, some people do not easily volunteer to speak up. So, I have started to just go around the room, and ask for concerns and things that are going on. Interestingly, now that I have given my managers the opportunity to open up, they talk about a lot of things that probably would have not come up before. Without inviting their input, I wouldn't have found out as many things as I now have. This new practice also helps in building our team, and the managers understand that their input is important in this division. The feedback I'm getting from my staff is that they really like the change. It's been very helpful.

Managers' attitudinal change extended also to their interdivisional relationships.

Discussing the divisional differences in the focus group meeting and role playing various scenarios about those differences made the managers proud about the characteristics they identified with and more appreciative about other divisions' idiosyncrasies. This resulted in better understanding of other divisions' priorities, values, and individuals. Participant "17" highlights this aspect of the training program:

Relationship building was an important part of the training. It was very valuable that I got to spend time with people from other divisions during this study in a setting that was something that was not routine. I feel that we could do better if there were more opportunities for settings where we could do two hours around 
some other topics than revenue. We are interested in each other, and we could benefit from spending time with each other. It's like learning a new language from each other. How can you move on to working well together when you know almost nothing about this other person?

"Lee" saw value in the mere process of discussing common issues and working

together:

Of the training, the most important concept was to have a common understanding of the things we are talking about, especially, when it's something that is not so obvious... The group as a whole benefited from the training because they got together to work on a single task. Even though some of us are working across divisional boundaries, touching different areas every now and then, the reality is that we probably work in different silos of activity. So, I think every time you get us together to work on something, it benefits the organization.

Participant "5" was glad to find out that others shared similar experiences with her:

Probably one of the things I liked the best or that was helpful about the training, was how we looked at the interview results in the focus group meeting. It was interesting to learn that many of us had similar experiences without knowing it. It was good and helpful for us to get to talk about these things.

One participant was annoyed by her new awareness of some workplace issues that had not bothered her before the training program. Nevertheless, without a doubt, managers' interaction in the training and their increased appreciation toward each other improved their relationships. This increased appreciation and understanding toward other divisions resulted in the desire to learn more about others and to understand their work even better. "Bob" attributed his new interest to know more about other divisions directly to the training:

I feel like I'm just now starting to poke my head out and beginning to look at what's going on elsewhere. I'm trying to see if I can mend bridges there or strengthen relationships. So, I haven't really done much out there. I feel like I'm just now kind of looking what I want to focus on... I think it is important to all of us on all levels to know what each of us do. I would like to start a model that reaches out and tries to understand other divisions a little bit and learn. Our 
relationships could have more depth. So, I'd like to focus on that. I think this is attributable to the training because I have already started to use some of the training [concepts]. I have also become more intentional about my communication and communication styles with my immediate staff. But now I want to broaden that scope into a larger organization and to begin to apply it to other venues and other relationships.

Affective changes can enable profound change, which can bring forth sustainable skills. Dialogic communication is not just a technique; it is a practical and applicable way of approaching life. Accordingly, some participants had also found the dialogic attitude and communication skills useful in their personal lives. One division manager described how dialogic communication had helped him in a difficult situation with a friend:

I'm in a really bad situation in which I and someone else no longer trust each other. And so, this person has become very antagonistic toward me. But, I've adopted a dialogic attitude also within this context, which has been very important for my own mental health. The training has absolutely helped with that. And I'm not getting angry. It's fascinating! Even when this other person starts out angry, I've noticed that dialogic communication can totally defuse anger from our discussion. Completely. And I can also calm myself down because I'm focusing more on the issues. I'm not thinking only by the emotional part of my brain.

Another participant had tried to use dialogic communication concepts and skills to help her change old communication patterns with a spouse:

We have always tended to have some communication problems, and I've never quite understood why. Maybe it's the Mars and Venus thing or something else. I don't know exactly what it is. Could be any number of things. Anyway, but it's at home. I try to stay engaged and not just throw up my hands and withdraw.

One participant thought that dialogic attitude and skills would have helped him in raising his children because dialogue helps people express their ideas without coming across as confrontational. He explains: 
In the arena of my own life, I wish I would have had some of this [dialogic communication training] earlier to help me specifically with, say, my children. With children, it is a challenge to figure out how can I be true to what I'm trying to communicate to them without presenting my view in a confrontational or rightwrong manner so that the other hears my viewpoint, is aware of it, and considers it. I think that this [dialogic] approach would have helped me in trying to get my kids hear what I have to say.

In her interview, "Lisa" summarized others' ideas: "It [dialogue] is not just [applicable to] business. It goes into all aspects of life. I think it's good."

As a result of dialogic communication training, five types of affective changes took place in the management team:

- Managers assumed a dialogic attitude toward people they communicate with.

- Managers' dialogic attitude was manifested in more open and inclusive organizational practices within their divisions.

- Managers achieved a greater understanding and appreciation about their divisional differences.

- Managers' interpersonal relationships within the organization improved.

- Managers applied dialogic communication concepts and skills in their personal lives. 


\section{Chapter 5: Discussion}

Moving to San Francisco Bay Area from Helsinki ten years ago immersed me in one of the most culturally diverse environments in the world. As I was observing the challenges that arose from working in one multicultural organization, I noticed that people were often greatly challenged by the differences they faced in their everyday encounters with others. Since then, I have sought out ways to understand this challenge better and help people in organizations to manage their diversity better in order to work more effectively together and enjoy each other more.

During my studies at San José State University, I learned that diversity does not only convey people's ethnic or cultural differences but also many other areas that make

people, teams, and organizations different from each other. I also became convinced that dialogic communication is an attainable, practical, and realistic solution to the challenge of managing diversity. For my thesis work, I wanted to explore some ways in which dialogic communication could be introduced into organizations and to study what would happen as a result.

An opportunity for this work came up in one of my graduate seminars where I met an Assistant Director from a city government organization. She was interested in dialogue and her organization graciously committed to carry out the study with me. Luckily, she has been pleased with the results in her organization that indicate that dialogic communication may be valuable for today's work organizations. 


\section{Meeting the Participants' Goals}

In the beginning of this study, the Assistant Director listed three goals that she hoped her organization would attain from the dialogic communication training. These goals were (a) to provide a professional development opportunity to the middle-level managers by expanding their existing facilitation and communications skills; (b) to assist City's middle-level managers with engaging their staff around budget issues, process improvement, and other relevant issues; and (c) to contribute to the larger organization's culture of communication, listening, and teambuilding.

The data answering the first research question, "What are the communication challenges facing a city government management team?" were integral for designing the dialogic communication training and answering the second research question, "What are the outcomes of dialogic communication training on a city government management team?" Diagnosing the challenge areas — challenges with subordinates, interdivisional challenges, organizational hierarchy, organizational climate, and customers — customized the communication training for this team and made it more relevant to the participants.

In general, the dialogic communication training achieved the goals the city government organization wished to attain. The organization's first desired outcome from the dialogic communication training was to enhance managers' facilitation and communication skills. The outcomes described in the Results section suggest that this was achieved as managers' ability to listen to others and express their own ideas effectively improved. Furthermore, a shared conceptual communication model provided 
the managers with analytical skills and introspection that will enable them to keep developing their communication skills further.

The city organization's second desired outcome was to find ways that managers could use to engage their staffs around various issues. As a result of the training, managers' communication with their subordinates became more open and less authoritarian. Furthermore, some managers adopted new managing practices that better invited their subordinates to take a part in organizational functions and decision making.

City organization's third desired outcome was to improve the organizational environment. While at the time of writing this research report it is too early to evaluate how the dialogic communication training impacted the larger organization, the results indicate that, with some time, managers' shared communication model, enhanced communication skills, affective changes, and particularly, managers' improved interpersonal relationships have a potential to contribute to a more desirable organizational culture overall. A larger institutional change, however, would require supportive involvement from other organizational levels.

\section{The Current Urgency for Dialogic Leadership}

The outcomes of this study are encouraging for other organizations as well. The dynamism of modern, highly unstable organizational environments caused by the rapid global diversification of societies and industries seems to be a new norm rather than a passing phase (see Heifetz, Grashow \& Linsky, 2009; Lewis, Goodman, Fandt, \& Michlitsch, 2007). Many tall, hierarchical organizations find themselves to be too rigid and slow to respond to these sorts of environments. Responsiveness and adaptability 
require fast dissemination of information and fluid communication and feedback channels, all of which require a flat organizational hierarchy. These, in turn, promote creativity and innovation that help organizations adapt to their environments. Necessary for adaptation, organizational restructuring and the following redistribution of organizational power might cause a significant amount of confusion and friction among organizations' employees. Within this environment, dialogic style of leadership can help organizations to manage their changes better and, ultimately, help organizations survive.

Dialogic communication is the nucleus of dialogic leadership (see Isaacs, 1999a). For that reason, dialogic communication training generates attitudes and practices that mark dialogic leadership. An example from this study supports that notion: After the training, "Flying Tomato" revised his meeting procedures into more inclusive and invited his managers' input into decision making. Similarly, in "Sue's" team, decision-making practices became more inclusive. Thus, it seems that dialogic communication training breeds dialogic leadership.

Dialogic leadership merges dialogic communication with participatory, adaptive, and transformational leadership practices. As a result, teams become more effective in their work because they are better able to understand and accomplish their tasks and because they build better interpersonal relationships (see Littlejohn \& Foss, 2005, pp. 233-236).

Task benefits from dialogic leadership. Dialogic leadership makes use of people's diversity and stimulates creativity, innovation, learning, and deeper 
understanding of complex issues. All these benefits facilitate an organization's adaptability to its environment.

The fast-increasing diversity is critical for contemporary organizations' growth and adaptation (e.g., Putnam, 1995). When managed well, diversity spawns creativity and innovation. Dialogic leadership provides effective tools to manage diversity well as "Flying Tomato" explains:

The training, at this point, helps me more with the people I work with because I have been able to improve my management skills by becoming conscious about the true setup of the day-to-day work... I think that dialogic communication is a more effective way to communicate because people might have certain opinions and they genuinely hold those opinions for a good reason. Dialogic communication makes me a better listener, and I don't set rules as fast as before. I know from my experience by managing this group, that when there is a good effort to listen and try to get somebody's idea, I know that it will succeed.

Dialogic leadership helps teams to surface multiple perspectives, including those that are not usually expressed, and helps facilitate understanding of those issues in more depth and breadth. As a result, dialogic leadership promotes detecting, assessing, and managing risks (Novak \& Sellnow, 2009). Participant “22's" quote below demonstrates how the dialogic communication training improved organizational risk management by helping a manager feel more confident about holding her opinion, which, in the long run, might prove very valuable to her organization:

The training triggered something in my brain that helps me stand my ground better. For example, I met with several managers earlier today. We were trying to redesign our organizational structure because my area is getting more responsibilities but not extra staff. In order to assume their new responsibilities, six of my employees would need to be trained. Instead of the suggested one-year training, I had to voice my concern that they would need two years because their new areas are very complex. My position was not immediately supported but I felt confident in expressing it. This decision affects six people's work for the next two years. It's not a minor thing. 
One obstacle for effective risk detection is a fear to openly communicate concerns in an organization where some people hold power to reward and punish others. In such organizations, power differences often make people less motivated to take risks to express their opinions candidly. In these situations, dialogic leadership improves risk detection because it changes the definition of power from the kind of power that is feared and held by a select few into the kind of power that is shared. Instead of reducing leaders' power, however, dialogic leadership increases the total amount of power by empowering all stakeholders around an issue and making them accountable about the outcomes. Hence, instead of power minus, taking power away from the leader and dividing it with others, dialogic leadership yields power plus, the kind of power that increases everyone's power by sharing it.

One of the ways in which dialogic leadership reforms organizational power is the kind of discourse it triggers. Since dialogic leadership challenges monologic, authoritative discourse and fosters democratic and inclusive communication, it invites team members to participate in decision-making and, thus, assume a greater responsibility for their work. Occasionally, teams that are led dialogically exceed expectations like the team in "Flying Tomato's" insightful example:

Occasionally, we have been losing some customer files. It's not a rampant because we are a big division, and every month, we see around 1,600 people at the counter. So, for one file to be misplaced once in maybe every three months is not too bad. But, it causes us a lot of headache because you still don't want to misplace anybody's file. So, we decided to institute some way of preventing that.

So, I sat down with some of my colleagues and our superior, and we came up with a plan of how to take care of this problem. Later, I met with my staff, but instead of dictating them how we are going to do it, I decided to tell them what our goals were: We wanted our section to deliver these files in full to the next 
step of the process they are in. Interestingly enough, just by giving my subordinates an opportunity for back-and-forth discussion and to give their input, we arrived at the same solution that my colleagues and I had come up with earlier.

Before the dialogic communication training, I think that I would have approached my team and said: "Well, missing customer files has been a problem. This is how we are going to fix it, and this is the person I'm going to assign for the task. Do you have any questions or comments?" But now I used a different approach by actually stating the problem, and then, evolving toward the goal together with the group. Having my subordinates participate in coming up with the solution helped my team to take ownership of the process. They now feel good about the solution and the process because they have built it themselves. And on the hindsight, nobody wants to say: "Oh man, that's a stupid idea!" So, now I have more confidence in the success of this program.

After the decision, I had to travel to Washington on Tuesday, and this new process was going to start on Wednesday. The fact that this was my team's own plan made it easier for me to trust them. To my delight, the process was implemented and started even in my absence. My subordinates were very happy about the process, which they implemented without any questions. If I had dictated the plan for them, they might not have taken the ownership of it, and while I was gone, they might have thought: "Okay, our boss is not here. We still have some questions about this process. So, we might start it in a week or so..." For me, this was a great experience! This new approach, made me feel good, and it made my team feel good.

On the side of increasing people's sense of agency and responsibility, dialogic leadership cultivates respect, loyalty, and high morale, which changes the way people communicate with each other. Rewired conversation flows, the communication structures that show more accurately how organizations function than organizational charts, make the transformation of organizational structures possible (see Webber, 1993, p. 28) and relocate managers from above their subordinates and below their superiors into leaders who are suddenly in the middle, managing both up and down, between vertical organizational layers, and also sideways. The following quote is an example of the 
practice of managing in the middle, and also shows how one manager extended the dialogic inclusiveness to his superiors:

One of the things I'm now more conscious about is that I try to provide an opportunity for input for both my subordinates and my superiors. When I give my superior input on my division to take to his superiors, I try to make sure that there is enough flexibility and room for my superiors' input, so that there is still enough opportunity for course corrections if necessary.

To summarize the task benefits, dialogic communication brings about dialogic leadership practices that, in turn, bring about better management of diversity and risks, increases organizational members' total power, accountability and responsibility, and reshapes organizational structures.

Relational benefits from dialogic leadership. Groups and organizations are systems that are engaged in "interactional practices that result in observable patterns of relationships, such as hierarchies, decision-making routines, newcomer assimilation procedures, and appraisal/advancement rituals" (Seibold \& Meyers, 2006, p. 144). People co-create and manage these relational systems by communicating together. According to Webber (1993), in today's organizational environments, creating communication or conversational structures and processes has become critically important to the work that managers do (p. 28). He writes:

Conversations are the way knowledge workers discover what they know, share it with their colleagues, and in the process create new knowledge for the organization... conversations rewire the company to leverage its knowledge base-so much so that the conversation is the organization.” (pp. 28-29) Employees' relationships that, in fact, define the organization are created through conversations (Webber, 1993, p. 28), the meaning-making processes that reflect the qualities of the conversations that were used to create them. Put another way, good 
conversations create good relationships. Good relationships, in turn, make teams effective (Littlejohn \& Foss, 2005, pp. 233-236), which helps teams to survive in their organizational environments. Good relationships (i.e., good communication) creates trust, which according to Webber (1993) is a "business imperative" in the new economy (p. 32). He believes that the most important job of a manager is to create good conversations that nurture trust (pp. 24).

If the new work of the company is conversation, then what is the job of the manager? Put simply: to create an environment where employees can have productive conversations rather than counterproductive ones, useful conversations rather than useless ones... In order to create an environment where people can have such conversations, managers must set a tone whereby people are secure enough to say what's really on their minds and aren't afraid to expose their ignorance or ask for help. (pp. 30-31)

Dialogic leadership can help create such conversations because it helps to build trust between people. Dialogic communication is inherently ethical, it requires an attitude of sympathetic awareness of others (cf., Shepherd, 2006, p. 24), and it increases cooperation among team members and across organizational boundaries.

As described earlier in the Results section of this report, dialogic communication training in this study increased managers' understanding and appreciation of each other's differences and improved their interpersonal relationships both within and outside the management team. The dialogic leadership practices that resulted from the training strengthened trust between the managers and their subordinates, which was exemplified in "Flying Tomato's" earlier story about a new process to handle customer files. Some managers had also found dialogic communication valuable for their relationships outside 
the organization. With managers' affective changes, these results forecast a further improving organizational climate.

\section{Theoretical and Practical Implications}

The action research process. Action research builds sustainable capacities in teams and organizations. The outcome of a truly successful action research project is a

process in which inquiry does not end when the researcher leaves the participants. Since the participants have already engaged in the research process, they will now have the skills to conduct systematic research themselves in the future, and they will also be able to apply their skills to other contexts (Stringer, 2007, p. 21).

This study resulted in participants' capacity to approach their communication situations from a new perspective. In essence, the social constructionist framework is a study tool in itself; it helps the participants to analyze the things that are made in communication. The framework, however, is not merely an analytical tool, but it also induces positive change by empowering the participants to reconstruct the things they make in communication in alternate ways with the dialogic communication skills the participants learned in the training. Hopefully, those skills will be used to build better social worlds both in their workplace and in their private lives.

A systematic research process within a team, however, takes focused attention and a considerable amount of time. Many times, team members are too busy to earnestly engage in a full research project that can easily require hundreds of hours of work from the researcher. In contrast, when a researcher facilitates inquiry, the participants can enjoy the benefits with minimal time investments. For example, in this study, each 
participant needed to spend relatively little time, ten hours, for the interviews, the focus group meeting and the training sessions. Moreover, rather than in a team setting, individual concerns are often best discussed privately with someone who has no immediate stake at a team's decisions. Besides, an outsider might be able to see a team's issues from a fresher viewpoint than those who are deeply involved with the issues. For these reasons, a dialogue practitioner can be valuable to a team as a research facilitator.

Episodic approach and dialogue practice. From an episodic perspective, dialogue is a quality of communication rather than an absolute label for something that either exists or does not exist in communication. For example, a person who is in the middle of a heated argument might suddenly say to the other, "Oh, I have never thought about this issue from that perspective." If the other replies, "See, you are wrong all the time," the first comment, can be seen as containing more dialogic quality than the second. Clearly, neither of these utterances classifies the whole communication episode as dialogue or non-dialogue, but reveals the evolving qualities of the discussion.

Dialogic moments, however, are distinct moments of spontaneously emerging, immediate, simultaneous, and open experiences of otherness (see Black, 2008; Peters, 2006, p. 213; Cissna \& Anderson, 1998, p. 74; Buber 1937/1950, p. 18). Unlike dialogic communication, they can be conceptualized as absolute; they either exist or they do not exist. On a continuum between non-dialogic communication and dialogic communication, dialogic moments define the ultimate end of dialogic communication, the ideal dialogue, whereas the quality of dialogic communication defines the continuum itself. 
In this study, an episodic approach to dialogue (e.g., Pearce, W. B. \& Pearce, K. A., 2004) proved to be a more practical and rewarding perspective than focusing on the emergence of dialogic moments. First, it was a more realistic goal to pursue than the unpredictable and somewhat rare dialogic moments. Although dialogic moments can certainly emerge during interaction, focusing solely on them might have set up the participants for unrealistic expectations and disappointments. Second, the episodic approach was useful in analyzing how the individual interviews of this study contributed to the larger dialogue between the participants. As discussed before, two phases alternate in a meaning-making process: emergence and convergence. Whereas emergence opens up meanings for questioning, evaluation, and reconstruction, convergence moves toward common definitions and meanings. The convergence phase is often unnecessarily rushed because there is a strong tendency to resolve the tension between meanings that do not seem to "fit" together. This regrettably limits the potential for truly groundbreaking and visionary emergent dialogic communication. A practitioner who can help a team to start from a not-knowing stance (Gurevitch, 1989), which is a prerequisite for the emergence of meaning, can provide a more creative and innovative starting point for dialogue.

In this study, the emergence of meaning was induced by interviewing the managers separately. Although individual interviews allowed no immediate interaction between the managers, they were individual turns in an extended opening dialogue in which all team members were given an equal amount of attention and speech time. Moreover, the interviews provided the participants with a safe space to express their viewpoints without being interrupted or judged by others. In a group discussion, it would 
not have been possible to explore such a wide array of issues and their definitions, because in a group, participants inevitably influence each other and dominant voices often define the issues and set the course for the discussion. This phase proved very valuable for the team members for understanding their collective strengths and challenge areas more fully before moving on to the convergent phase in the focus group discussion.

The value of learning both theory and practice. Most participants thought that learning about the social construction model profoundly changed how they understood communication. Many of them thought that, to them, this was more important than learning about individual dialogic communication skills. Additionally, while some of the skills might be easily forgotten, some other skills would require time to mature. For example, participant " 22 " thought that the use of dialogic communication might "lapse quickly, particularly, when people return to their familiar working environments." Having a framework that the participants could use to highlight their pre-existing skills and that could be used as a guide in developing one's communication skills organically, was initially seen as more useful than individual dialogic communication skills.

The Assistant Director, however, believed that both theory and skills were equally important. Whereas the theoretical framework would help the participants immediately, developing skills would take some time. Here is a quote from her:

I think it is not one or the other [theory or the skills], but they go together. The root of these managers' interaction is that they are thoughtful and that they care about the quality of interaction. They might have had an intuitive approach to how they listen or hold their ground well, and before the training they might have tried to understand the best they can why certain communication styles work better than others. But the social construction model finally gave them a framework to fit things together, to make sense of it all. I think it [the framework] was really a missing piece from their skill development, the aha-moment: We are 
co-creating [meaning]! Although we probably will need to do a refresher [training], the skills will continue to evolve.

Thus, dialogic communication training sparked a process of changing communication attitudes and practices in the study organization. Since the outcome is a process, the results will look different depending on when they are assessed.

After the training, the trainees first needed some time to adopt a new perspective on communication that would gradually start changing attitudes and mature into manifest communication practices. They needed also time to apply and practice their new skills in various situations. While some skills might have been grasped immediately and some will flourish later, some others might dry out completely. Thus, depending on the point in time when the results are assessed, the outcomes will look different.

At the time of writing this study report, it was too early to evaluate changes in the organizational climate. The Evaluation Phase, a data collection phase that was aimed at producing the major part of the study results, took place only a few weeks after the last training session. At that time many study participants had just returned from their summer vacations. This meant that there had not been much interaction between the study participants themselves or between the participants and their subordinates, superiors or customers. Nevertheless, some trends were already clearly noticeable, and reporting findings at this point of time was possible. Naturally, the results will inevitably look different after a few months or after a year.

Dialogic communication training breeds dialogic leadership practices. With time, if dialogue is fostered in the organization, dialogic leadership may become institutionalized in the organizational structure and practices. Although it was too early 
to evaluate the results of this study process on a larger organizational scale, the division managers believed that this is just the beginning. One of them put it this way: "I think that this is a seed that we are sowing, and in the long run, it's going to bear fruit."

The Assistant Director has invited me to meet with the division managers in order to discuss how the dialogic communication skills are used in their organization. This meeting will give a chance to refresh those skills that are falling out of practice and also potentially introduce one or two new ones.

\section{Limitations and Future Recommendations}

One of the greatest challenges in conducting a study with busy professionals is scheduling meetings with them. Because of this difficulty, the time between the first interview and the first training session was a lengthy twenty weeks, which is why the final evaluation phase needed to be more rushed. Unfortunately, due to the university's fast-approaching graduating deadlines, the participants were left with only a short amount of time for practicing their new dialogic communication skills and evaluating the outcomes of dialogic communication in their organizations. This problem was exacerbated by the fact that the training and the practice took place during a summer vacation season.

A possible factor that might have deflated some participants' motivation to participate in the beginning of the study process was the unclear purpose of this study. Several participants mentioned this in their final evaluative interviews, and they would have appreciated a brief study introduction before starting the research process. As an organically evolving action research process, however, even a longer introduction might 
have been too vague to explain what was about to take place: The study method was to reveal itself as the research progressed.

Perhaps attributable to the fact that the participants were already fully employed by their work and organizational changes, not all participants were equally able to invest their time to take part in all phases of this study. Although participation in this study was strictly voluntary from the researcher's part, it is possible that, at times, some participants' felt pressured to participate in the study by some organizational members. This raises an interesting ethical question about conducting research in organizations and teams: When a team wishes to study its communication and the successfulness of the study is dependent on everybody's participation, how and to what extent should everyone's consent be acquired?

Another limitation to this study was the lack of resources to study the larger organizational system. In her final interview, the Assistant Director mentioned that it would have been valuable to study and to extend the dialogic communication training also to the organizational layers immediately below and above the management team. This would have provided a fuller and more faceted assessment of the situation the participants were navigating in their everyday work. Instead, by training only one horizontal layer of managers, this study never truly addressed the organizational power issues that, undoubtedly, strongly shaped the organization and its communication.

This limitation reinforced the pre-existing communication patterns in the organization, and communication between upper vertical layers remained hierarchical. Moreover, the benefits of dialogic communication were more limited because not all 
stakeholders were able to engage in dialogue with each other. For example, the outcomes of dialogic communication training would have looked different in managers' teams if also their subordinates had been trained.

In the future, it might be revealing to choose a vertical dissection of participants from an organization and replicate this study. Even with limited resources, this would likely produce different outcomes than a merely horizontal study.

\section{Dialogue's Appeal}

The nine division managers found the dialogic communication training valuable to themselves, and quoting "Flying Tomato," practical enough to implement in their work:

You could probably tell that people were into the training and that people were enjoying it all, the role plays and so on. So, I think it was a very valuable experience, and we all learned a lot from it. I came back from the training with two of my colleagues, and we were all talking about it. We went into those techniques and made them our own, and glued them into how we manage our divisions. It was a very good experience.

Some managers had already shared some of the content of the training with their subordinates or superiors. This had kindled "a kind of eagerness for a new technique" in some parts of the organization. Moreover, the managers believed that the dialogic communication training they received would also benefit their organization more if other organizational members shared the same knowledge and ability to engage in dialogue with them.

The division managers saw that dialogic communication training would be beneficial to their subordinates in three ways. First, the subordinates would be better able 
to manage their differences within the division. One manager shared an example about this challenge:

Two of my subordinates, who are like oil and water, are going to be working together as a supervisor and a subordinate. Their situation is very complex, and it ripples elsewhere making some people very miserable. They are both wonderful assets to this division, but they are hard to work with. It would be great to do this same study with them and my other subordinates.

Second, the managers believed that some of their subordinates who had regular contact with customers could benefit from understanding multiple social realities and more sensitive approach to the people they engage with. One division manager describes this challenge:

This training would be excellent for my subordinates. Some of them are used to be out on the field, and they are used to dealing with contractors, for example. So, they are rougher around the edges. Their response is often: "I communicate, so I tell them [customers] what to do." I think that it would be beneficial for them to deal with customers with more finesse.

Another division manager shared the same concern:

Of my subordinates, especially those who are dealing with customers could benefit from learning how they can use communication tools to interact well instead of just stating a position. Many times, in dealing with customers, they assert, "There is my way and there's your way. My way is right and your way is wrong." Instead of being too authoritarian, they could seek out ways to come together and really explain a common goal or what we are after. And I think that it distills down to the way you communicate, not so much to what you communicate.

Dialogic communication training would likely help division managers' subordinates to interact also with customers who are particularly difficult. Toward the end of this study process, I had a chance to observe a very challenging community meeting. In this meeting, it was evident that the community members saw the city officials as their adversaries. Rude behavior, abusive language, interruptions, and insulting slogans 
characterized communication from the community members' side. One manager who had participated in this meeting believed that dialogic communication training might help the city employees approach situations like this more effectively:

I think the other piece we should include [in the dialogic communication training] is working with customers. We are public servants, and we are a service organization. We need to bring our customers into the mix somehow. There are some regular customers we have who can be very challenging and who pretty much elicit defensive behavior from the others. When we interact with these customers, one piece is just realizing that it's not going well. In the heat of that moment, it can be difficult. Another piece is to just say "timeout, wait a minute." It would be useful for some people to know how to facilitate community meetings too.

Training subordinates would address communication on the level below the nine managers in the organizational chart. The managers expressed, however, that they would wish to share the things they learned in the training program also with the higher organizational levels: "We need to create a similar framework for all of us so that our communication could be improved. I think that it would be helpful if all the executive staff would be involved in that conversation."

The results of this study and participants' eagerness to expand the training within their organization indicate that many people see dialogue as inherently appealing and useful to them. Since communication refers to both a process and an outcome (Striphas, 2006, p. 238), dialogic communication is not a mere communication tool-it is a way of being, thinking, and doing. People become motivated in participating in dialogue because the process makes them feel validated and respected and because its outcomes are practical, ethical, viable, and sustainable. 
Gurevitch, (1989) sees dialogue as a quality of conversation that "begins with an other." Returning to Foucault's (1966/1994, p. xxiv) quotation at the beginning of this study report, dialogic communication embraces the "madness" of the other, its foreignness and disorder with curiosity and wonder, not with defensiveness and suspicion. Instead of seeing an immediate danger, dialogue sees potential. Dialogue provides organizations with a way to learn, adapt, and grow, all of which are imperative in the rapidly changing environments in which we live today. 


\section{References}

Adler, N. J. (2008). International dimensions of organizational behavior. Mason, OH: Thomson.

Anderson, R., Baxter, L. A., \& Cissna, K. N. (2004). Texts and contexts of dialogue. In R. Anderson, L. A. Baxter, \& K. N. Cissna (Eds.), Dialogue: Theorizing difference in communication studies, (pp. 1-17). Thousand Oaks, CA: Sage.

Austin, J. L. (1962/1975). How to do things with words. Cambridge, MA: Harvard University Press.

Bakhtin, M. M. (1981). The dialogic imagination (M. Holquist, Ed.; C. Emerson, \& N. Holquist, Trans.). Austin, TX: University of Texas Press.

Baxter, L. A. (1982). Conflict management: An episodic approach. Small Group Behavior, 13(1), 23-42.

Baxter, L. A. (2006). Communication as dialogue. In G. J. Shepherd, J. St. John, \& T. Striphas (Eds.), Communication as. ... Perspectives on theory, (pp. 101-109). Thousand Oaks, CA: Sage.

Baxter, L. A. (2007). Problematizing the problem in communication: A dialogic perspective. Communication Monographs, 74, 118-124.

Belasco, J. A. \& Stayer, R. C. (1993). Flight of the Buffalo: Soaring to excellence, learning to let employees lead. New York, NY: Warner Books.

Berger, P. L., \& Luckmann, T. (1967). The social construction of reality: A treatise in the sociology of knowledge. Garden City, NY: Doubleday.

Black, L. W. (2008). Deliberation, storytelling, and dialogic moments. Communication Theory, 18(1), 93-116.

Bohm, D. (1980). Wholeness and implicate order. London: Routledge.

Bohm, D. (1996). On dialogue, (L. Nichol, Ed.). New York: Routledge.

Buber, M. (1937/1950). I and Thou (R. G. Smith, Trans.). Edinburg, UK: T. \& T. Clark.

Cissna, K. N., \& Anderson, R. (1998). Theorizing about dialogic moment: The BuberRogers position and postmodern themes. Communication Theory, 8, 63-104.

Craig, R. T. (1999). Communication theory as a field. Communication Theory, 9, 119161. 
Craig, R. T. (2006). Communication as practice. In G. J. Shepherd, J. St. John, \& T. Striphas (Eds.), Communication as. . .. Perspectives on theory, (pp. 38-47). Thousand Oaks, CA: Sage.

Davis, J. H. (1969). Group performance. Reading, MA: Addison-Wesley.

De Bono, E. (1985). Six thinking hats. Boston, MA: Little, Brown.

Deetz, S. A. (1992). Democracy in an age of corporate colonization: Developments in communication and the politics of everyday life. Albany: State University of New York.

Deetz, S., \& Simpson, J. (2004). Critical organizational dialogue: Open formation and the demand for "otherness.” In R. Anderson, L. A. Baxter, \& K. N. Cissna (Eds.), Dialogue: Theorizing difference in communication studies, (pp. 141-158). Thousand Oaks, CA: Sage.

Diehl, M., \& Stroebe, W. (1987). Productivity loss in brainstorming groups: Toward the solution of a riddle. Journal of Personality and Applied Psychology, 53, 497-509.

Ellinor, L. \& Gerard, G. (1998). Dialogue: Rediscover the transforming power of conversation. New York: John Wiley.

Fayol, H. (1930). Industrial and general administration. New York: Pitman.

Foucault, M. (1966/1994). The order of things: An archaeology of the human sciences. New York, NY: Random House Vintage Books.

Gouran, D.S., \& Hirokawa, R.Y. (2003). Effective decision making and problem solving in groups: A functional perspective. In R. Y. Hirokawa, R. S. Cathcart, L. A. Samovar, \& L. D. Henman (Eds.), Small group communication: Theory \& practice, (pp. 27-38). Los Angeles, CA: Roxbury.

Gurevitch, Z. D. (1989). The power of not understanding. The meeting of conflicting identities. The Journal of Applied Behavioral Science, 25(2), 161-173.

Heifetz, R. A. (1994). Leadership without easy answers. Cambridge, MA: Harvard University Press.

Heifetz, R. A., Grashow, A., \& Linsky, M. (2009, July-August). Leadership in a (permanent) crisis. Harvard Business Review, 62-69.

Herzig, M., \& Chasin, L. (2006). Fostering dialogue across divides: A nuts and bolts guide from the Public Conversations Project. Watertown, MA: Public Conversations Project. Retrieved February 26, 2010 from http://www.publicconversations.org/docs/resources/Jams_website.pdf 
Isaacs, W. N. (1994). Team learning. In P. Senge, A. Kleiner, C. Roberts, R. B. Ross, \& B. J. Smith (Eds.), The fifth discipline fieldbook: Strategies and tools for building a learning organization, (p. 376). New York: Doubleday.

Isaacs, W. N. (1999a). Dialogic leadership. The Systems Thinker, 10(1), 1-5.

Isaacs, W. N. (1999b). Dialogue and the art of thinking together: A pioneering approach to communicating in business and in life. New York: Random House.

Janis, I. L. (1972). Victims of groupthink. Boston: Houghton Mifflin Company.

Janis, I. L. (1989). Crucial decisions: Leadership in policy-making and management. New York: Free Press.

Kaplan, A. (1969). The life of dialogue. In J. D. Roslansky (Ed.), Communication: A discussion at the Nobel Conference, (pp. 87-108). Amsterdam: North-Holland.

Kelly, A., \& Gluck, R. (1979). Northern Territory community development. Unpublished manuscript. University of Queensland, St. Lucia, Australia.

Kelshaw, T. (2006). Communication as political participation. In G. J. Shepherd, J. St. John, \& T. Striphas (Eds.), Communication as. ... Perspectives on theory, (pp. 155-163). Thousand Oaks, CA: Sage.

Kim, J., \& Kim, E. J. (2008). Theorizing dialogic deliberation. Communication Theory, $18(1), 51-70$.

Kimmons, R. (1999). Building effective teams in multicultural environment. In G. Perry (Ed.), Perspectives: Intercultural communications, (pp. 49-50). St. Paul, MN: Coursewise Publishing.

Konopaske, R., \& Ivancevich, J. M. (2004). Global management and organizational behavior. New York: McGraw-Hill.

Lamm, H., \& Trommsdorff, G. (1973). Group versus individual performance on tasks requiring ideational proficiency (brainstorming): A review. European Journal of Social Psychology, 3(4), 361-388.

Leino, A. (2010). Dialogin aika: Digitaalisen markkinoinnin ja viestinnän mahdollisuudet [Time of dialogue: The potential for digital marketing and communication]. Helsinki, Finland: Infor Oy.

Lewis, P. S., Goodman, S. H., Fandt, P. M., \& Michlitsch, J. F. (2007). Management: Challenges for tomorrow's leaders, $\left(5^{\text {th }}\right.$ ed.). Mason, $\mathrm{OH}$ : Thomson. 
Littlejohn, S. W., \& Domenici, K. (2007). Communication, conflict, and the management of difference. Long Grove, IL: Waveland Press.

Littlejohn, S. W., \& Farge, L. (2006). Difficult dialogues at the University of Nebraska at Omaha: Resource guide. Unpublished manuscript. Omaha, NE: University of Nebraska.

Littlejohn, S. W., \& Foss, K. A. (2005). Theories of human communication. Belmont, CA: Wadsworth.

Mead, G. H. (1934). Mind, self, and society. Chicago: University of Chicago Press.

Novak, J. M., \& Sellnow, T. L. (2009). Reducing organizational risk through participatory communication. Journal of Applied Communication Research, 37(4), 349-373.

Pearce, W. B. (1989). Communication and the human condition. Carbondale, IL: Southern Illinois University Press.

Pearce, W. B., \& Pearce, K. A. (2000). Combining passions and abilities: Toward dialogic virtuosity. Southern Communication Journal, 65, 161-175.

Pearce, W. B., \& Pearce, K. A. (2004). Taking a communication perspective on dialogue. In R. Anderson, L. A. Baxter, \& K. N. Cissna (Eds.), Dialogue: Theorizing difference in communication studies, (pp. 39-56). Thousand Oaks, CA: Sage.

Pearce, K. A., Spano, S., \& Pearce, W. B. (2009). The multiple faces of the public dialogue consortium: Scholars, practitioners, and dreamers of better social worlds. In L. R. Fry \& K. N. Cissna (Eds.), Handbook of applied communication research, (pp. 611-632). New York: Routledge.

Peters, J. D. (2006). Communication as dissemination. In G. J. Shepherd, J. St. John, \& T. Striphas (Eds.), Communication as...: Perspectives on theory, (pp. 211-222). Thousand Oaks, CA: Sage.

Poulakos, J. (1974). The components of dialogue. Western Speech, 38, 199-212.

Putnam, L. L. (1995). Formal negotiations: The productive side of the organizational conflict. In A. M. Nicotera (Ed.), Conflict and organizations: Communicative process, (pp. 183-200). New York: SUNY Press.

Rothenbuhler, E. W. (2006). Communication as ritual. In G. J. Shepherd, J. St. John, \& T. Striphas (Eds.), Communication as. ... Perspectives on theory, (pp. 13-21). Thousand Oaks, CA: Sage. 
Rubin, R. B., Rubin, A. M., \& Piele, L. J. (2005). Communication research: Strategies and sources, (6th ed.). Belmont, CA: Wadsworth.

Schulz-Hardt, S., Jochims, M., \& Frey, D. (2002). Productive conflict in group decision making: Genuine and contrived dissent as strategies to counteract biased information seeking. Organizational Behavior and Human Decision Processes, $88,563-586$.

Searle, J. (1969). Speech acts: An essay in the philosophy of language. Cambridge: Cambridge University Press.

Seibold, D. R., \& Myers, K. K. (2006). Communication as structuring. In G. J. Shepherd, J. St. John, \& T. Striphas (Eds.), Communication as. . . Perspectives on theory, (pp. 143-152). Thousand Oaks, CA: Sage.

Senge, P. M. (1990). The fifth discipline. New York: Doubleday.

Shannon, C. E., \& Weaver, W. (1949). The mathematical theory of communication. Urbana, IL: University of Illinois Press.

Shepherd, G. J. (2006). Communication as transcendence. In G. J. Shepherd, J. St. John, \& T. Striphas (Eds.), Communication as. . . Perspectives on theory, (pp. 22-30). Thousand Oaks, CA: Sage.

Spano, S. (2006). Emergent and convergent forms of dialogue in a city government organization. Unpublished manuscript, Communication Studies Department, San José State University, San José, CA.

Spano, S. (2007). The communication perspective. [Handout for Comm 156 course]. Communication Studies Department, San José State University, San José, CA.

Spano, S. (2010). Dialogue resource guide. Communication Studies Department, San José State University, San José, CA.

Steiner, I. (1972). Group process and productivity. New York: Academic Press.

Stewart, J. (1978). Foundations of dialogic communication. The Quarterly Journal of Speech, 64, 183-201.

Stewart, J., \& Zediker, K. (2000). Dialogue as tensional, ethical practice. Southern Communication Journal, 65, 224-242.

Stewart, J., Zediker, K. E., \& Black, L. (2004). Relationships among philosophies of dialogue. In R. Anderson, L. A. Baxter, \& K. N. Cissna (Eds.), Dialogue: Theorizing difference in communication studies, (pp. 21-38). Thousand Oaks, CA: Sage. 
Stringer, E. T. (2007). Action research, (3 ${ }^{\text {rd }}$ ed.). Thousand Oaks, CA: Sage.

Striphas, T. (2006). Communication as translation. In G. J. Shepherd, J. St. John, \& T. Striphas (Eds.), Communication as. . .. Perspectives on theory, (pp. 232-241). Thousand Oaks, CA: Sage.

Taylor, D. W., Berry, P. C., \& Block, C. H. (1958). Does group participation when using brainstorming facilitate or inhibit creative thinking? Administrative Science Quarterly, 3(1), 23-47.

Taylor, F. W. (1911/1998). The principles of scientific management. Mineola: NY: Dover.

Yankelovich, D. (2001). The magic of dialogue: Transforming conflict into cooperation. New York: Touchstone.

Webber, A. M. (1993, January-February). What's so new about the new economy? Harvard Business Review, 24-42.

Weber, M. (1927). General economic history, (F. H. Knight, Trans.). London, UK: Allen \& Unwin.

Weick, K. E. (1995). Sensemaking in organizations. Thousand Oaks, CA: Sage.

Wittgenstein, L. (1953/2001). Philosophical investigations, (G. E. M. Anscombe, Trans.), $\left(3^{\text {rd }}\right.$ ed.). Oxford: Blackwell Publishing.

Wonder, J., \& Donovan, P. (1984). Whole-brain thinking: Working from both sides of the brain to achieve peak job performance. New York: Ballantine Books. 


\section{APPENDIX A: Informed Consent Form}

\section{AGREEMENT TO PARTICIPATE IN RESEARCH}

Responsible Investigator: Minna J. Holopainen, graduate student, San José State University, Communication Studies Department

Title of Protocol: Process and Content Outcomes of Dialogic Communication Training on a Task-Oriented Team

You have been asked to participate in a research study investigating the ways in which dialogic communication training affects task-oriented teams.

You will be asked to participate in one focus group meeting, lasting 90-120 minutes, two to four 60-minute sessions in dialogue training, and potentially in a 60-minute individual interview with Minna Holopainen at a time, date, and location that is mutually convenient. All interview discussions will be audio taped.

While you are participating in this study, you may choose to reflect on personal experiences that are challenging or uncomfortable. You may also enjoy having the opportunity to share your experiences as a member of your work team.

Although the results of this study may be published, absolutely no information that could identify you will be included in the final document, or in any file, notes, or subsequent papers.

You will receive no monetary compensation for participation in this research study.

Questions about this research may be addressed to Minna Holopainen, (408) 768-7983, minnajholopainen@hotmail.com, or Dr. Shawn Spano Shawn.Spano@sjsu.edu. Complaints about the research may be presented to Dr. Stephanie Coopman, Interim Department Chair, Department of Communication Studies, (408) 924-5360. Questions about research subjects' rights, or a research-related injury, may be presented to Dr. Pamela Stacks, Associate Vice President, Graduate Admissions and Program Evaluations, (408) 924-2427.

No service of any kind, to which you are otherwise entitled, will be lost or jeopardized if you choose to not participate in this study.

Your consent is being given voluntarily. You may refuse to participate in the entire study or in any part of the study. If you decide to participate in the study, you are free to withdraw at any time without any negative effect on your relations with San José State University or with any other participating institutions or agencies.

At the time that you sign this consent form, you will receive a copy of it for your records, signed and dated by the investigator.

The signature of a participant on this document indicates agreement to participate in the study.

The signature of a researcher on this document indicates agreement to include the above named participant in the research and attestation that the participant has been fully informed of her or his rights.

Participant's Signature

Investigator's Signature
Date

Date 


\section{APPENDIX B: Interview Guide}

\section{Interview Guide}

\section{Outcomes of Dialogic Communication Training on a Task-Oriented Team}

\section{Orientation}

The purpose of this applied thesis research is to investigate the process and content outcomes of a dialogic communication training on a task-oriented team. This will be achieved by, first, working with the team members to help you identify the main challenges you are facing in your work teams, your staffs, customers, and other stakeholders you regularly interact with; second, designing and implementing a customized dialogic communication training program for your team to help you meet those challenges; and third, assessing the impact of the training in terms of the achievement of process and content outcomes.

Tentative timeline for the project:

Early February Individual interviews

Late February Focus group interview

March 3-4 training sessions

Early April Evaluation

The purpose of this interview is to explore what you consider to be the most significant strengths and challenges in your work with your colleagues and other stakeholders.

With your permission, this interview will be digitally recorded and later transcribed. The information shared in this interview is confidential, and you will have a chance to check the transcription for accuracy.

\section{Questions}

Question 1: What is your name and position in this organization? How long have you been managing your current team? Describe shortly what you do.

Question 2: What are you proud of in your work with the management team/your own team? What is working well?

How would you characterize your communication strengths as a leader? What do you do well? What are your unique contributions? With which groups/individuals/stakeholders are you effective with? Why?

Question 3: What concerns do you have about the work in this management team/your own team?

What are your communication challenges as a team member/leader? What areas do you need to improve? With which groups/individuals/stakeholders are you not as effective with? Why?

Question 4: What would communication in an ideal team be like in your view? 


\section{APPENDIX C: Focus Group Packet}

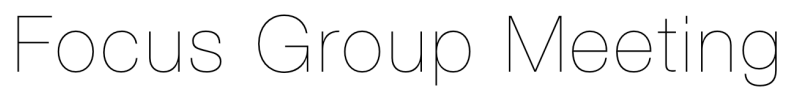

for Master's thesis "Outcomes of dialogic communication training in a city government management team"

Meeting Agenda

Interview Summary Report

Discussion Questions

Training Plan

Evaluation

Wrap-up and Next Steps

MINNA HOLOPAINEN SJSU Communication Studies One Washington Square San José, CA 95192-0112Ｅmail minnaiholopainen@hotmail.com 


\section{Focus Group Meeting Agenda}

Date: $\quad$ Friday May 21, 2010

Time:

1:30-3:00 pm

Location: Undisclosed

Attendees: Undisclosed

Desired Outcomes

- To validate the interview findings and elaborate on them

- To agree on the topics for the upcoming training

- To identify the outcomes of a successful training (evaluation criteria) and the method for assessing those outcomes

Guidelines for Constructive Communication

- Listen openly, speak candidly

- Confidentiality

- Everyone contributes

\begin{tabular}{|c|c|}
\hline Time & Topic \\
\hline 1:30-1:40 pm & $\begin{array}{l}\text { Context setting } \\
\text { - Welcome (Assistant Director) } \\
\text { - Purpose and phases of the study } \\
\text { - Preview of the agenda }\end{array}$ \\
\hline 1:40-2:25 pm & $\begin{array}{l}\text { Interview summary } \\
\text { - Main findings from the interviews } \\
\text { - Discussion and feedback } \\
\text { - Exploring divisional differences (dialogic discussion) }\end{array}$ \\
\hline 2:25-2:35 pm & $\begin{array}{l}\text { Training focus } \\
\text { - Suggested training plan } \\
\text { 1. Ideas about communication (theory) grounded in practical situations (working on } \\
\text { divisional differences)-90 minutes } \\
\text { 2. Dialogic communication skills }-90 \text { minutes } \\
\text { - Discussion }\end{array}$ \\
\hline 2:35-2:55 pm & $\begin{array}{l}\text { Evaluation } \\
\text { - Identifying the outcomes of a successful training (evaluation criteria) } \\
\text { - Choosing the method for assessing the outcomes (instrument/s) } \\
\text { - Ongoing evaluation }\end{array}$ \\
\hline 2:55-3:00 pm & $\begin{array}{l}\text { Wrap-up and next steps } \\
\text { - Summary } \\
\text { - Next steps and timeframe }\end{array}$ \\
\hline
\end{tabular}

MINNA HOLOPAINEN SJSU Communication Studies One Washington Square San José, CA 95192-0112 Email minnajholopainen@hotmail.com 


\section{Interview Summary Report}

for Master's thesis "Outcomes of dialogic communication training in a city government management team"

Work position

Service time for the City

Managers' team sizes

Cuts in teams
Division Manager (8), Administrative Officer (1)

Range: 21.5 (3.5-25 years), Mean: 18 years, Standard deviation: 8.12

Range: 49 (7-58), Mean: 27 subordinates, Standard deviation: 18

Reductions in personnel 30-75\%, demotions; recent cuts in February 2009, July 2009, and November 2009; one division will have its first cuts soon

\section{Managing philosophy}

Public servant

Advocate manager "What battles do you want me to fight for you?"

Promoting independence

Openness

- Approachability and access: Minimal barriers to communicating with people; free flow of information from top down; open door policy: "It's a feeling of freedom to pop into my office."

- Open to suggestions, not an immediate negative response; effective listening; sensitivity to others' responses, confidence in voicing opinions; non-judgmental

Collaborator Fluid boundaries with other managers; crossing lines and responsibilities (cross-pollination); sharing knowledge, information, and staff

Effective and frequent communication and feedback

Empathetic Providing a safe place, concerned about individuals and their success; respect, trust, appreciation, non-confrontational, non-authoritative, honest, not taking oneself too seriously

Personal "Good relationships make it easier for us to communicate." Face-to-face rather than emails

MINNA HOLOPAINEN SJSU Communication Studies One Washington Square San José, CA 95192-0112 Email minnajholopainen@hotmail.com 


\section{Challenges}

Organizational environment- "There is a cloud hanging over us."

\section{Flattening hierarchy}

Flattening organizational hierarchy requires open access, fast communication channels, effective feedback, and fast dissemination of information in order to provide fast responsiveness to the changing environment.

Span of control is increasing. "We are stretched thin."

"We have not gotten to the point of stability yet. If it never comes, we will need to learn how to work in an unstable environment."

Flattening of hierarchy might challenge middle managers' credibility?

\section{Efficiency}

"Old organization was too heavy in the management side. Restructuring was necessary. Budget cuts make us rethink our structures and procedures in order to be more efficient."

"We have taken cuts but we haven't lost any productivity (need to plan well). Our department has cut personnel tremendously while there are considerable inefficiencies elsewhere in the city organizations."

Challenge on relationships

Battle: "We need to defend our positions. When things get stressful, you see the true nature of people come out, and people are doing what they need to do to survive."

Challenges within one's own teams

Acknowledging loss and effort while dealing with the reality (doing more with less)

- Family "We have grown up together. We have lost family members. This has changed the dynamics in our family." Concern about the future and continuity: "We have lost all our babies, the youthful and vital new generation, and their ideas."

- Emotional support Finding balance between providing adequate support and pushing the employees over the edge so that they “start swimming again”; Interpersonal sensitivity: "people don't understand our pain"

- Symptoms of cuts: rumors, short tempers, arguments

- Quality of work Getting behind (overdue reports), accepting lower quality when perfection is not absolutely necessary (C-level work instead of A) (Is this the new norm? Do we talk about it? How, and with whom? Quality of appearance and quality of substance)

Challenging subordinates: fairness and equity; entitlement mentality, cop mentality; giving constructive feedback without criticizing or challenging

Challenges with customers

Lying customers, complaints, neighborhood fights

Unhappy customers because project managers change all the time and delivery time is longer

MINNA HOLOPAINEN SJSU Communication Studies One Washington Square San José, CA 95192-0112 Email minnajholopainen@hotmail.com 
Challenges for the Management team

Competition over resources (budget cuts) and divisional differences challenge relationships and communication.

Divisional silos: Three divisions speak different languages, they think differently, and they have different outcomes.

- The Investigators Hard-working people. Black/white, life/death, yes/no. Absolute. Answers come right away. Less risk-taking.

- The Guards Nice party people. Understand many shades of gray. Insulated. Ideologically between strict (The Investigators) and liberal (The Strategists).

- The Strategists Idealistic, flowery people. Spend a lot of time thinking, which is why it might take some time to get an answer. Flexible, indeterminate, almost always negotiable.

\section{Discussion Questions}

Acknowledge the difficult topic.

Remind the participants of the ground rules:

- Listen openly, speak candidly

- Confidentiality

- Everyone contributes

1. How do we benefit from our divisional differences? That is, what are the advantages and strengths of being in a department with different divisions?

2. How are we challenged by our divisional differences? That is, what are some of the ways that our differences hinder us?

3. How do we create and recreate our divisional differences?

MINNA HOLOPAINEN SJSU Communication Studies One Washington Square San José, CA 95192-0112 Email minnajholopainen@hotmail.com 
Training Plan

\section{Looking at Communication}

Ideas about communication (theory) grounded in practical situations (working on divisional differences). A few theoretical concepts applied to real-life situations. Co-construction of the divisional differences. What are the impacts and consequences.

\section{Facilitation Skills}

Facilitation skills for dialogic discussion. These are not only practical in group discussions, but also in all interpersonal relationships, for example, with staff, customers, coworkers, and the director.

MINNA HOLOPAINEN SJSU Communication Studies One Washington Square San José, CA 95192-0112 Email minnajholopainen@hotmail.com 
Evaluation

\section{Evaluation Criteria}

Identifying the outcomes of a successful training

Assessment Method(s)

Ongoing evaluation

MINNA HOLOPAINEN SJSU Communication Studies One Washington Square San José, CA 95192-0112 Email minnajholopainen@hotmail.com 


\section{Wrap-up and next steps}

\section{Summary}

- Interview summary

- Discussion on divisional differences

- Training in two sessions (looking at communication, facilitation skills)

- Evaluation criteria and method(s)

\section{Next steps and timeframe}

Training session I: Looking at Communication June 21-25, 2010

Training session II: Facilitation Skills June 28-July 2, 2010

Evaluation August 2-13 or August 30-September 3

Final report September-October

MINNA HOLOPAINEN SJSU Communication Studies One Washington Square San José, CA 95192-0112 Email minnajholopainen@hotmail.com 


\section{APPENDIX D: Training I Packet}

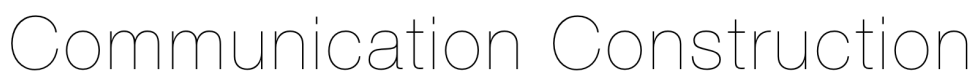

Dialogic Communication Training I for Master's thesis "Outcomes of dialogic communication training in a city government management team"

Date \& time Wednesday June 30, 2010 at 1:30-3:00 pm

Location Undisclosed

Attendees Undisclosed

Trainer Minna Holopainen

Desired Outcomes

- To see communication as a meaning-making process (social construction)

- To understand one's own contributions to the meaning-making process as crucial in shaping the end result

- To regard differences as potentially valuable and sometimes requiring special "management"

- To apply the learned concepts into practice in the previously identified challenge areas

Guidelines for Constructive Communication

- Listen openly, speak candidly

- Confidentiality

- Everyone contributes

\begin{tabular}{l|l} 
Time & Topic \\
& $\begin{array}{l}\text { Context setting } \\
\text { - Purpose for the training session I } \\
\text { - Guidelines for constructive communication } \\
\text { - Preview of the agenda }\end{array}$ \\
\hline 1:35-1:45 pm & $\begin{array}{l}\text { Outcomes of the previous meeting } \\
\text { - Short 1-2-sentence reflection from each participant }\end{array}$ \\
\hline 1:45-2:00 pm & $\begin{array}{l}\text { Constructing communication } \\
\text { What are we making together? } \\
\text { Managing differences }\end{array}$ \\
\hline 2:00-2:45 pm & Practice \& analysis: Role plays \\
\hline 2:45-2:50 pm & Dialogic communication \\
\hline 2:50-3:00 pm & $\begin{array}{l}\text { Wrap-up } \\
\text { - Summary and next steps } \\
\text { Reflection }\end{array}$ \\
\hline
\end{tabular}

MINNA HOLOPAINEN SJSU Communication Studies One Washington Square San José, CA 95192-0112 Email minnajholopainen@hotmail.com 


\section{Communication Construction}

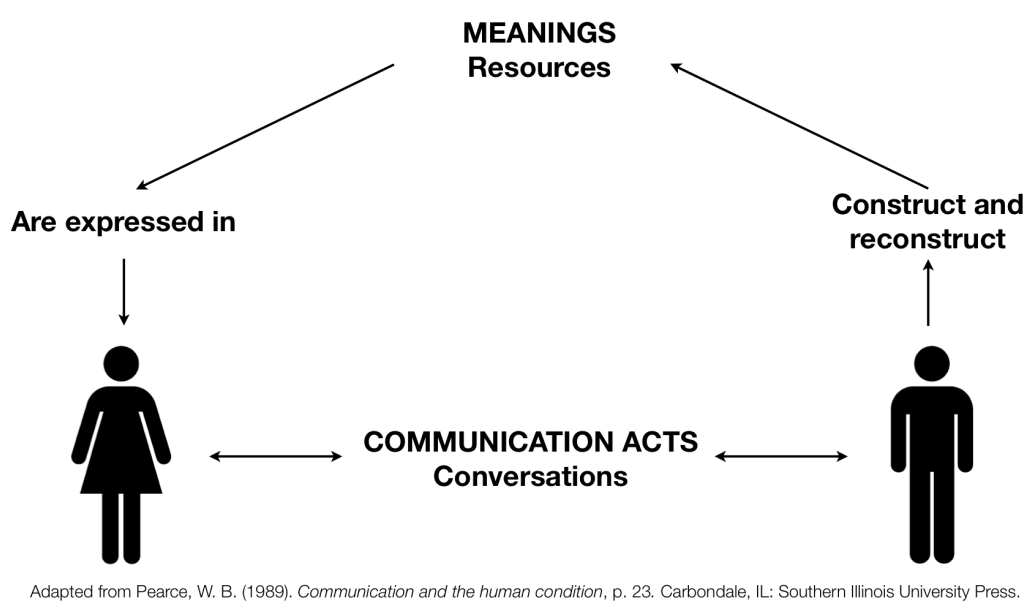

Key Points about Communication Construction Spano, S. (2010). Dialogue resource guide, p. 5. San José State University, CA.

- Communication is a process of making and doing, not just sending and receiving (transmission of information).

- People co-construct meaning (e.g., relationships) through communication actions.

- As people make meaning within the boundaries of their social worlds, there is a need to create communication bridges between different social worlds.

The Truth versus many truths

MINNA HOLOPAINEN SJSU Communication Studies One Washington Square San José, CA 95192-0112 Email minnajholopainen@hotmail.com 


\section{What Are We Making Together?}

Spano, S. (2007). Handouts. Comm 156 Qualitative Communication Inquiry. San José State University, CA.

Meaning is made through the joint contributions of all the participants.

Individual messages lack meaning until we hear the response from the other.

Example

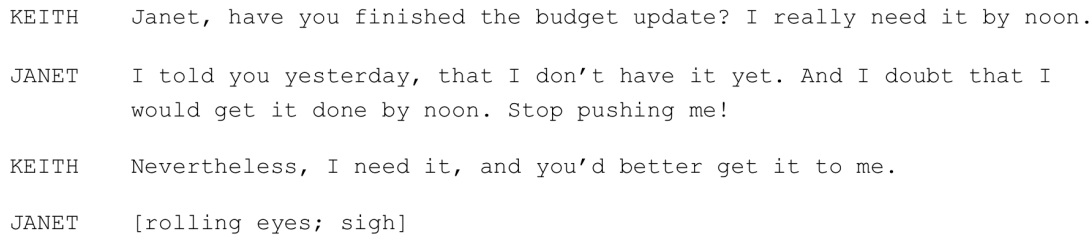

What is being created in this discussion? How can the outcome be changed?

\section{Managing Differences}

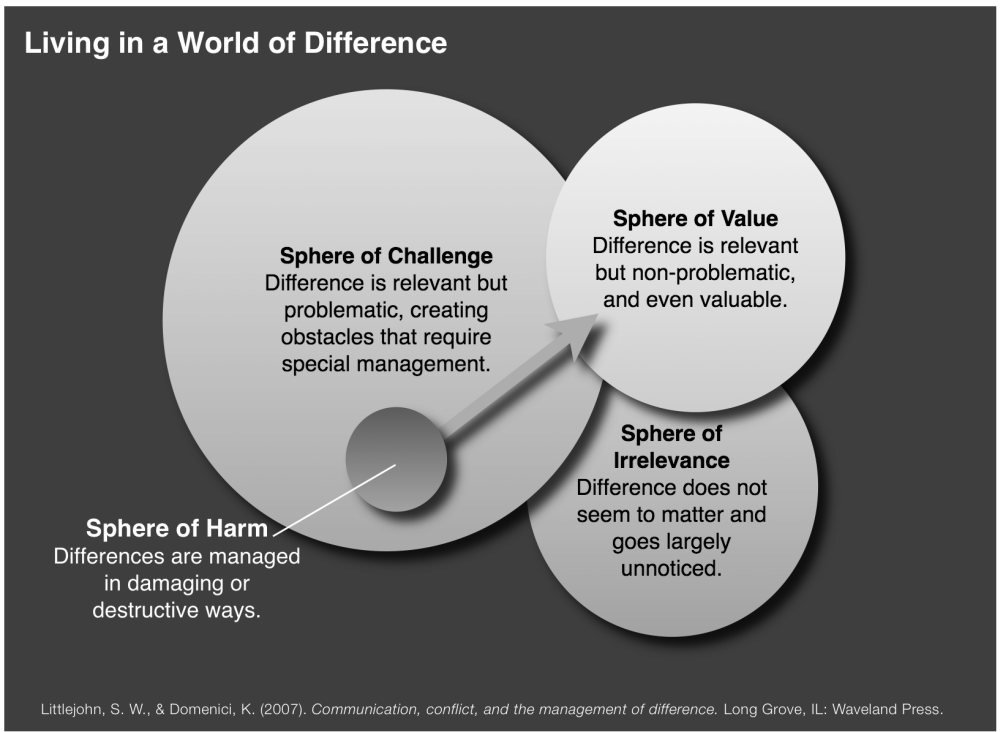

Challenge: Sometimes we might need to uphold conflicting views simultaneously; things do not always make sense together.

MINNA HOLOPAINEN SJSU Communication Studies One Washington Square San José, CA 95192-0112 Email minnajholopainen@hotmail.com 
Role Plays

Perform a typical challenging situation at work. What is being made in these situations?

- Team 1: A challenging situation when working with superiors/executive level

- Team 2: A challenging situation when working with people from other divisions (interdivisional)

- Team 3: A challenging situation with subordinates

- Team 4: A challenging situation with customers

Next, come up with an alternative scenario. Focus on the interaction between the interactants.

\section{Dialogic Communication}

Adapted from Spano, S. (2010). Dialogue resource guide, p. 5. San José State University, CA.

Dialogue is a form of communication that helps create unique and distinctive social worlds, different from what gets made in other, non-dialogic forms of communication.

Since all forms of communication construct social reality (communication construction), the question is not whether to create but how to use communication to create social worlds that are satisfying,

humane, and enriching.

Buber's Three Conditions for Dialogue

Buber, M. (1970). I and thou (W. Kaufman, Trans.). New York: Scribner. (Original work published 1937).

Spano, S. (2010). Dialogue resource guide, pp. 10-11. San José State University, CA.

1. Holding your ground

2. Being open to the other

3. Remaining in the tension between 1 (self) and 2 (other)

Dialogic Communication Skills

July 7, 2010 at 10:00-11:30 A.M.

MINNA HOLOPAINEN SJSU Communication Studies One Washington Square San José, CA 95192-0112 Email minnajholopainen@hotmail.com 


\section{Reflection}

Please, take a few moments to reflect on the things you learned during this first training session.

1. What did you enjoy the most about this training? What worked the best for you?

2. What did you enjoy the least about this training session? What could be improved on?

Next, reflect on your learnings in response to the challenges identified in the interviews.

3. How can you use the things we learned today to improve work within your own team and with your subordinates (acknowledging effort and the loss of "family" members while doing more with less)?

4. How can you use the things we learned today to facilitate interaction with customers?

5. How can you use the things we learned today to improve work between divisions (competition over resources and divisional generalizations)?

6. How can you use the things we learned today to improve work with the executive level/your superiors?

7. How can you use the things we learned today to improve your organizational environment ("There is a cloud hanging over us")?

On the back side of this sheet of paper, please, feel free to share any other thoughts you have about this training session. Your candid feedback is warmly welcomed. Thank you for your time!

MINNA HOLOPAINEN SJSU Communication Studies One Washington Square San José, CA 95192-0112 Email minnajholopainen@hotmail.com 


\section{APPENDIX E: Training II Packet}

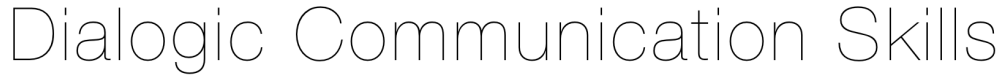

Dialogic Communication Training II for Master's thesis "Outcomes of dialogic communication training in a city government management team"

Date \& time Wednesday July 7, 2010 at 10:00-11:30 am

Location Undisclosed

Attendees Undisclosed

Trainer Minna Holopainen

Desired Outcome

- To practice dialogic communication skills in the previously identified challenge areas

Guidelines for Constructive Communication

- Listen openly, speak candidly.

- Be concise.

- Everyone contributes.

- Confidentiality

\begin{tabular}{l|l} 
Time & Topic \\
\hline $\mathbf{1 0 : 0 0 - 1 0 : 0 5}$ am & $\begin{array}{l}\text { Context setting } \\
\text { - Purpose for the training session II } \\
\text { - Guidelines for constructive communication } \\
\text { - Preview of the agenda }\end{array}$ \\
\hline $\mathbf{1 0 : 0 5 - 1 0 : 1 0 ~ a m ~}$ & $\begin{array}{l}\text { Warm-Up Question } \\
\text { - How are the challenge areas made? }\end{array}$ \\
\hline $\mathbf{1 0 : 1 0 - 1 0 : 2 0 ~ a m ~}$ & Characteristics of Dialogic Communication \\
\hline $\mathbf{1 0 : 3 5 - 1 1 : 2 0 ~ a m ~}$ & $\begin{array}{l}\text { Role Plays } \\
\text { - Team 3: A typical challenging situation with subordinates } \\
\text { - Team 4: A typical challenging situation with customers }\end{array}$ \\
$\begin{array}{l}\text { Dialogic Communication Skills } \\
\text { - Curiosity and wonder } \\
\text { - Acknowledging } \\
\text { - Restating } \\
\text { - Reflecting feelings } \\
\text { - Reframing } \\
\text { - Appreciative questioning } \\
\text { - Systemic questioning }\end{array}$ \\
\hline $\mathbf{1 1 : 2 0 - 1 1 : 3 0 ~ a m ~} \begin{array}{l}\text { Wrap-up } \\
\text { - Summary and next steps } \\
\text { - Reflection }\end{array}$ \\
\hline
\end{tabular}

MINNA HOLOPAINEN SJSU Communication Studies One Washington Square San José, CA 95192-0112 Email minnajholopainen@hotmail.com 


\section{Dialogic Communication}

Adapted from Spano, S. (2010). Dialogue resource guide, pp. 5, 10-11. San José State University, CA.

According to Martin Buber, dialogue takes place in the tension between holding one's own ground while being genuinely open to the other.

Dialogue enriches understanding of issues by moving away from simplistic either/or to multidimensional both/and definitions.

Characteristics of Dialogue

Spano, S. (2010). Dialogue resource guide, pp. 12-13. San José State University, CA.

1. Mutual

2. Creative

3. Inclusive

4. Authentic

5. Empathic

6. Collaborative

\section{Role Plays}

Perform a typical challenging situation at work. What is being made in these situations?

Team 3: A challenging situation with subordinates

Team 4: A challenging situation with customers

\section{Dialogic Communication Skills}

Adapted from Spano, S. (2010). Dialogue resource guide, pp. 11, 37-41. San José State University, CA.

Opportunities for dialogic communication exist routinely in everyday life, at home, work, or play with friends, family, and colleagues. Although dialogue emerges spontaneously, we can be intentional about creating the conditions for it around issues that are important to us. The following list is an example of communication skills that help us in creating such conditions:

- Demonstrating curiosity and wonde

- Acknowledging

- Restating

- Reflecting feelings

- Reframing

- Appreciative questioning

- Systemic questioning

MINNA HOLOPAINEN SJSU Communication Studies One Washington Square San José, CA 95192-0112 Email minnajholopainen@hotmail.com 


\section{Systemic Questioning Exercise}

From your organization, choose one issue that feels like a challenge to you. Reflecting on that issue, write down some ideas to answer the following questions. You are welcome to but not required to share these ideas with the researcher and/or other participants.

1. How does your experience with this issue compare with the experiences of others? How is it similar and how is it different?

2. Who do you talk to about your concerns with this issue? Who don't you talk to?

3. Why do you think this issue has become so important to this group?

4. How has this issue been talked about in the past?

5. What has been your role in this issue?

6. What are some unspoken things in this issue? What makes it so difficult to talk about these things?

7. How would your life be different if this problem did not exist in this organization? How would it be the same?

8. What would change if this issue would be discussed in a different way?

9. What would need to happen for the discussion on this issue to take a different form?

MINNA HOLOPAINEN SJSU Communication Studies One Washington Square San José, CA 95192-0112 Email minnajholopainen@hotmail.com 


\section{Reflection}

Please, take a few moments to reflect on the things you learned during this first training session.

1. What did you enjoy the most about this second training session? What worked the best for you?

2. What did you enjoy the least about this second training session? What could be improved on?

\section{Next, reflect on your learnings in response to the challenges identified in the interviews.}

3. How can you use the things we learned today to improve work within your own team and with your subordinates (acknowledging effort and the loss of "family" members while doing more with less)?

4. How can you use the things we learned today to facilitate interaction with customers?

5. How can you use the things we learned today to improve work between divisions (competition over resources and divisional generalizations)?

6. How can you use the things we learned today to improve work with the executive level/your superiors?

7. How can you use the things we learned today to improve your organizational environment ("There is a cloud hanging over us")?

On the back side of this sheet of paper, please, feel free to share any other thoughts you have about this training session. Your candid feedback is warmly welcomed. Thank you for your time!

MINNA HOLOPAINEN SJSU Communication Studies One Washington Square San José, CA 95192-0112 Email minnajholopainen@hotmail.com 


\section{APPENDIX F: Make-Up Training Packet}

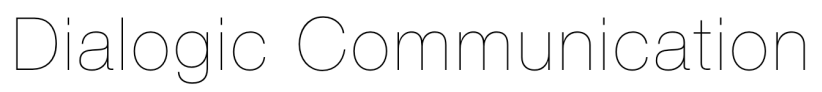

Dialogic Communication Training for Master's thesis "Outcomes of dialogic communication training in a city government management team"

Date \& time Monday July 26, 2010 at 3:00-5:00 pm

Location Undisclosed

Attendees Undisclosed

Trainer Minna Holopainen

Desired Outcomes

- To see communication as a meaning-making process (social construction)

- To understand one's own contributions to the meaning-making process as crucial in shaping the end result

- To regard differences as potentially valuable and sometimes requiring special "management"

- To practice dialogic communication skills in the previously identified challenge areas

Guidelines for Constructive Communication

- Listen openly, speak candidly

- Be concise

- Confidentiality

- Everyone contributes

\begin{tabular}{l|l} 
Time & Topic \\
\hline 3:00-3:05 pm & $\begin{array}{l}\text { Context setting } \\
\text { - Purpose for the training session III } \\
\text { - Guidelines for constructive communication } \\
\text { - Preview of the agenda }\end{array}$ \\
\hline 3:05-3:25 & $\begin{array}{l}\text { Constructing communication } \\
\text { What are we making together? } \\
\text { Managing differences }\end{array}$ \\
\hline 3:25-3:40 pm & Practice \& analysis: Role play \\
\hline 3:40-3:55 pm & Dialogic communication \\
\hline 3:55-4:45 pm & Dialogic communication skills and practice \\
\hline 4:45-5:00 pm & $\begin{array}{l}\text { Wrap-up } \\
\text { - Summary and next steps } \\
\text { - Reflection }\end{array}$ \\
\hline
\end{tabular}

MINNA HOLOPAINEN SJSU Communication Studies One Washington Square San José, CA 95192-0112 Email minnajholopainen@hotmail.com 


\section{Communication Construction}

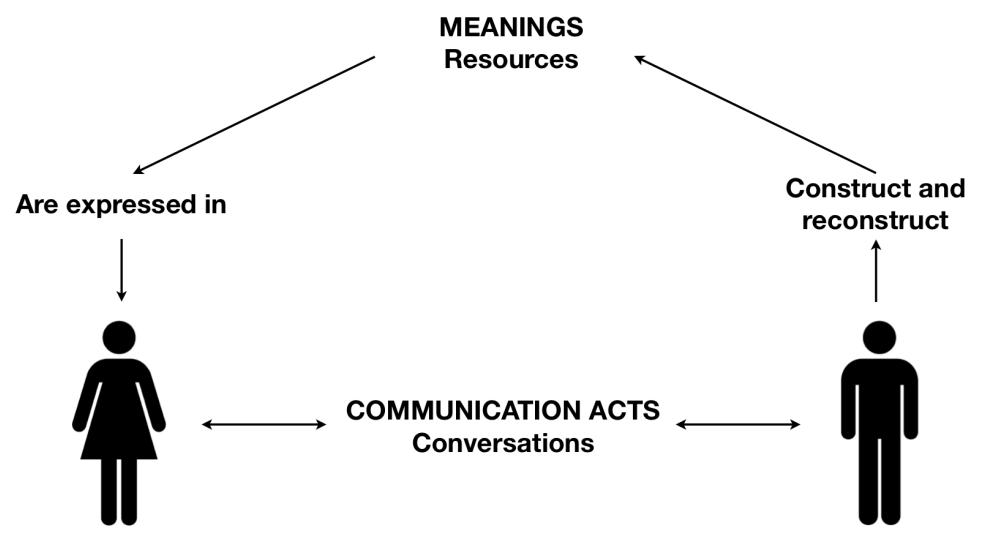

Adapted from Pearce, W. B. (1989). Communication and the human condition, p. 23. Carbondale, IL: Southern Illinois University Press.

Key Points about Communication Construction

Spano, S. (2010). Dialogue resource guide, p. 5. San José State University, CA.

- Communication is a process of making and doing, not just sending and receiving (transmission of information)

- People co-construct meaning (e.g., relationships) through communication actions.

- As people make meaning within the boundaries of their social worlds, there is a need to create communication bridges between different social worlds.

The Truth versus many truths

\section{What Are We Making Together?}

Spano, S. (2007). Handouts. Comm 156 Qualitative Communication Inquiry. San José State University, CA.

Meaning is made through the joint contributions of all the participants. Individual messages lack meaning until we hear the response from the other.

Example

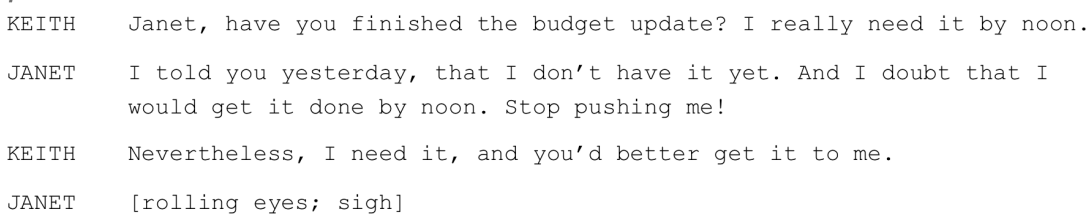

What is being created in this discussion? How can the outcome be changed?

MINNA HOLOPAINEN SJSU Communication Studies One Washington Square San José, CA 95192-0112 Email minnaiholopainen@hotmail.com 


\section{Managing Differences}

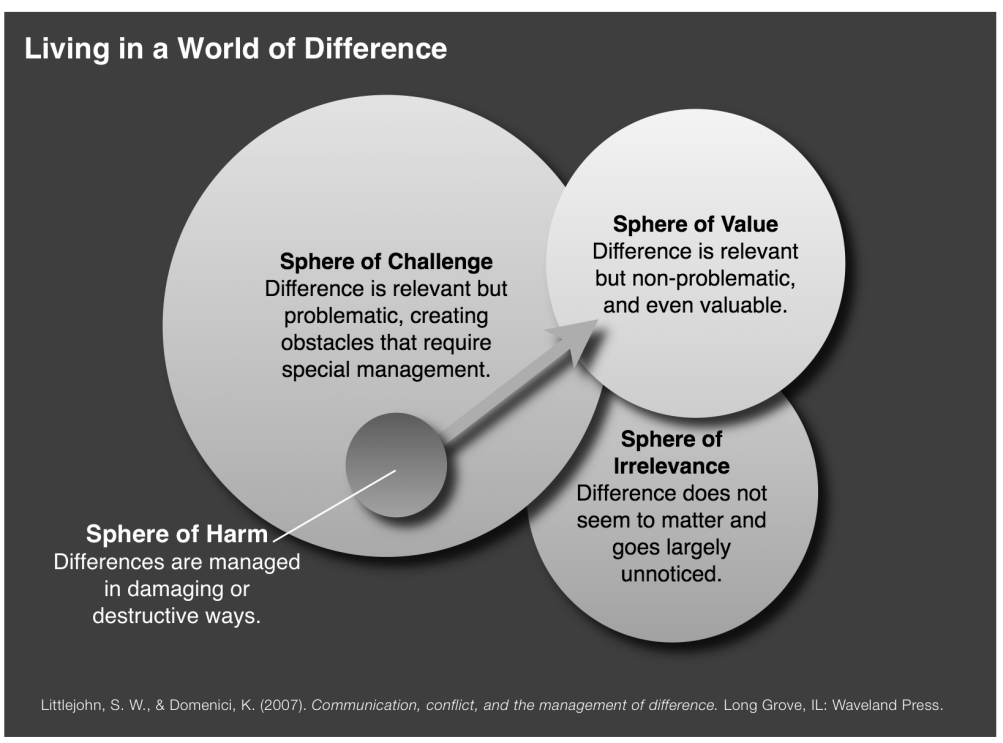

Role Play

Perform a typical challenging situation at work. What is being made in these situations?

Choose one of the challenge areas identified in the focus group session:

- communication with the superiors

- divisional generalizations

- challenging subordinates

- challenging customers

How are these challenges made?

\section{Dialogic Communication}

Adapted from Spano, S. (2010). Dialogue resource guide, pp. 5, 10-13, 37-41. San José State University, CA.

Dialogue is a form of communication that helps create unique and distinctive social worlds, different from what gets made in other, non-dialogic forms of communication. Dialogue enriches our understanding of issues by moving away from simplistic either/or to multidimensional both/and definitions.

Since all forms of communication construct social reality (communication construction), the question is not whether to create but how to use communication to create social worlds that are satisfying, humane, and enriching.

MINNA HOLOPAINEN SJSU Communication Studies One Washington Square San José, CA 95192-0112 Email minnajholopainen@hotmail.com 
Buber's Three Conditions for Dialogue

1. Holding your ground

2. Being open to the other

3. Remaining in the tension between 1 (self) and 2 (other)

Characteristics of Dialogue

1. Mutual

2. Creative

3. Inclusive

4. Authentic

5. Empathic

6. Collaborative

Dialogic Communication Skills

Opportunities for dialogic communication exist routinely in everyday life, at home, work, or play with friends, family, and colleagues. Although dialogue emerges spontaneously, we can be intentional about creating the conditions for it around issues that are important to us. The following list is an example of communication skills that help us in creating such conditions:

- Demonstrating curiosity and wonder

- Acknowledging

- Restating

- Reflecting feelings

- Reframing

- Appreciative questioning

- Systemic questioning; examples

- How does your experience with this issue compare with the experiences of others? How is it similar and how is it different?

- Who do you talk to about your concerns with this issue? Who don't you talk to?

- Why do you think this issue has become so important to this group?

- How has this issue been talked about in the past?

- What has been your role in this issue?

- What are some unspoken things in this issue? What makes it so difficult to talk about these things?

- How would your life be different if this problem did not exist in this organization? How would it be the same?

- What would change if this issue would be discussed in a different way?

- What would need to happen for the discussion on this issue to take a different form?

Role Play Practice

Using the previous role play, come up with an alternative scenario in which you use dialogic communication skills.

MINNA HOLOPAINEN SJSU Communication Studies One Washington Square San José, CA 95192-0112 Email minnajholopainen@hotmail.com 


\section{Reflection}

Please, take a few moments to reflect on the things you learned during this training session.

1. What did you enjoy the most about this training? What worked the best for you?

2. What did you enjoy the least about this training session? What could be improved on?

\section{Next, reflect on your learnings in response to the challenges identified in the interviews.}

3. How can you use the things we learned today to improve work within your own team and with your subordinates (acknowledging effort and the loss of "family" members while doing more with less)?

4. How can you use the things we learned today to facilitate interaction with customers?

5. How can you use the things we learned today to improve work between divisions (competition over resources and divisional generalizations)?

6. How can you use the things we learned today to improve work with the executive level/your superiors?

7. How can you use the things we learned today to improve your organizational environment ("There is a cloud hanging over us")?

On the back side of this sheet of paper, please, feel free to share any other thoughts you have about this training session. Your candid feedback is warmly welcomed. Thank you for your time!

MINNA HOLOPAINEN SJSU Communication Studies One Washington Square San José, CA 95192-0112 Email minnajholopainen@hotmail.com 